NASA Technical Memorandum 103628

AIAA-90-3983

\title{
Noise Measurements From an Ejector Suppressor Nozzle in the NASA Lewis 9 - by 15-Foot Low Speed Wind Tunnel
}

Eugene A. Krejsa and Beth A. Cooper

National Aeronautics and Space Administration

Lewis Research Center

Cleveland, Ohio

and

David G. Hall and Abbas Khavaran

Sverdrup Technology, Inc.

Lewis Research Center Group

Brook Park, Ohio

Prepared for the

13th Aeroacoustics Conference

sponsored by the American Institute of Aeronautics and Astronautics

Tallahassee, Florida, October 22-24, 1990 


\title{
NOISE MEASUREMENTS FROM AN EJECTOR SUPPRESSOR NOZZLE IN THE
}

\author{
NASA LEWIS 9- BY 15-FOOT LOW SPEED WIND TUNNEL \\ Eugene A. Krejsa* and Beth A. Cooper \\ National Aeronautics and Space Administration \\ Lewis Research Center \\ Cleveland, Ohio 44135
}

and

David G. Hall* and Abbas Khavaran

Sverdrup Technology, Inc.

Lewis Research Center Group

Brook Park, Ohio 44142

\section{SUMMARY}

In response to recent interest in high speed civil transports, NASA has initiated a program to develop the enabling technology required by such an aircraft. This report presents the acoustic results of a cooperative nozzle test program between NASA and Pratt \& Whitney that was conducted in the NASA Lewis Research Center 9- by 15-Foot Anechoic Wind Tunnel.

The nozzle tested was the Pratt \& Whitney "Hypermix" Nozzle concept, a two-dimensional lobed mixer nozzle followed by a short ejector section designed to promote rapid mixing of the nozzle flow with the flow induced by the ejector. Acoustic and aerodynamic measurements were made to determine the amount of ejector pumping, the degree of mixing, and the noise reduction achieved.

A series of tests were run to verify the acoustic quality of this tunnel. Measurements were found to be consistent with prediction and with previous measurements of jet noise source location, indicating that the tunnel test section is reasonably anechoic. Measurement noise floors were not a significant problem for conic nozzles at high pressure ratios, but can limit the amount of suppression observed from suppressor nozzles. Also, a possible internal noise was observed in the air supply system.

The Pratt \& Whitney ejector suppressor nozzle demonstrated the potential of this concept to significantly reduce jet noise. Significant reduction in low frequency noise was achieved by increasing the peak jet noise frequency. This was accomplished by breaking the jet into segments with smaller dimensions than those of the baseline nozzle. Variation in ejector parameters, such as ejector to nozzle area ratio and diffuser half-angle, had little effect on the noise for the range of temperatures and pressure ratios tested. 


\section{INTRODUCTION}

In recent years, the commercial aircraft industry has expressed a resurgence of interest in the development of a commercial supersonic cruise aircraft. The major advantages of such an aircraft over a subsonic cruise aircraft are its decreased flight time and improved productivity, measured in seat-miles over time (ref. 1). Serious environmental issues must be addressed for the successful development of a supersonic transport aircraft, namely, community noise, sonic booms, and atmospheric emissions. These result from the increased flight speed and the higher engine performance levels required for supersonic flight. The importance of these problems is illustrated by the history of the British-French Concorde (ref. 2).

To address the technical issues associated with a supersonic cruise aircraft, NASA has initiated the High speed Research (HSR) Program. This program has focused on the development of a 250- to 300-passenger aircraft with a range of 5500 to $6500 \mathrm{~nm}$ and cruise speeds between Mach 2 and 3 . Advances in propulsion system technologies are critical to the solution of the ever present environmental problems. Nozzle technology research efforts are concentrated on meeting the Federal Aviation Administration FAR 36 Stage III noise rules, which would require the removal of as much as 99 percent of the jet engine noise (20 EPNdB) with acceptable performance penalties. The magnitude of this challenge is evident when considering that the four olympus engines of the Concorde produce noise levels that are 12, 18, and $13 \mathrm{EPNdB}$ above the FAR 36 Stage III guidelines for sideline, cutback, and approach, respectively.

Research under the NASA Supersonic Cruise Aircraft Research (SCAR) program in the 1970's and 1980's was directed at the development of a supersonic jet engine noise suppressor. These concepts, which represent the current state-of-the-art in jet engine noise suppression, achieve a tradeoff of noise reduction to thrust loss of about 2 EPNdB per percent thrust loss (using the best optimized performance with the suppressor concepts). Meeting the current noise regulations will require a suppression on the order of 4 EPNdB per percent thrust loss. Results of studies performed during the SCAR program indicate that this community noise goal cannot be achieved by previous noise suppressor designs, singly or in combination (ref. 3 ).

As part of the recently initiated HSR Program, research on low-noise nozzle concepts is continuing in the form of contractual and cooperative relationships with airframe and engine manufacturers. This report presents the results of a cooperative nozzle test program between NASA and Pratt \& Whitney that was conducted in the NASA Lewis 9- by 15-Foot Anechoic Wind Tunnel during the summer of 1989. Pratt \& Whitney provided the model hardware and instrumentation, and NASA provided tunnel time and support.

The nozzle concept tested was a mixer-ejector nozzle developed by Pratt \& Whitney. The concept consists of a two-dimensional lobed mixer nozzle followed by a short ejector section, as shown in figure 1. This combination of a mixer nozzle and ejector shroud has the capability of entraining and rapidly mixing large amounts of air in a short exhaust system. The primary nozzle 
airflow, when fully mixed with that induced by the ejector, will have significantly lower velocity and produce less noise than the flow from the primary nozzle alone. However, the overall noise level may be increased by noise generated within the ejector, which then needs to be absorbed by acoustic treatment of the ejector shroud.

The objectives of the test program were to verify the acoustic quality of the 9- by 15-Foot Anechoic Wind Tunnel and to measure the amount of ejector pumping, the degree of internal mixing, and the noise reduction achieved by a series of mixer-ejector configurations. Both a convergent and a convergentdivergent mixer nozzle were tested with the ejector, varying the ratio of ejector to primary nozzle area. Measurements were also made on the mixer nozzles alone and on a conic baseline nozzle. Both acoustic and aerodynamic measurements were made over a range of primary nozzle pressure ratios at primary nozzle temperatures of $120^{\circ}$ and $450^{\circ} \mathrm{F}$ with and without tunnel flow. A series of tests were run with the baseline conic nozzle to verify the acoustic quality of this tunnel. This report emphasizes the acoustic results of the test. Aerodynamic results are reported in reference 4.

\section{APPARATUS AND PROCEDURE}

NASA Lewis Research Center 9- by 15-Foot Anechoic Wind Tunnel

The test of the Pratt \& Whitney mixer-ejector nozzle concept was conducted in the NASA Lewis 9- by 15-Foot Anechoic Wind Tunnel. This tunnel was designed for the purpose of measuring the aerodynamic and acoustic performance of aircraft components under simulated takeoff conditions (ref. 5). The acoustically treated test section, which is located in the low speed return leg of the 8- by 6-Foot Supersonic Wind Tunnel (fig. 2), is 9 feet high by 15 feet wide by 27 feet long. Airflow through the test section is available up to a maximum nominal Mach number of 0.2 to simulate takeoff flight effects.

The test section of the wind tunnel has been acoustically treated to minimize reflections (from the tunnel walls) that could interfere with the measurement of the direct sound from the model under test. The floor and ceiling of the test section are completely treated, and the walls are treated similarly. Acoustic treatment is also located behind four horizontal bleed slots, each $\sim 4$ in. wide, which extend along each vertical wall for the length of the test section. The treatment consists of a $13.5 \mathrm{in}$. depth of Kevlar, a bulk fibrous material that is capable of withstanding the tunnel environmental conditions (ref. 6) and has a nominal absorption coefficient of 0.95 with a low frequency cutoff of $250 \mathrm{~Hz}$. This material was originally chosen to accommodate the testing of high-speed turboprop propulsion systems. The tunnel acoustic treatment material is contained in boxes with perforated plate facing. These modular units, which replaced the original tunnel walls, fit between the structural beams of the tunnel and are removable to allow test models to be mounted from the beams.

The test of the Pratt \& Whitney mixer-ejector nozzle concept is the 
first time that the 9- by 15-Foot Anechoic Wind Tunnel has been used for jet noise testing. The test results are valuable in the assessment of the suitability of the tunnel for jet noise testing in general.

Recent time-delay spectrometry tests of the acoustic treatment material indicated that the installed treatment had an absorption coefficient greater than $\alpha=0.95$ over the frequency range $250 \mathrm{~Hz}$ to $4 \mathrm{kHz}$, confirming impedance tube data and analytical prediction (ref. 7). Above and below this range, the absorption steadily decreased (but not below 0.8), also in agreement with analytical prediction and available impedance tube data. Furthermore, analytical predictions indicate that the absorption coefficient does not change significantly out to an angle of incidence of $45^{\circ}$ from normal. Further information about the tunnel acoustic treatment may be found in reference 7 .

\section{Air Supply System}

Test model hardware was mounted in the tunnel test section with a support system previously used in the $8-$ by 6 -Foot Supersonic Wind Tunnel. The mounting arrangement (figs. 3 and 4 ) consisted of a strut ( $0^{\circ}$ sweep) with a thickness-to-chord ratio of 0.036 and a forebody with a maximum diameter of $8.5 \mathrm{in}$. Test nozzles were mounted to the forebody via a cylindrical adaptor section. The support system was positioned in the corner of the upstream end of the tunnel ceiling (as shown in fig. 5) to maximize distance to the microphone array. This strut support system provided the model hardware with heated air up to $500^{\circ} \mathrm{F}$ at $20 \mathrm{lb} / \mathrm{sec}$. Air flow was controlled by a valve located upstream of the mounting system. Air was supplied to this valve at a pressure of 450 psi.

\section{Test Nozzles}

Acoustic data were obtained for three different nozzles in combination with an ejector shroud of varying area ratio and diffuser half-angle. Figures 6 to 8 are photos of the conical, convergent (lobed) mixer, and convergent-divergent (lobed) mixer nozzles, respectively. All nozzles had a throat area of $0.057 \mathrm{ft}^{2}(0.27 \mathrm{ft}$ diam). The hydraulic diameter $(4 \mathrm{x}$ area $\div$ wetted perimeter) of the mixer nozzles was $0.07 \mathrm{ft}$. The convergent-divergent mixer was designed for a pressure ratio of 3.4. Key dimensions of the convergent mixer nozzle are indicated in figure 1.

Figure 9 shows the convergent mixer nozzle with the ejector shroud. Ejector area ratio, defined as the ratio of the total mixing cross-sectional area at the nozzle exit plane to primary exit area, was varied between 3.77 and 5.16. The diffuser half-angle (between the ejector plate internal surface and nozzle axis) was $+4^{\circ}$ for most of the tests. Limited data were obtained for diffuser half-angles of $-1^{\circ},+6 \cdot 3^{\circ}$, and $+9^{\circ}$. More detailed information on the nozzle designs is given in reference 4. Acoustic data were obtained for the configurations listed in table I. 


\section{Aerodynamic Instrumentation}

Primary nozzle total pressure and temperature were measured using four rakes located in the adaptor, upstream of the nozzle, as shown in figure 3 . The rakes were positioned at $90^{\circ}$ azimuthal separations. Each rake consisted of five total pressure taps and four total temperature probes. Static pressure taps were located on the ejector shrouds. Each shroud had two axial rows of 20 pressure taps per row. One row on each shroud was located opposite a lobe peak, and the other was located opposite the valley between lobes. Nonacoustic tests were conducted during which total pressure and temperature surveys were performed just downstream of the ejector exit to determine the degree of mixing. More details are provided in reference 4.

\section{Acoustic Instrumentation}

Acoustic data were obtained using two microphone arrays. The standard array configuration (fig. 10), used for all but the first (conic nozzle) test, consisted of 11 microphones along a linear array to measure axial noise variation and 9 microphones arranged in three polar arcs to measure azimuthal noise variation. An alternate array of 20 microphones, used only for the conic nozzle, was arranged to facilitate the measurement of the variation in noise level with distance from various points in the jet. These data were then used to determine the degree to which the tunnel acoustic environment simulated an anechoic free field.

Locations of the standard array microphones (in a coordinate system with its origin at the nozzle exit) are tabulated in table II along with the source-to-microphone distance and angle with respect to the nozzle exit plane. Microphone angles are measured from the nozzle inlet axis to the vector between the nozzle exit and the microphone. The nozzle exit plane locations are the same for each of the nozzle-alone configurations. Distances and angles with respect to the shroud exit plane are also tabulated for ejector configurations. Microphone locations, distances, and angles for the alternate array are tabulated in table III.

Each microphone was oriented parallel to the tunnel wall with its diaphragm facing upstream. All microphones used in the test were $1 / 4 \mathrm{in.}$, fitted with nose cones. A photograph of a typical microphone installation is shown in figure 11 .

The standard microphone array configuration was arranged such that microphones in the linear array were located at nominal angles of $50^{\circ}$ to $150^{\circ}$. The linear array formed a $7^{\circ}$ angle with the tunnel wall to minimize self noise from flow over adjacent (upstream) microphones. The $90^{\circ}$ microphone was located at a distance of 105 in. from the jet axis.

The azimuthal arrays (polar arcs) of the standard microphone array configuration were located at $60^{\circ}, 90^{\circ}$ and $130^{\circ}$ with respect to the nozzle inlet axis, each consisting of three microphones at a nominal distance of $4 \mathrm{ft}$ from the jet axis, as illustrated in figure 10. 
The alternate microphone array configuration consisted of the four parallel linear arrays shown in figure 12, each of which formed a $7^{\circ}$ angle with the nozzle inlet axis, and one vertical 3-microphone array directly beneath the nozzle exit plane.

\section{Test Procedure}

Acoustic measurements were made at a tunnel mach number of 0.2 (maximum for the 9- by 15-Foot Anechoic Wind Tunnel) and 0 (static) conditions, for nozzle pressure ratios in the range 1.5 to 4 at $120^{\circ}$ and $450^{\circ} \mathrm{F}$ nozzle exhaust flow temperatures.

Acoustic data quality was monitored during testing using a two-channel spectrum analyzer. A visual display of simultaneous microphone and tape recorder outputs was also used to monitor the range of data channels. Data were recorded for one minute per test point on two 14-channel analog tape recorders using IRIG wideband group I (FM) at 60 ips. The frequency response of the system was $\sim 0$ to $40 \mathrm{KHz}$.

\section{Data Reduction}

Post-test data reduction was performed by playing back the analog data tapes at 30 ips and processing the signals with a 16-channel softwarecontrolled spectrum analyzer. This analyzer produced two 640-line narrowband digital spectra for each microphone channel using Fast Fourier Transform (FFT) algorithms. The first (low frequency) spectrum had an effective range of 0 to $2560 \mathrm{~Hz}$ and a resolution of $4 \mathrm{~Hz}$. The second had an effective range of 0 to $40 \mathrm{kHz}$ and a resolution of $64 \mathrm{~Hz}$. Frequency domain averaging and a Hanning window function were used during spectral calculations. These spectra were then transferred to personal computer systems for further analysis.

To facilitate comparisons between microphones and between configurations (except for the comparisons with background noise levels) the effects of atmospheric attenuation were removed and the data adjusted to a one foot distance. Compensation was also performed to account for frequency-dependent nonuniform directional gain of the measuring microphones. The adjusted narrow band data were then processed to yield one-third octave band power levels.

One-third octave band processing was performed using a filtering algorithm with an eighth-order Chebychev bandpass response characteristic. The low frequency spectral data ( 0 to $2560 \mathrm{~Hz}$ ) were used to synthesize the $1600 \mathrm{~Hz}$ and lower one-third octave bands. The high frequency spectral data ( 0 to $40 \mathrm{KHz}$ ) were used to synthesize the higher frequency one-third octave bands. Frequency dependent corrections were then added to the one-third octave band power levels to account for facility cabling, amplifier gain and tape recorder response. The combined cabling and tape recorder response corrections were zero at low frequencies and less than $1 \mathrm{~dB}$ at the higher frequencies. 
Only data with levels at least $3 \mathrm{~dB}$ above the measured background will be presented, and these data were corrected by subtracting the measured background on an antilogarithmic basis.

\section{RESULTS AND DISCUSSION}

Tunnel Acoustic Environment Evaluation

Because the test of the Pratt \& Whitney mixer-ejector nozzle concept was the first jet noise test to be performed in the 9- by 15-Foot Anechoic Wind Tunnel, it was necessary to evaluate the tunnel acoustic environment, especially in regard to those features unique to scale model jet noise testing. Previous acoustic testing in the 9- by 15-Foot has been limited to fan and propeller testing. These noise sources are dominated by tones, are well represented by point sources at reasonable distances from the source, and are limited to frequencies below $20 \mathrm{kHz}$. In contrast, jet noise is a broadband, distributed source, and for scale model nozzles can require measurements at frequencies up to $100 \mathrm{kHz}$. Three areas of concern for this type of test are: (1) anechoic quality, especially at high frequencies; (2) internal flow noise; and (3) background noise with tunnel flow.

For the purpose of evaluating the tunnel acoustic environment, a series of reference (conic) nozzle tests were run using the standard microphone array and a specially arranged alternate microphone array. This alternate array was designed to facilitate comparisons of measured noise levels with inverse square variation with distance from the source. Microphones were placed at differing distances from the jet centerline, as shown in figure 12 .

To accomplish the task of comparing measured variation of levels with distance from the source, the source location as a function of frequency must be known. Unfortunately, a search of the literature (refs. 8 to 10) revealed considerable inconsistency among previous estimates of source location as illustrated in figure 13. As an alternate approach, the data obtained with the alternate microphone array were used to estimate the source location as a function of frequency, and this was compared with previous data. The estimated source location was assumed to be that which had a linear regression fit with a slope of -20 versus log distance. The following are the calculation steps used to arrive at the regression fit.

(1) Compute distance and angle from assumed source location to microphone.

(2) Correct measured level for directivity effect using:

$$
\mathrm{SPL}_{C}=\mathrm{SPL}+30.0 * \log _{10}\left(1.0+\mathrm{M}_{\mathrm{C}} * \cos (\theta)\right)
$$

(3) Correct for atmospheric attenuation based on distance from assumed source location to microphone.

(4) The source location that resulted in the best fit with a slope of -20 was taken as the apparent source location. 
The analysis was limited to data from microphones located in the forward quadrant since the equation used in step 2 is not valid near the jet axis, where refraction effects become important. The results of this analysis are shown in figure 14. Comparison of these results with previous estimates is shown in figure 15. As can be seen, the source location results are consistent with those of previous researchers.

Another check on the acoustic environment in the 9- by 15-Foot Anechoic Wind Tunnel was made by comparing predicted jet noise levels, using well documented prediction procedures, such as those of stone (ref. 11) with the measured data. Figure 16 shows the comparison of Stone's predictions, (ref. 11) with data measured at a subsonic nozzle condition with no tunnel flow. Two predicted curves are shown, one for assumed source location at the nozzle exit, and the other with the source located at axial locations determined using the alternate array microphones as described above. As can be seen, the data agree with the prediction accounting for source location except at the far aft angles and at high frequencies. At the far aft angles, the data fall between the two predictions. At high frequencies the predictions are nearly identical, but are lower than the data by as much as 8 and $9 \mathrm{~dB}$, indicating the probable existence of another noise source, most likely flow noise through the air supply system.

In figure 17 the data are compared with predictions for a supersonic nozzle exit condition with pressure ratio $=4$. For this case the spectra are shock noise dominated and the predictions are not sensitive to the source location assumption for the mixing noise. Two prediction curves are shown; one is using Stone's shock noise prediction procedure (ref. 11), and the other uses the Harper-Bourne Fisher (HBF) procedure (ref. 12) as programmed in reference 13. Stone's procedure is based on curve fits to experimental data. The Harper-Bourne Fisher procedure is based on a theoretical model of jet turbulence - shock cell interaction with scale factors to match measured data. For both shock noise predictions, the source of shock noise was assumed to be located $4.4\left(\mathrm{M}_{j}^{2}-1\right)^{1 / 2}$ nozzle diameters downstream of the nozzle exit (where $M$ is the jet Mach number). This location corresponds to approximately midway between the third and fourth shock cells in the HBF model. Although some discrepancy exists between the predicted and measured levels at high frequency, it is not clear whether this is due to an inadequacy in shock noise prediction or whether the internal noise is still contributing.

In figures 16 and 17 , comparisons with predictions were made with no tunnel flow. With the tunnel operating, several additional sources of noise exist that can obscure the noise from the research nozzle. Possible sources of background noise are tunnel drive equipment, flow noise over tunnel surfaces, and flow noise over the microphone itself. In figure 18, background noise levels, measured with no flow through the test nozzle, are compared with measured levels with flow through the test nozzle. Comparisons are made at several nozzle pressure ratios ranging from 1.8 to 4.0 . In all cases, the tunnel mach number is 0.2 . These data are shown as measured (not adjusted to a $1 \mathrm{ft}$ radius). As can be seen, the background level obscures the nozzle noise at frequencies below $500 \mathrm{~Hz}$ for all pressure ratios and angles. For most angles, the nozzle noise exceeds the background levels at frequencies above $1000 \mathrm{~Hz}$ for pressure ratios above 2. The dominance of background noise 
levels at frequencies below $500 \mathrm{~Hz}$ is not considered to be a problem since the low frequency levels will not be important when the data are scaled (typically by a factor of 10 ) to full scale. However, the background levels could obscure measurements from quiet suppressor nozzles. It is believed that background noise levels are the result of self noise of the microphones and/or vortex shedding from the micro-phone holders. Redesign of the microphone stands will relieve this problem for future tests.

Comparisons of background levels with levels from a convergent mixer ejector nozzle, one of the quieter configurations tested, are shown in figure 19. As can be seen, the background levels are much more dominant for this quieter nozzle and can obscure the noise from the nozzle over much of the frequency range, even at pressure ratios of 3 . Based on these results, only data with levels at least $3 \mathrm{~dB}$ above the measured background will be presented, and these data will be corrected by subtracting the measured background on an antilogarithmic basis.

To summarize the tunnel acoustic environment evaluation, it is concluded that, although a completely quantitative evaluation of the tunnel anechoic properties could not be made, it appears that the tunnel is reasonably anechoic over the frequency range of interest. However, a high frequency noise source was observed, and this noise source could obscure comparisons of suppressor configurations. Also, background noise levels are dominant at low frequencies and can be significant at higher frequencies for quieter suppressor nozzles. The low frequency dominance of background noise is not considered to be a problem since these low frequency levels will not be important when the data are scaled to full scale.

\section{Configuration Comparisons}

In this section, spectra from the various configurations will be compared to show the effect of the nozzle geometry on nozzle-alone noise, the benefit of adding an ejector to the mixer nozzles, and the effect of the ejector geometry on ejector/suppressor noise level.

Mixer nozzles. - In figure 20, spectra from the convergent mixer nozzle, without an ejector, is compared with the conic nozzle spectra at a pressure ratio of 3.5. Both sets of data are corrected for background level. As can be seen, the main effect of the mixer nozzle is to shift the peak to a much higher frequency with a reduction in level of about 3 to $5 \mathrm{~dB}$. At the pressure ratio of 3.5 , the noise is dominated by shock noise, the frequency of which, according to reference 14, should scale with the inverse of the hydraulic diameter $(4 \mathrm{x}$ area $\div$ wetted perimeter $)$. Since the hydraulic diameter of the mixer nozzle is smaller than that of the conic nozzle, the frequency shift is as expected. The high frequency levels for the mixer nozzle are higher than those of the conic nozzle and could result in increased perceived noise levels when scaled to full-scale. 
In figure 21, the convergent-divergent mixer nozzle is compared to the convergent mixer at a pressure ratio of 3.4 , which is the design pressure ratio of the convergent-divergent nozzle. Some reduction is achieved near the peak, but significant shock noise still appears to exist. The lack of reduction could be indicative of the difficulty in designing a geometrically complex nozzle to be shock free. However, as a word of caution, the region of apparent shock noise for the mixer nozzles is also the frequency range where excess noise, apparently from the supply system, was evident with the conic nozzle.

Ejector shrouds. - In figure 22, noise from the convergent mixer nozzle with an ejector shroud is compared with that of the mixer nozzle alone and that of the conic nozzle. Several dB reduction is achieved at the high frequencies, with the ejector compared to the mixer alone. At lower frequencies, the noise reduction, if any, is obscured by ejector levels within $3 \mathrm{~dB}$ of the background. (No levels are plotted if they are within $3 \mathrm{~dB}$ of the background.) It is recognized that the ejector would be most effective if the shroud were treated to remove internally generated mixing noise. While an investigation of a treated ejector was beyond the scope of this work, such a study will be important to the development of a successful mixer ejector concept.

In figures 23 to 26 , spectra from a variety of different ejector and nozzle combinations are compared. Although there are no great differences between the results, some trends can be observed.

(1) Increasing the ejector area increased the noise level slightly (fig. 23). This is in spite of the fact that increasing the ejector area increases ejector pumping (ref. 4). As area ratio is increased, the effective $L / D$ decreases, and the two streams are less well mixed. Thus, the increase in noise may be associated with more nonuniform exit velocity profiles.

(2) Noise levels for the convergent-divergent mixer nozzle were slightly quieter than those of the convergent mixer nozzle (fig. 24). Because the exit areas of the convergent and convergent-divergent nozzles are different, the area ratios for the same ejector area are not the same.

(3) Increasing the diffuser half-angle from $4^{\circ}$ to $9^{\circ}$ resulted in some decrease in noise (about $2 \mathrm{~dB}$ ) at forward angles with almost no change in noise at aft angles. Decreasing the diffuser half-angle from $4^{\circ}$ to $-1^{\circ}$ produced no change in noise (fig. 26).

\section{CONCLUDING REMARKS}

The following conclusions can be made from the analysis of acoustic data obtained during the testing of the Pratt \& Whitney ejector suppressor nozzle in the NASA Lewis 9- by 15-Foot Anechoic Wind Tunnel.

(1) The 9- by 15-Foot Anechoic Wind Tunnel appears to be anechoic over the frequency range of 500 to $40000 \mathrm{~Hz}$. 
(2) Background noise levels are not a significant problem for conic nozzles at high pressure ratios, but can limit the amount of suppression observed from suppressor nozzles. This would be less problematic for tests conducted with higher temperature jet flows and correspondingly higher jet velocities. Redesign of the microphone holders to reduce the noise due to vortex shedding from the microphone stands may also help.

(3) A possible internal noise in the air supply system was observed. Care should be taken in future tests to eliminate this source of extraneous noise.

(4) The Pratt \& Whitney ejector suppressor nozzle demonstrated the potential of this concept to significantly reduce jet noise. Significant reduction in low frequency noise was achieved by increasing the peak jet noise frequency. This was accomplished by breaking the jet into segments with smaller dimensions than those of the baseline nozzle. The remaining high frequency levels may be reduced by proper design of a convergent-divergent nozzle or with acoustic treatment in the ejector.

(5) Variation in ejector parameters, such as ejector to nozzle area ratio, and diffuser half-angle had little effect on the noise for the geometries and the range of temperatures and pressure ratios tested.

\section{REFERENCES}

1. Stitt, L.E.: Exhaust Nozzles for Propulsion Systems With Emphasis on Supersonic Cruise Aircraft. NASA RP-1235, 1990.

2. Smith, M.J.T., et al.: Future Supersonic Transport Noise - Lessons from the Past. AIAA Paper 88-2989, July 1988.

3. Seiner, J.M.; and Krejsa, E.A.: Supersonic Jet Noise and the High Speed Civil Transport. AIAA Paper 89-2358, July 1989.

4. Lord, W.K., et al.: Mixer-Ejector Nozzle for Jet Noise Suppression. AIAA Paper 90-1909, 1990.

5. Yuska, J.A., et al.: Lewis 9-By 15-Foot V/STOL Wind Tunnel. NASA TM X-2305, 1971.

6. Dahl, M.D.; and Rice, E.J.: Measured Acoustic Properties of Variable and Low Density Bulk Absorbers. NASA TM-87065, 1985.

7. Dahl, M.D.; and Woodward, R.P.: Comparison Between Design and Installed Acoustic Characteristics of NASA Lewis 9- by 15-Foot Low-Speed Wind Tunnel Acoustic Treatment. NASA TP-2996, 1990.

8. Tester, B.J.; Derby, U.K.; and Fisher, M.J.: Engine Noise Source Breakdown: Theory, Simulation and Results. AIAA Paper 81-2040, Oct. 1981. 
9. Hoglund, L.E.: The Use of Cross-Correlations in Place of Multiple Sidelines for Source Location -- in Jet Noise Measurement. AIAA Paper 79-0618, Mar. 1979.

10. Morfey, C.L.; and Tester, B.J.: Noise Measurements in a Free Jet Flight Simulation Facility: Shear Layer Refraction and Facility-To-Flight Corrections. J. Sound Vibr., vol. 54, no. 1, 1977, pp. 83-106.

11. Stone, J.R.; and Montegani, F.J.: An Improved Prediction Method for the Noise Generated in Flight by Circular Jets. NASA TM-81470, 1980.

12. Harper-Bourne, M.; and Fisher, M.J.: The Noise From Shock Waves in Supersonic Jets. Noise Mechanisms -- AGARD Conference on Propagation and Reduction of Jet Noise, AGARD CP-131, Advisory Group for Aerospace Research and Development, Paris, 1973, pp. 11-1 to 11-13.

13. Brausch, J.F.; Motsinger, R.E.; and Hoerst, D.J: Simulated Flight Acoustic Investigation of Treated Ejector Effectiveness on Advanced Mechanical Suppressors for High Velocity Jet Noise Reduction. NASA CR-4019, 1986.

14. Janardan, B.A., et al.: Experimental Investigation of Shock-Cell Noise Reduction for Dual-Stream Nozzles in Simulated Flight. NASA CR-3846, 1984. 
TABLE I. - PRATT \& WHITNEY MIXER/EJECTOR NOZZLE 9x15 WIND TUNNEL TEST MATRIX

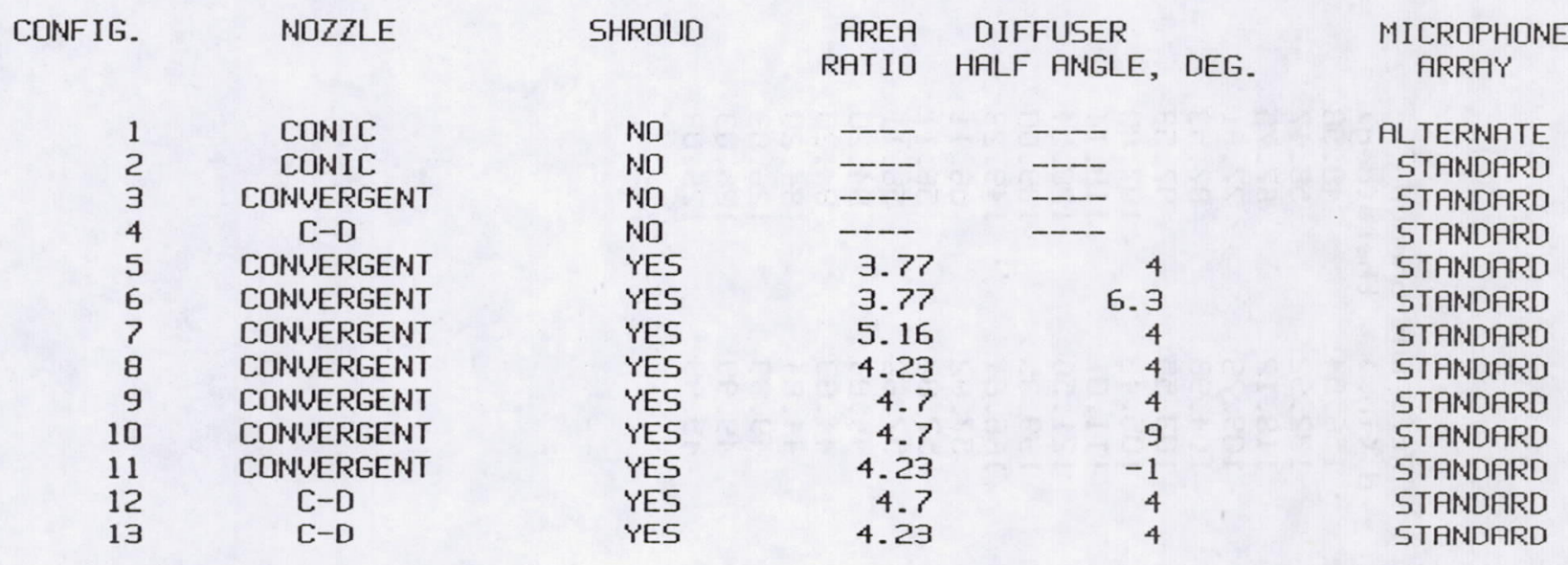


TABLE II. - STANDARD ARRAY MICROPHONE LOCATIONS REFERENCED

TO NOZZLE EXIT PLANE

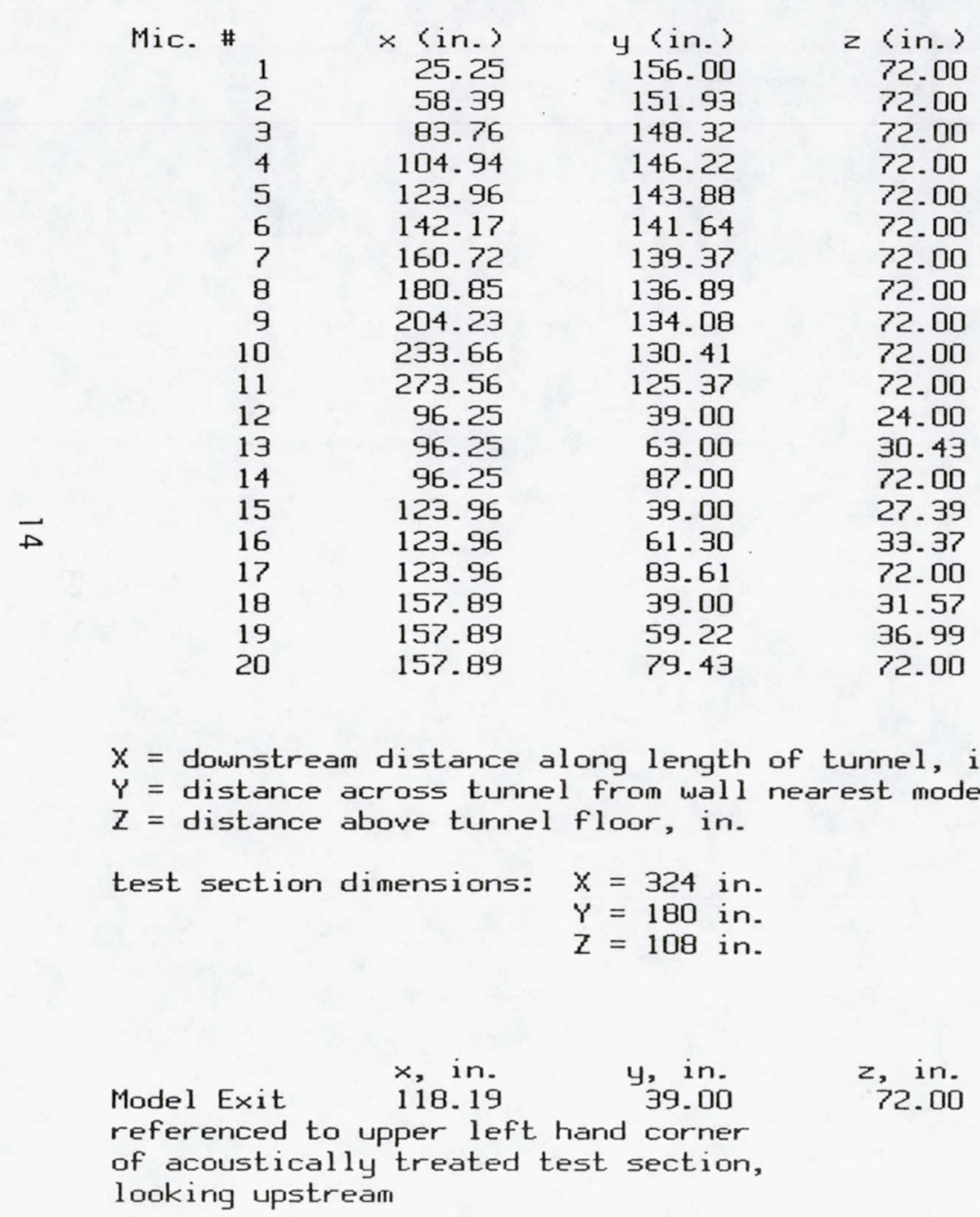

Ref. Nozzle Exit

(in.)

thetas

127.56

114.37

107.79

104.79

105. 16

108.78

116.02

128.05

147.12

177.64

52.66

52.56

52.55

44.86

44.75

44.73

56.58

56.50

56.49
51.48

62.05

72.48

82.94

93.16

103.18

113.02

122.69

132.22

141.71

151.00

65.38

65.33

65.32

97.39

97.41

97 41

134.57

134.65

134.66
Ref. End-Shroud

156.04

theta (deg)

48.58

58.17

$\begin{array}{ll}118.12 & 67.75 \\ 109.78 & 77.61\end{array}$

$104.98 \quad 87.53$

$103.55 \quad 97.59$

$105.42 \quad 107.80$

$111.01 \quad 118.14$

$121.56 \quad 128.54$

$139.35 \quad 139.00$

$168.84 \quad 149.23$

$57.82 \quad 56.11$

$57.82 \quad 56.11$

$57.82 \quad 56.11$

44.84 84.20

44.83 84.20

$44.84 \quad 84.20$

$49.99 \quad 126.03$

$49.99 \quad 126.03$

$49.99 \quad 126.03$

$X=$ downstream distance along length of tunnel, in.

$X=324$ in.
$Y=180$ in.

$Y=180 \mathrm{in}$.
$Z=108 \mathrm{in}$.

of acoustically treated test section, looking upstream 
TABLE III. - ALTERNATE ARRAY MICROPHONE LOCATIONS REFERENCED TO NOZZLE EXIT PLANE

$\begin{array}{rr}\text { Mic. \# } & \times\langle\text { in. }\rangle \\ 2 & 58.31 \\ 3 & 83.88 \\ 5 & 122.06 \\ 7 & 159.50 \\ 10 & 232.13 \\ \mathrm{a} & 81.25 \\ \mathrm{~b} & 92.94 \\ \mathrm{c} & 124.00 \\ \mathrm{~d} & 154.06 \\ \mathrm{e} & 199.38 \\ \mathrm{f} & 101.88 \\ 17 & 123.44 \\ \mathrm{~g} & 145.94 \\ \mathrm{~h} & 167.69 \\ \mathrm{i} & 112.75 \\ \mathrm{j} & 123.25 \\ \mathrm{k} & 141.63 \\ \mathrm{l} & 125.75 \\ \mathrm{~m} & 125.75 \\ 15 & 125.75\end{array}$

$\begin{array}{rr}y \text { (in.) } & \text { zin. } \\ 151.13 & 71.88 \\ 148.50 & 71.88 \\ 143.81 & 72.19 \\ 139.63 & 71.94 \\ 131.06 & 72.06 \\ 119.00 & 71.94 \\ 117.25 & 72.00 \\ 113.38 & 71.88 \\ 109.88 & 71.88 \\ 103.81 & 72.13 \\ 86.06 & 71.81 \\ 83.75 & 71.75 \\ 80.81 & 71.94 \\ 77.81 & 72.00 \\ 57.06 & 72.06 \\ 56.94 & 71.75 \\ 54.50 & 71.88 \\ 39.75 & 51.88 \\ 39.75 & 38.44 \\ 39.75 & 25.44\end{array}$

Ref. Nozzle Exit d (in.) theta〈deg. $\rangle$ $126.89 \quad 61.84$ $114.51 \quad 72.56$ $104.63 \quad 92.12$ $108.54 \quad 112.37$ 146.33 141.14 87.89 65.15 $81.99 \quad 72.06$ $74.35 \quad 94.48$ $79.21 \quad 116.93$ $103.73 \quad 141.51$ $49.57 \quad 70.79$ $44.81 \quad 96.73$ $49.98 \quad 123.73$ $62.75 \quad 142.08$ 18.6273 .03 $18.40 \quad 105.97$ $27.96 \quad 146.95$ $21.39 \quad 110.71$ $34.29 \quad 102.74$ $47.05 \quad 99.25$

$X$ = downstream distance along length of tunnel, in.

$Y=$ distance across tunnel from wall nearest model, in.

$Z=$ distance above tunnel floor, in.

test section dimensions: $X=324 \mathrm{in}$.

$$
\begin{aligned}
& Y=180 \mathrm{in} . \\
& Z=108 \mathrm{in} .
\end{aligned}
$$

Model Exit

$$
x \text {, in. }
$$

referenced to upper left hand corner y, in. 39.00 $z$, in. of acoustically treated test section, looking upstream 


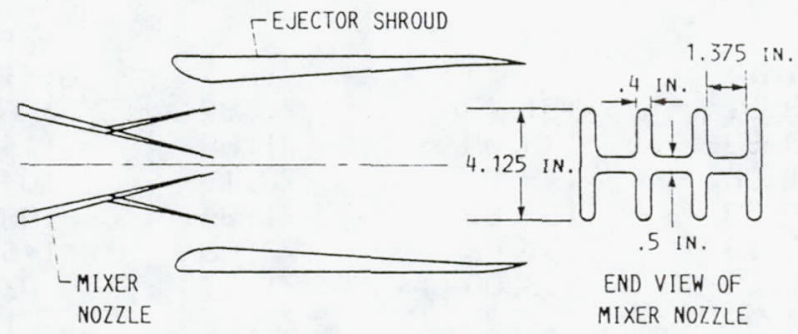

FIGURE 1. - SCHEMATIC OF PRATT AND WHITNEY MIXER-EJECTOR NOZZLE TESTED IN NASA LEWIS $9^{\prime} \times 15^{\prime}$ WIND TUNNEL.

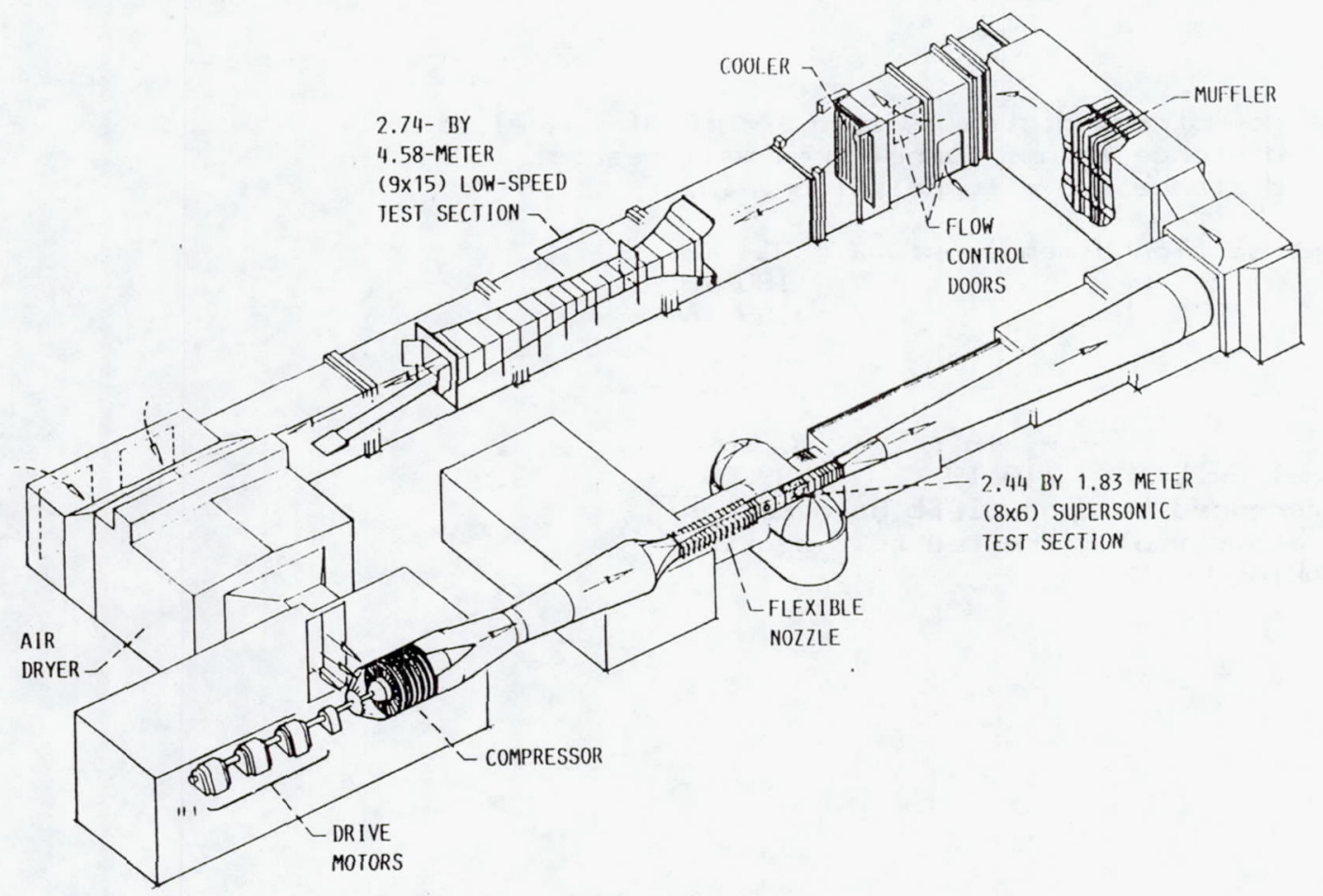

FIGURE 2. - NASA LEWIS $9^{\prime} \times 15^{\prime}$ AND $8^{\prime} \times 6^{\prime}$ WIND TUNNELS. 


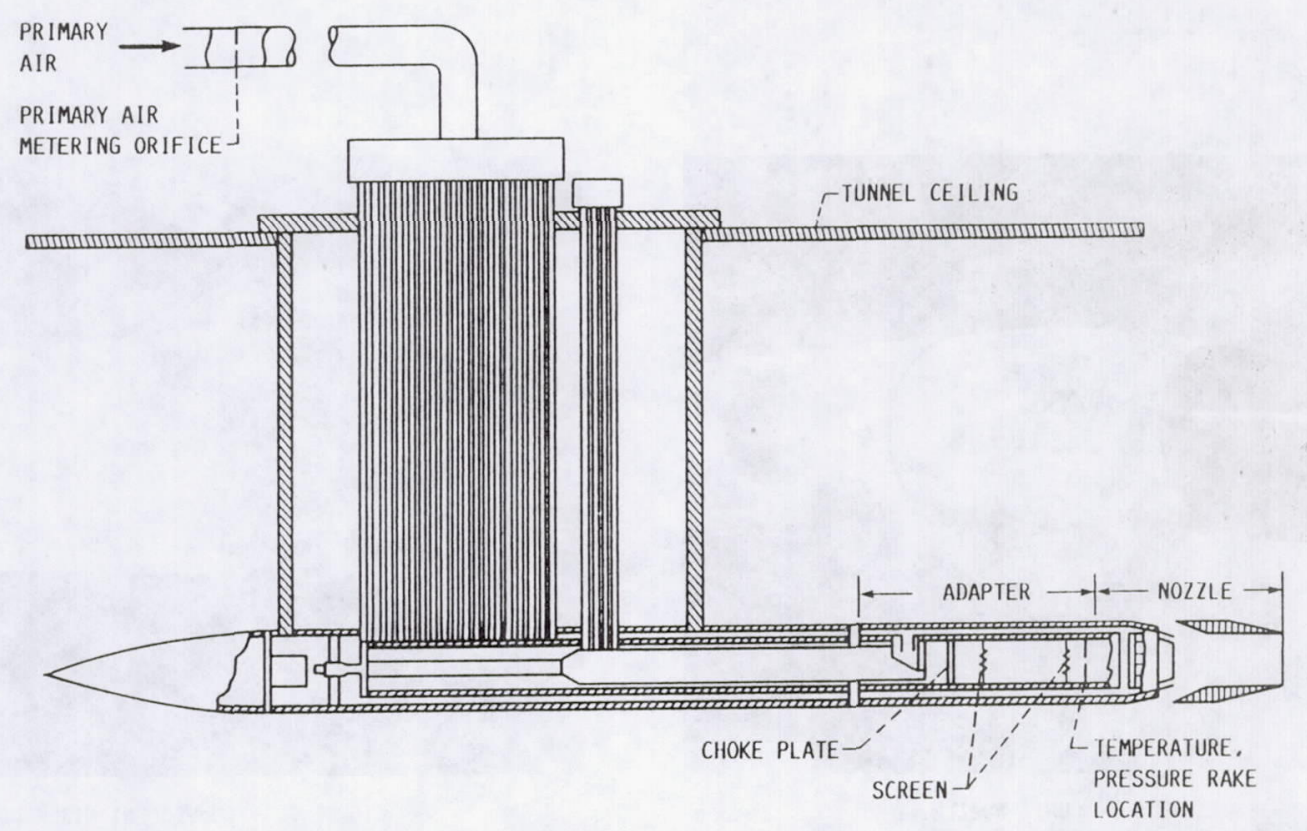

FIGURE 3. - SCHEMATIC OF AIR SUPPLY ANI MOUNTING ARRANGEMENT FOR PRATT AND WHIIINEY MIXER-EJECTOR IN NASA L.EWIS $9^{\prime} \times 15^{\circ}$ WIND TUNNEL.

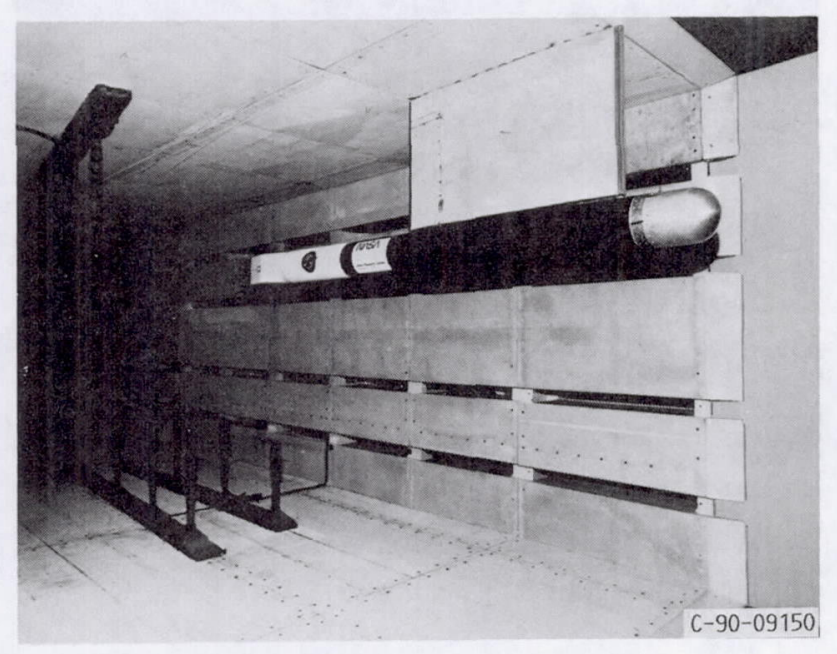

FIGURE ". - IFST NOI/II SIRIJI MOUNIIT) IN IUNNFL. (IOOKING IJOWNSIREAM. )

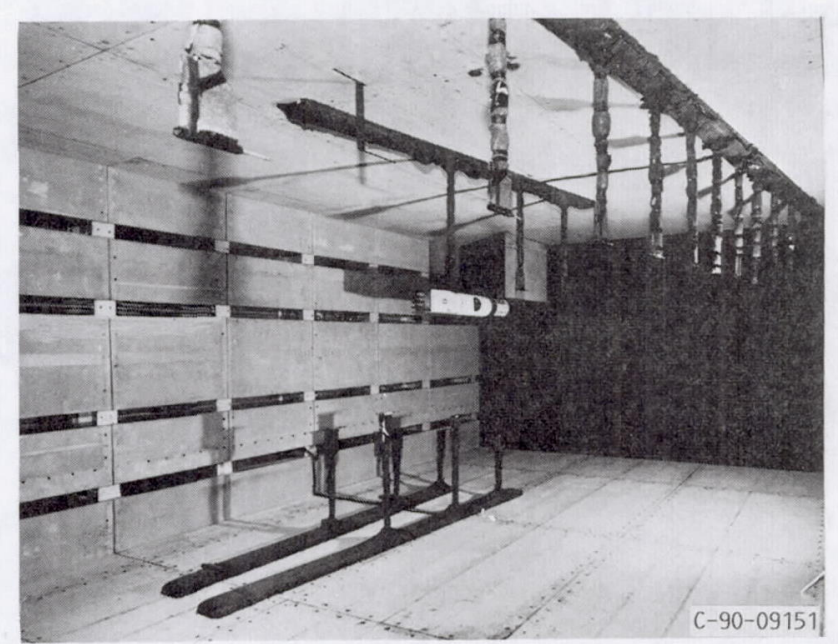

FigURE 5. - TEST NOZZLE MOUNTEI) IN TUNNEL. (LOOKING UPSTREAM.) 


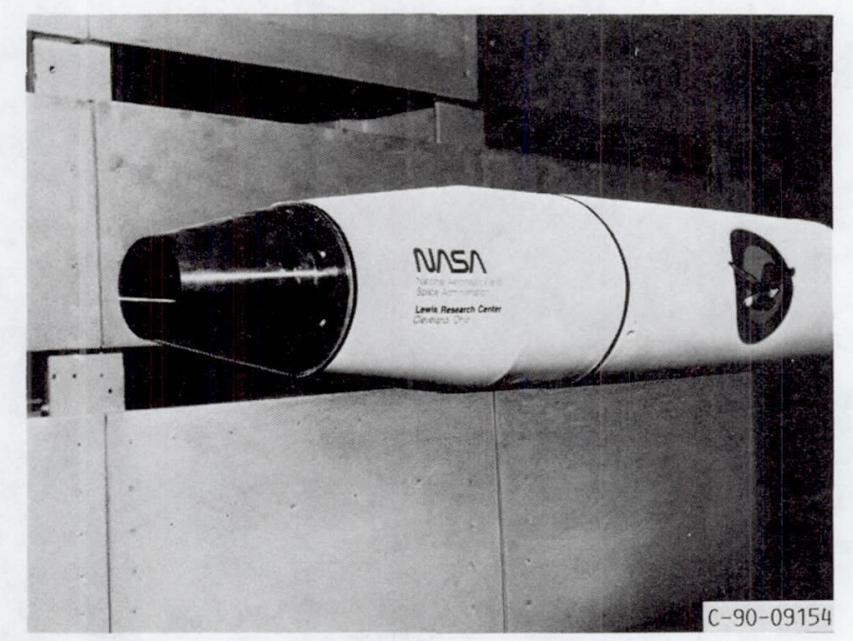

FIGURE 6. - CONIC NOZZLE.

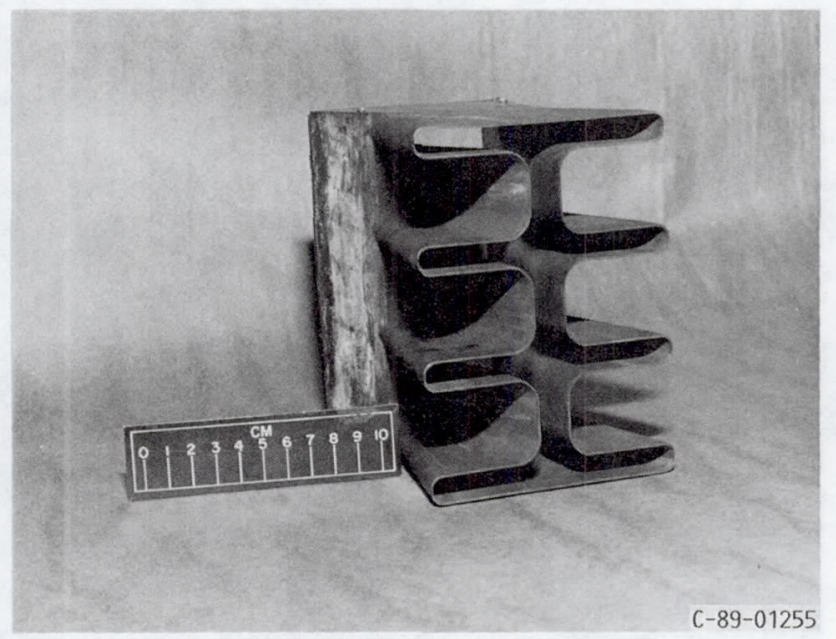

FIGURE 8. - CONVERGENT-DIVERGENT MIXER NOZZLE.

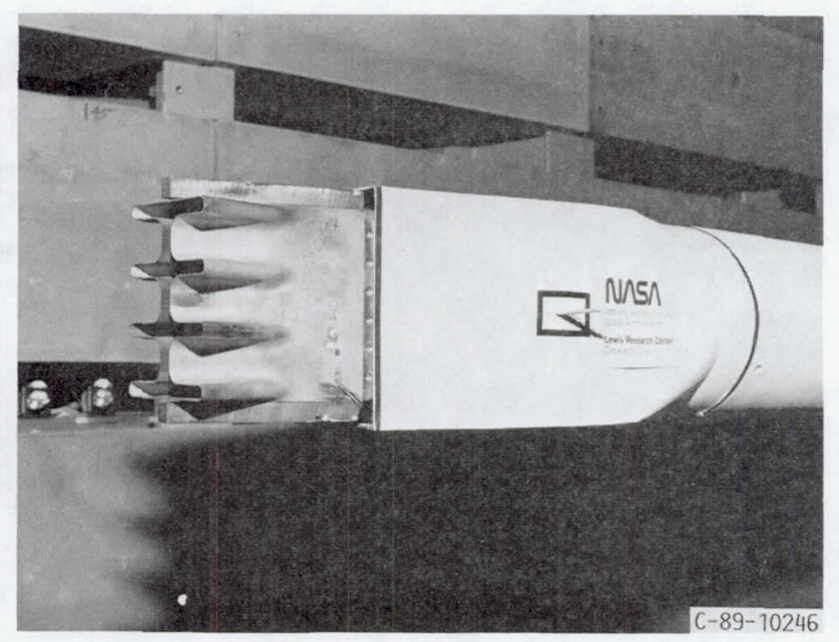

FIGURE 7. - CONVERGENT MIXER NOZZLE.

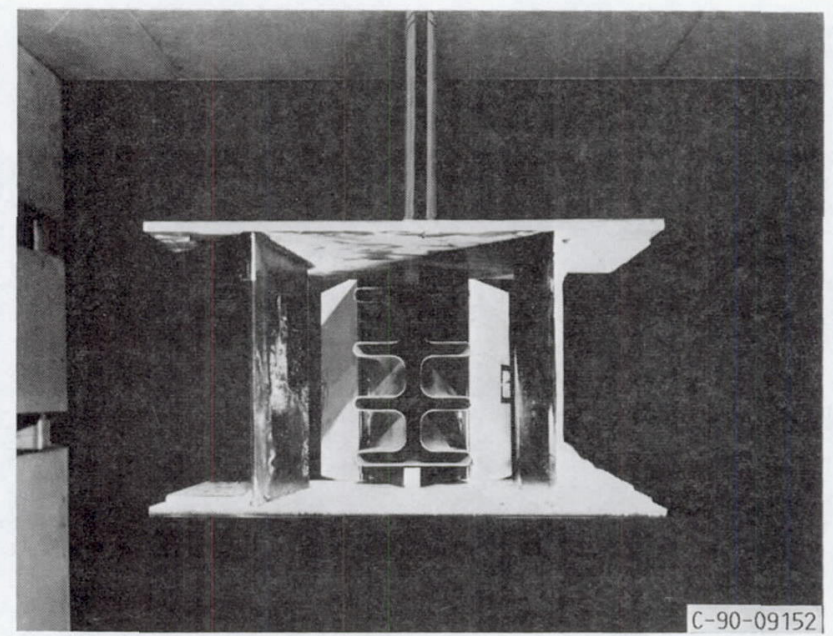

FIGURE 9. - CONVERGENT MIXER NOZZLE WITH EJECTOR SHROUI). 


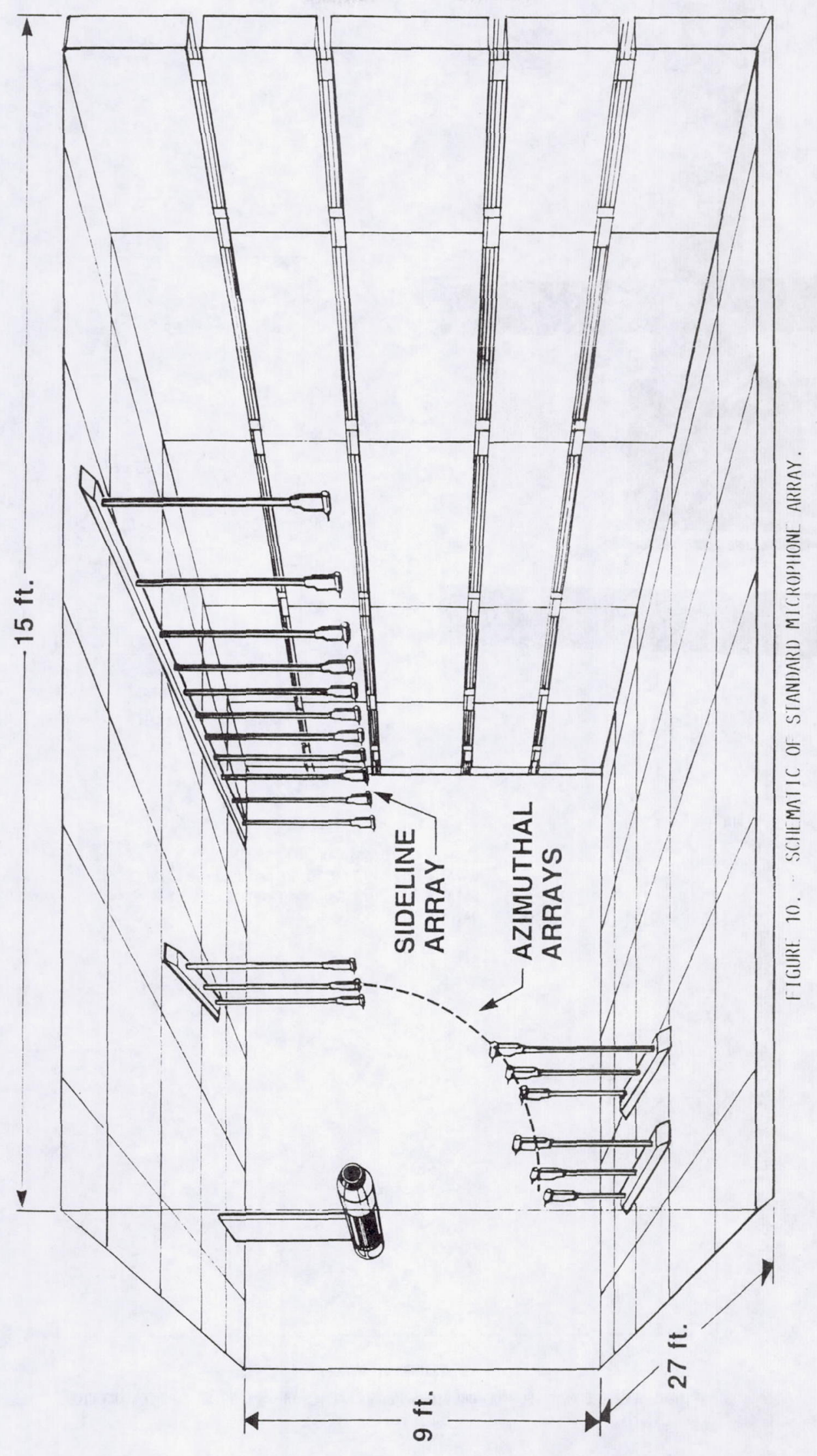




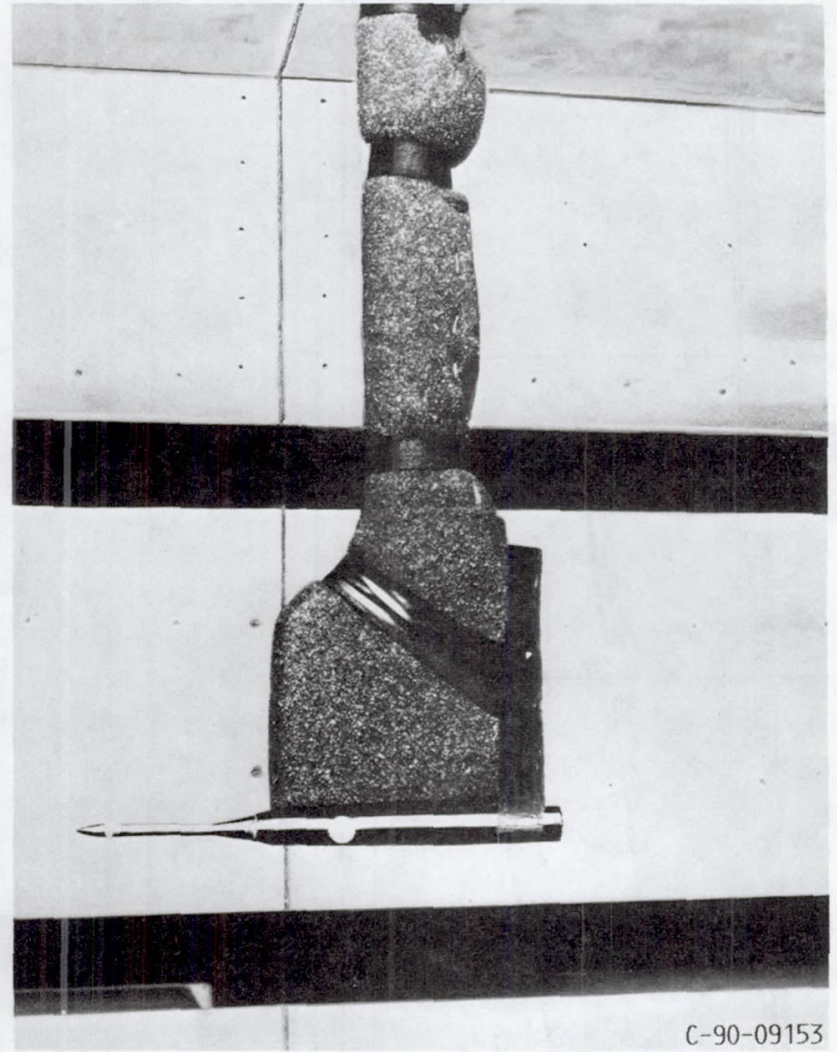

FIGURE 11. - TYPICAL MICROPHONE INSTALLATION.

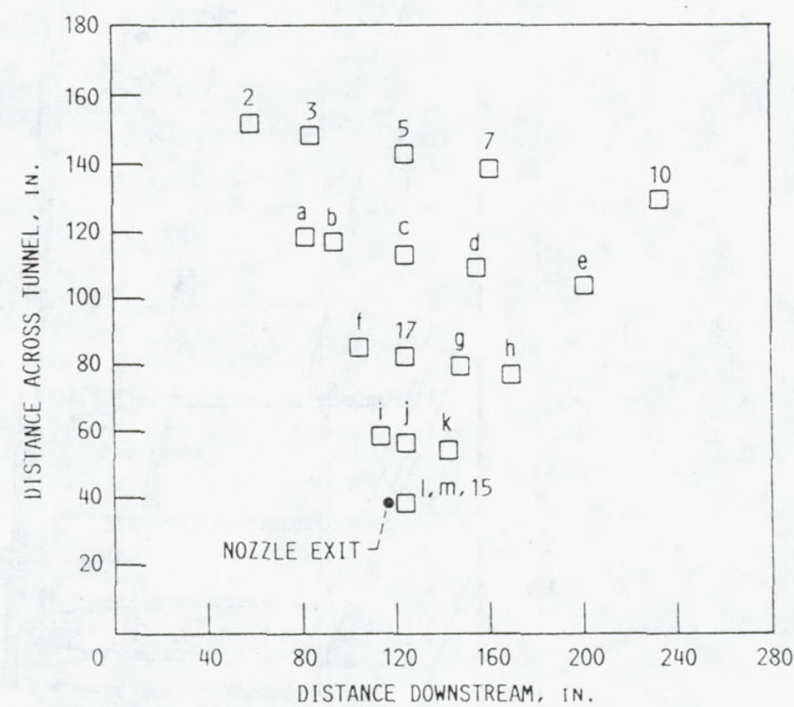

FIGURE 12. - TOP VIEW OF ALTERNATE MICROPHONE ARRAY.

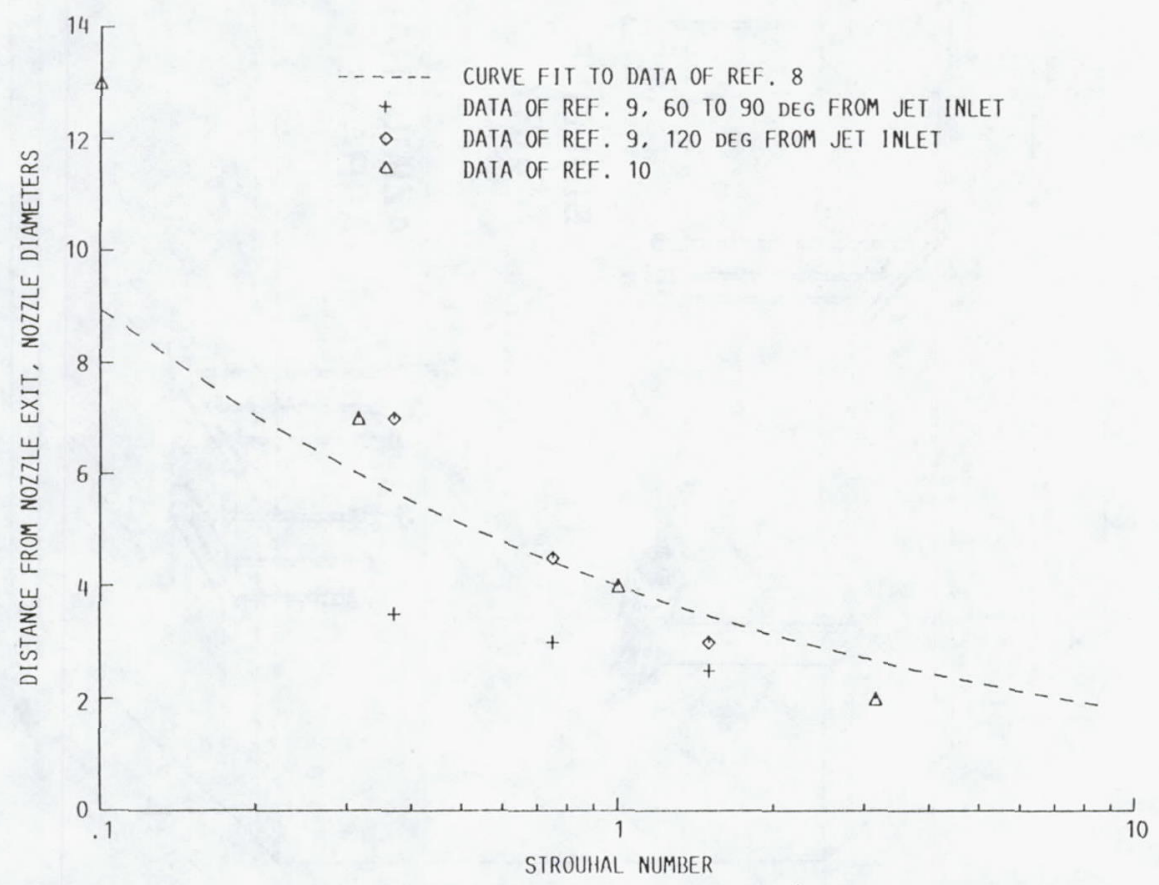

FIGURE 13. - COMPARISON OF PREVIOUS MEASUREMENTS OF JET NOISE SOURCE LOCATION. 


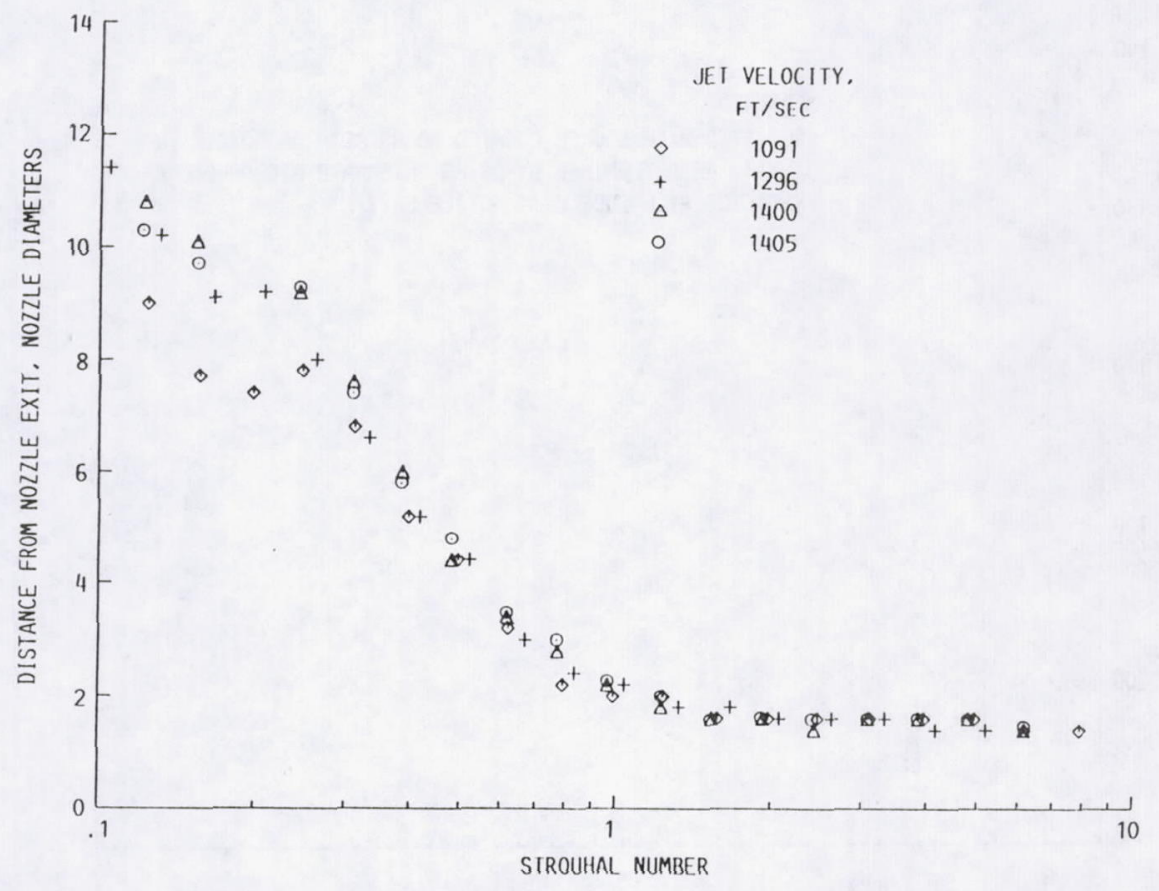

FIGURE 14. - CURRENT MEASUREMENTS OF JET NOISE SOURCE LOCATION.

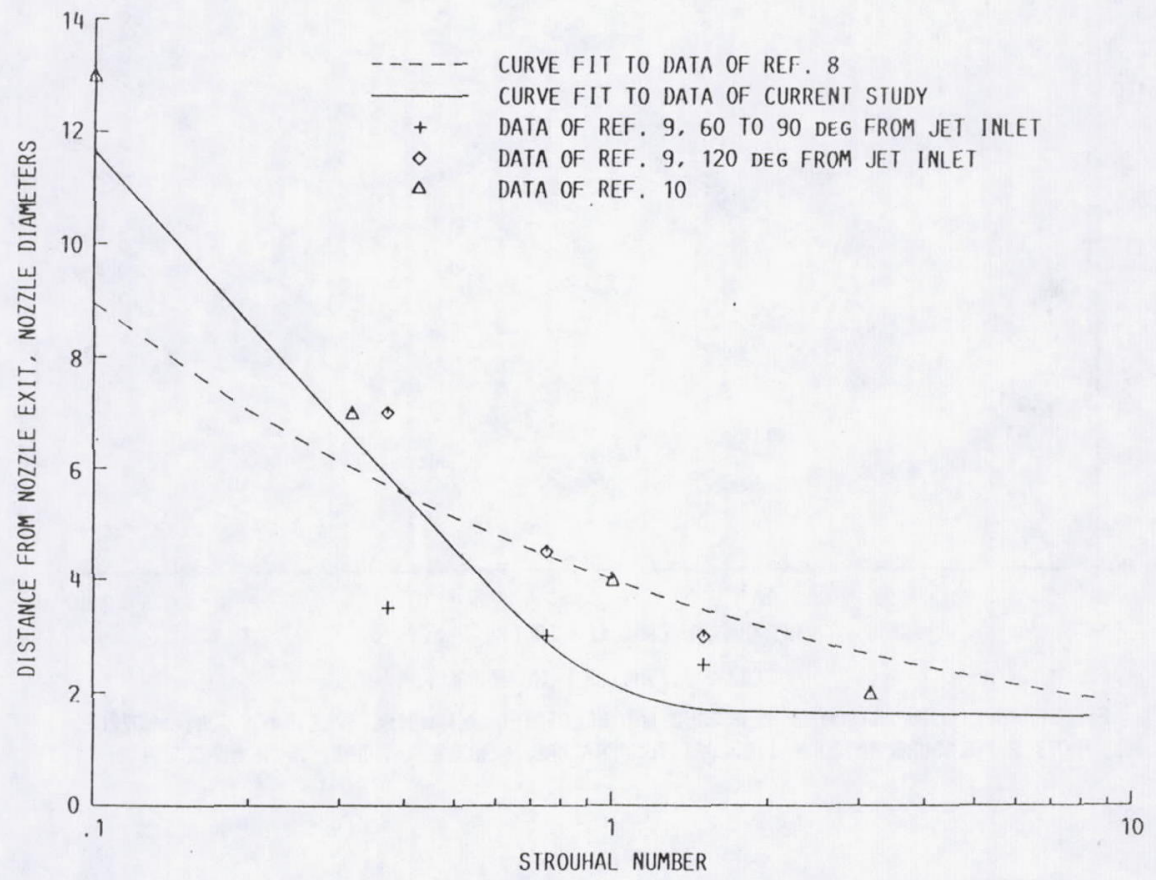

FIGURE 15. - COMPARISON OF CURRENT AND PREVIOUS MEASUREMENTS OF JET NOISE SOURCE LOCATION. 


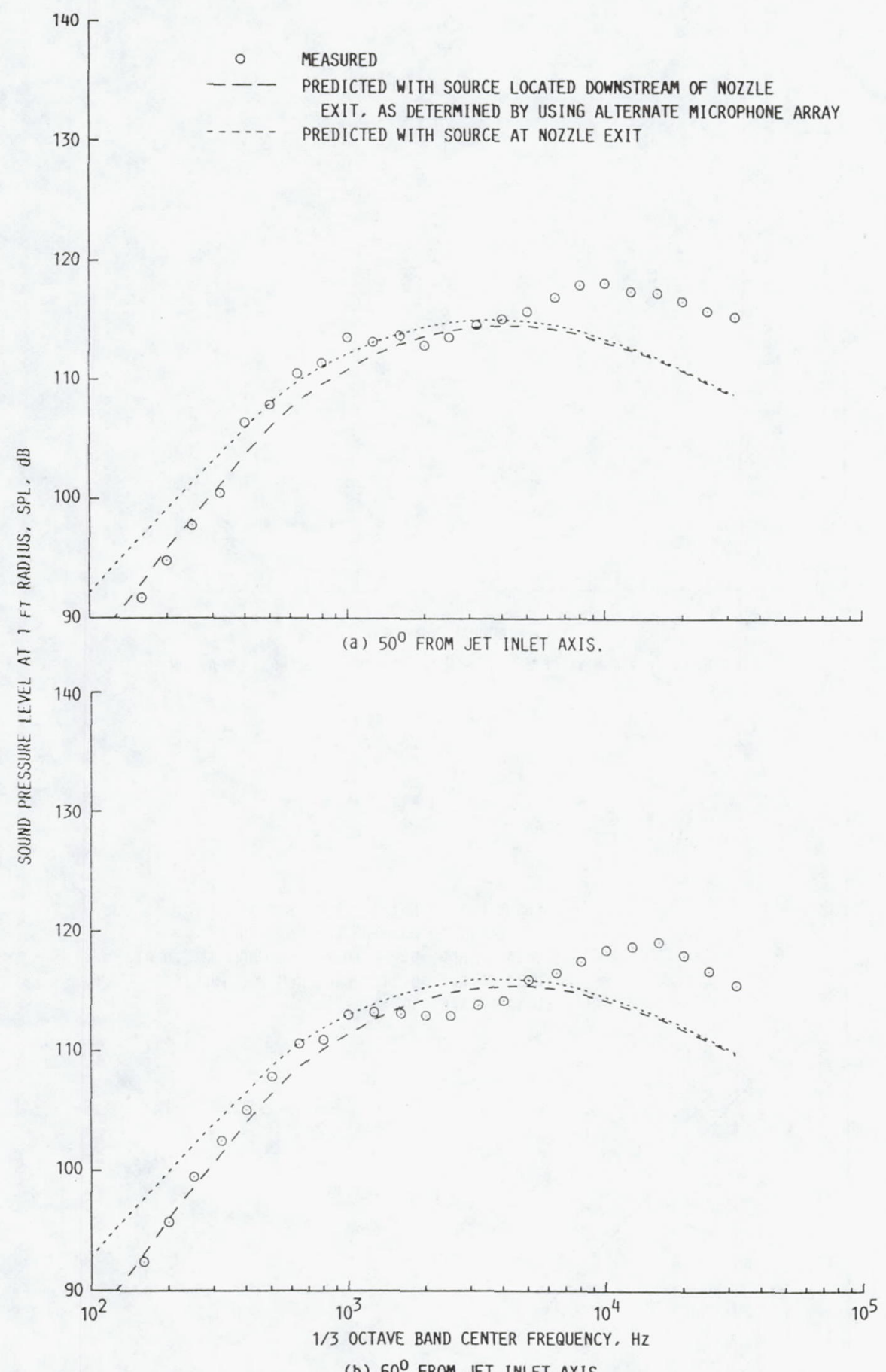

(b) $60^{\circ}$ FROM JET INLET AXIS,

FIGURE 16. - COMPARISON OF MEASURED AND PREDICTED JET NOISE SPECTRA. CONIC NOZZLE, NOZZLE PRESSURE RATIO $=1.8$. JET TEMPERATURE $=903^{\circ} \mathrm{R}$, , TUNNEL MACH NUMBER $=0$. 


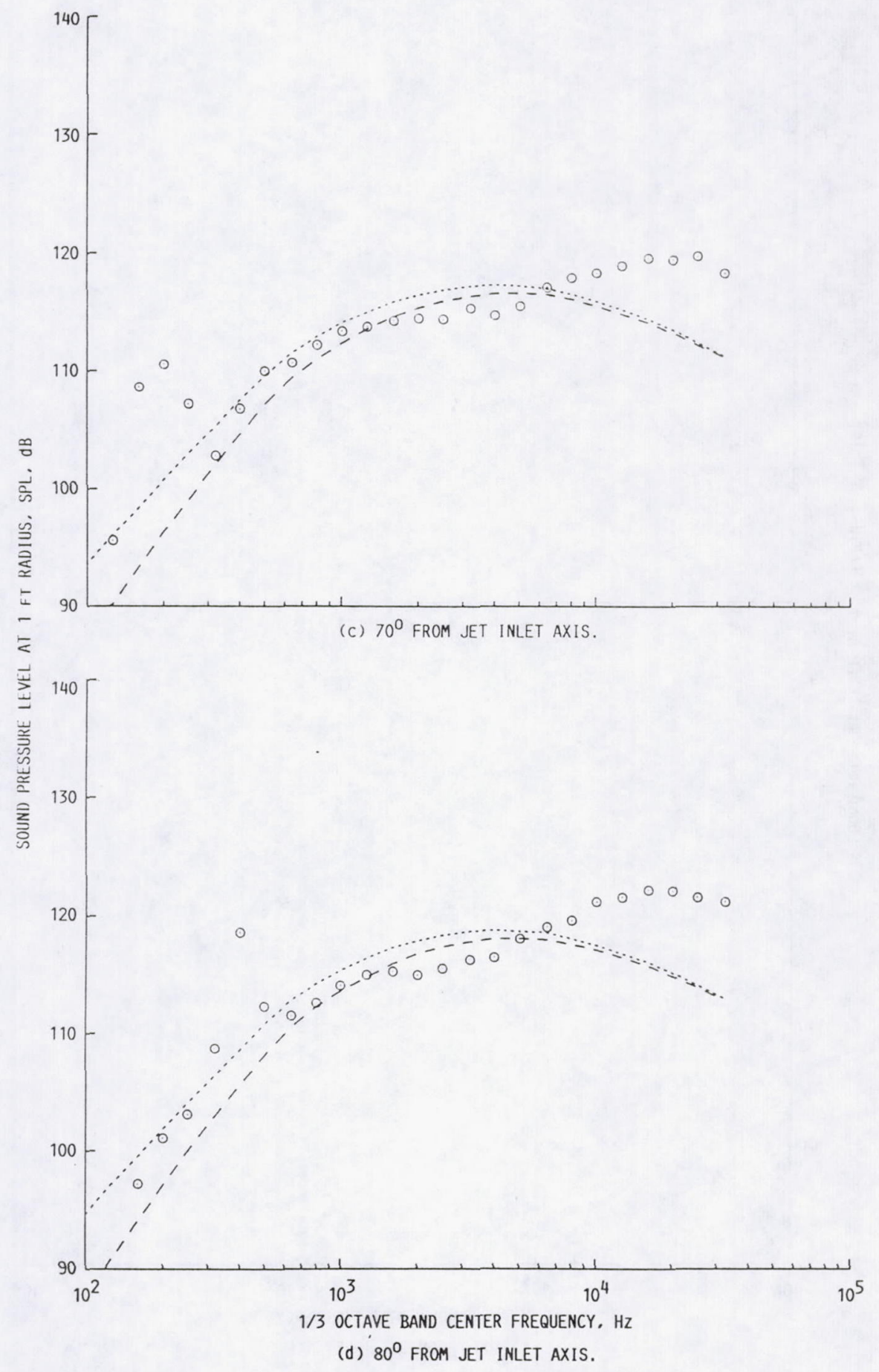

FigURE 16. - CONTINUED. 


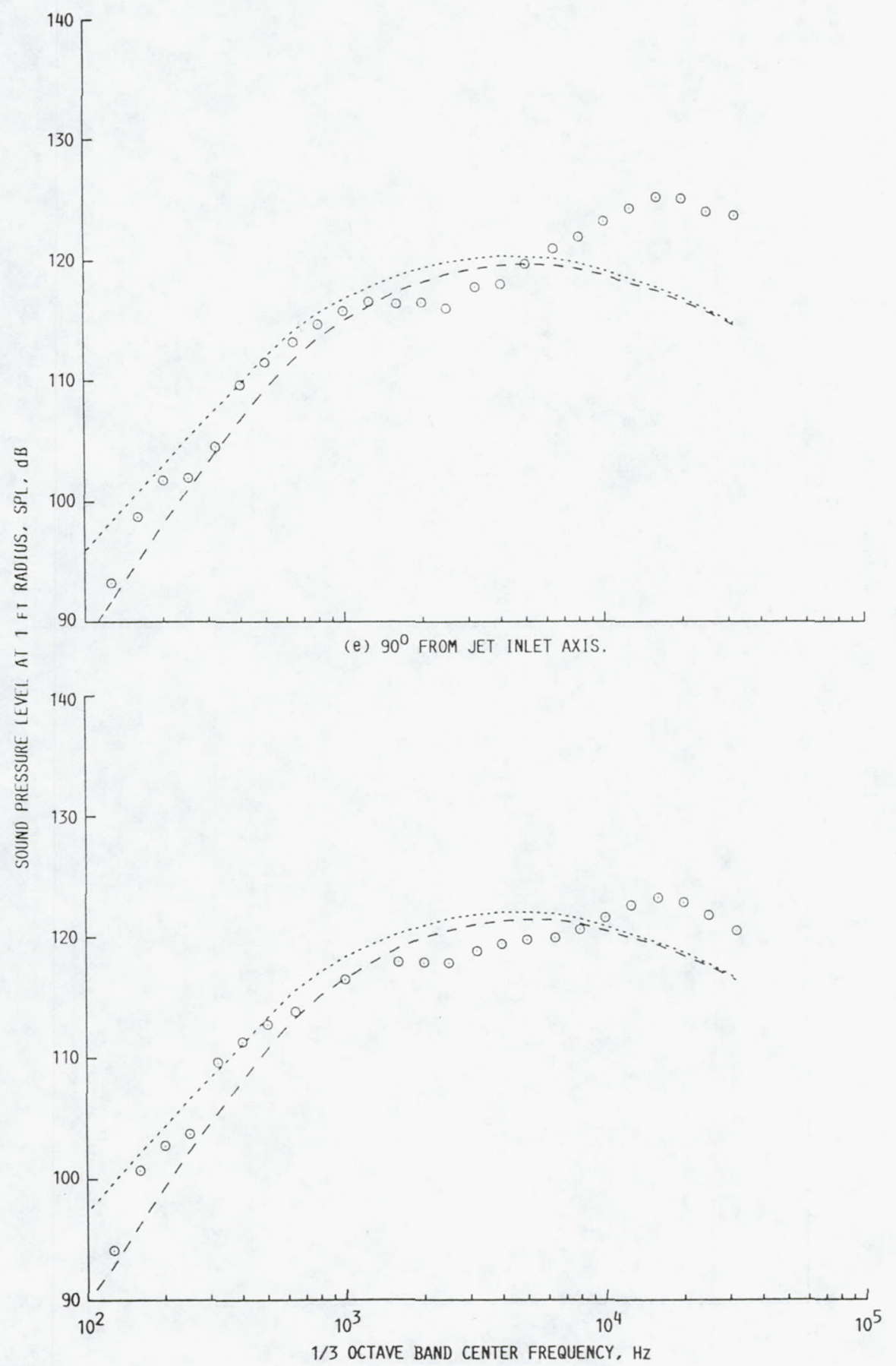

(f) $100^{\circ}$ FROM JET INLET AXIS.

FIGURE 16. - CONTINUED. 


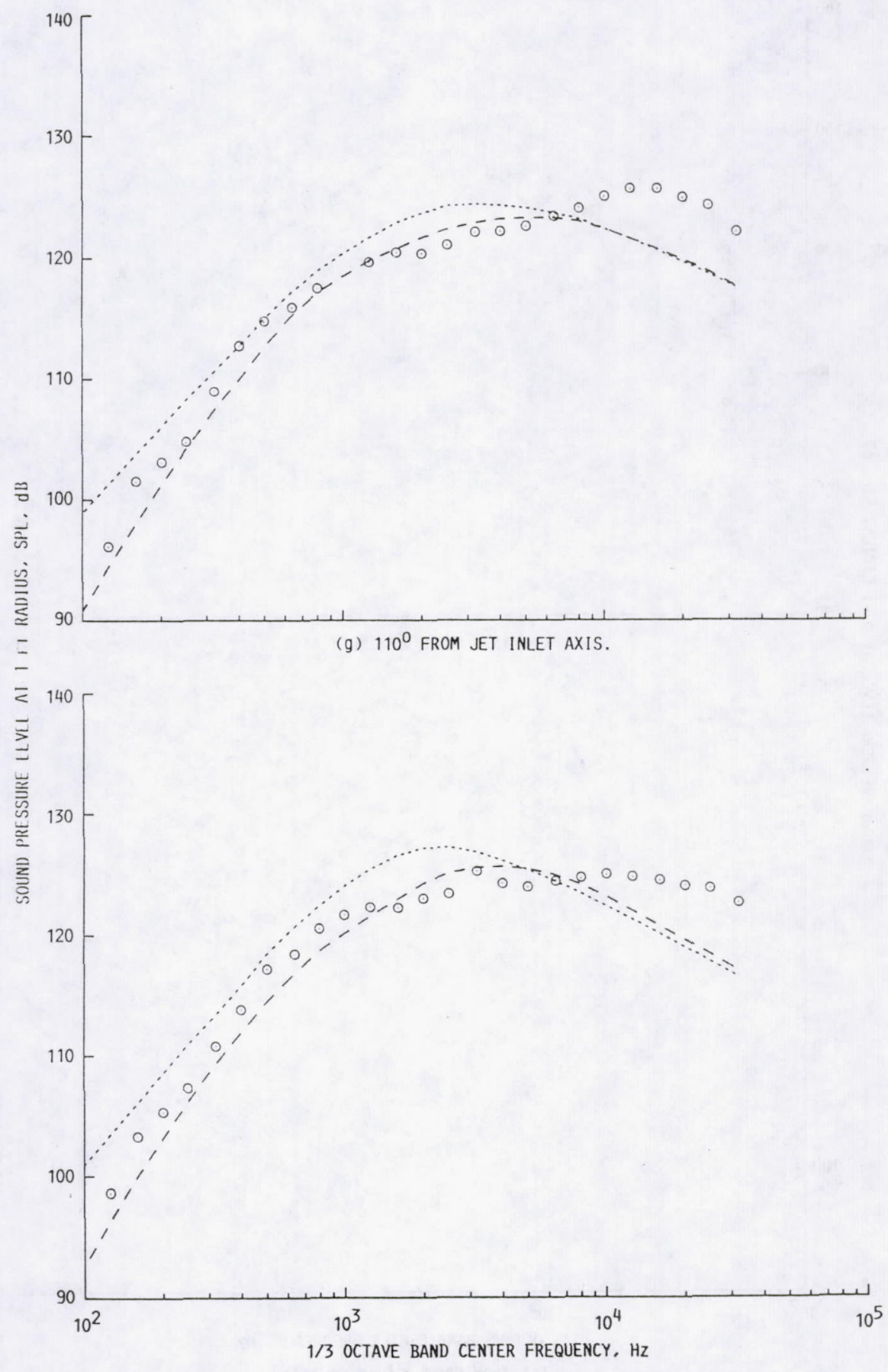

(h) $120^{\circ}$ FROM JET INLET AXIS.

FIGURE 16. - CONTINUED. 


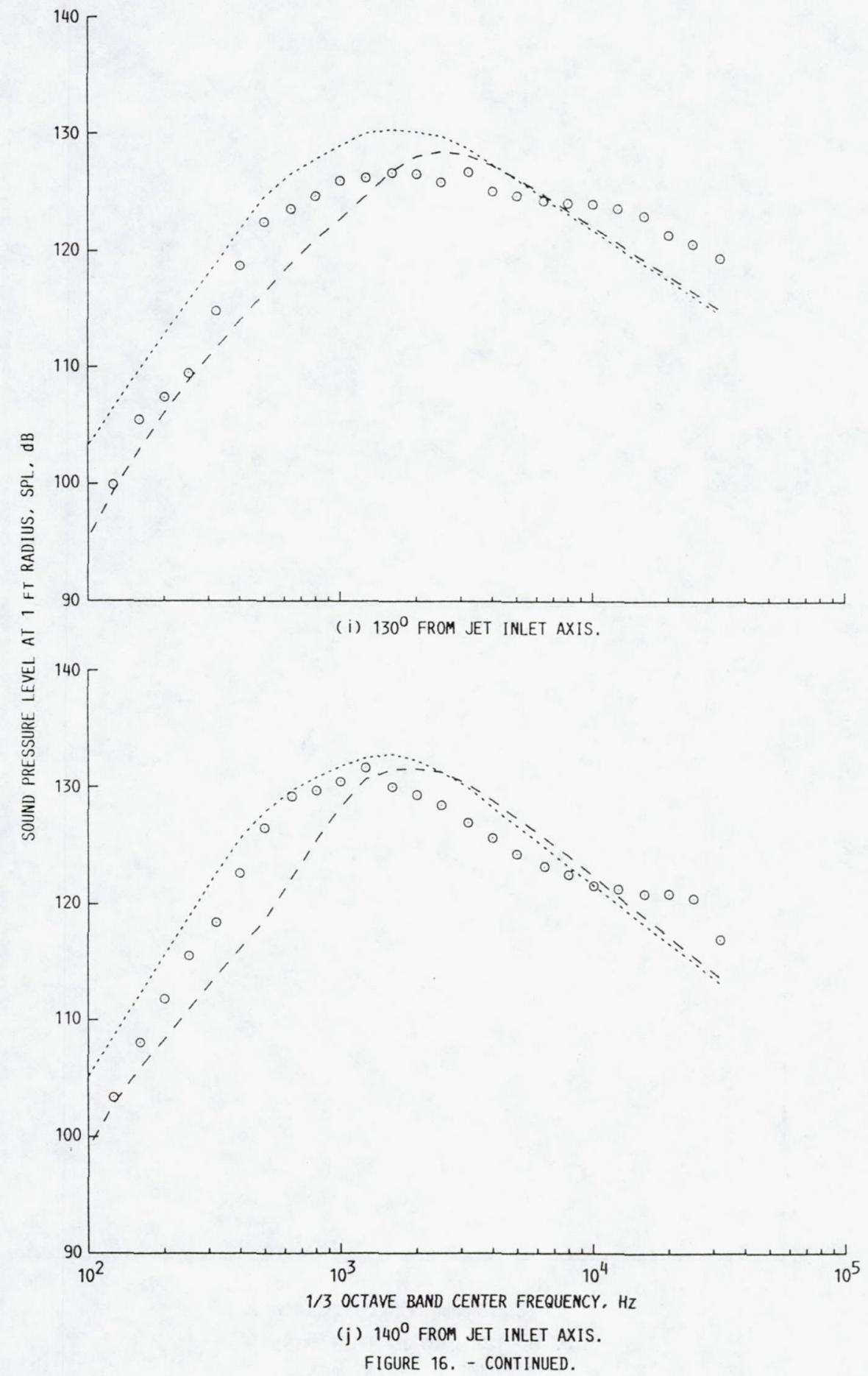




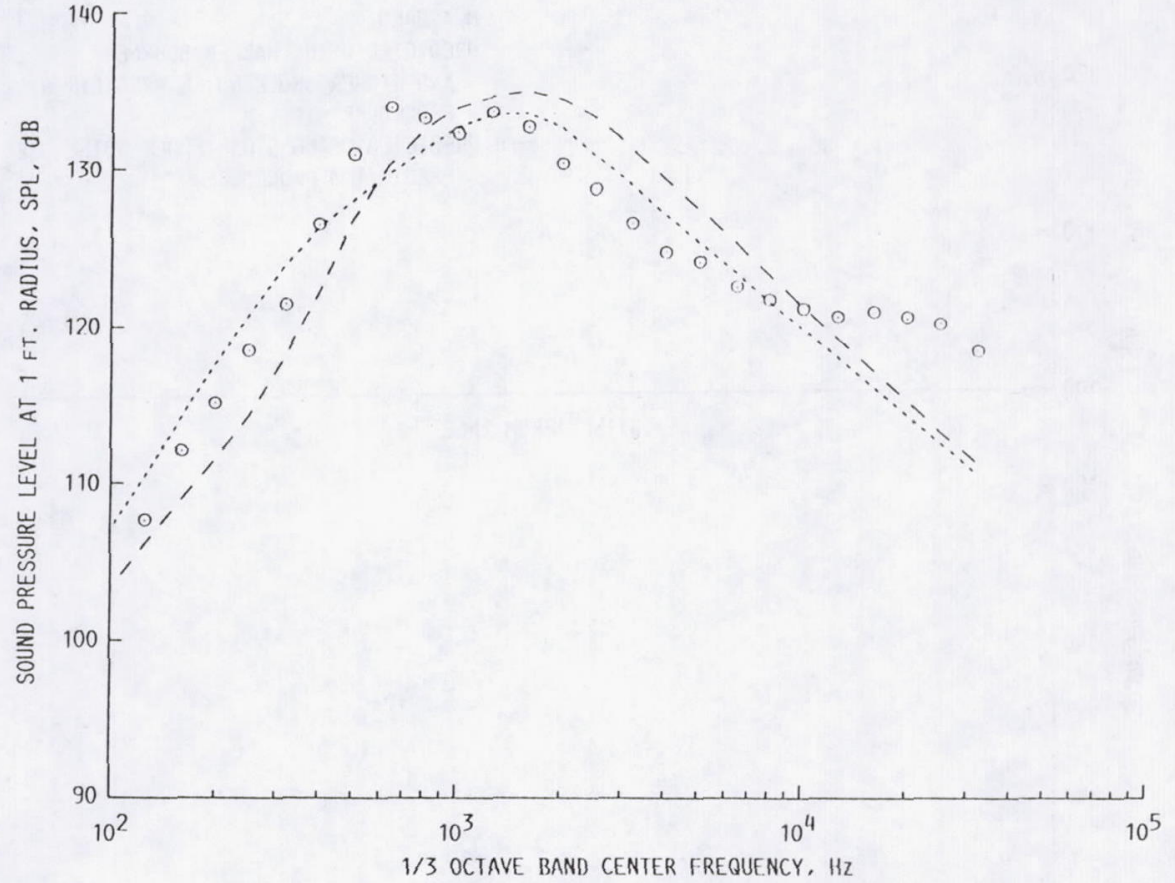

(k) $150^{\circ}$ FROM JET INLET AXIS.

FIGURE 16. - CONCLUDED. 


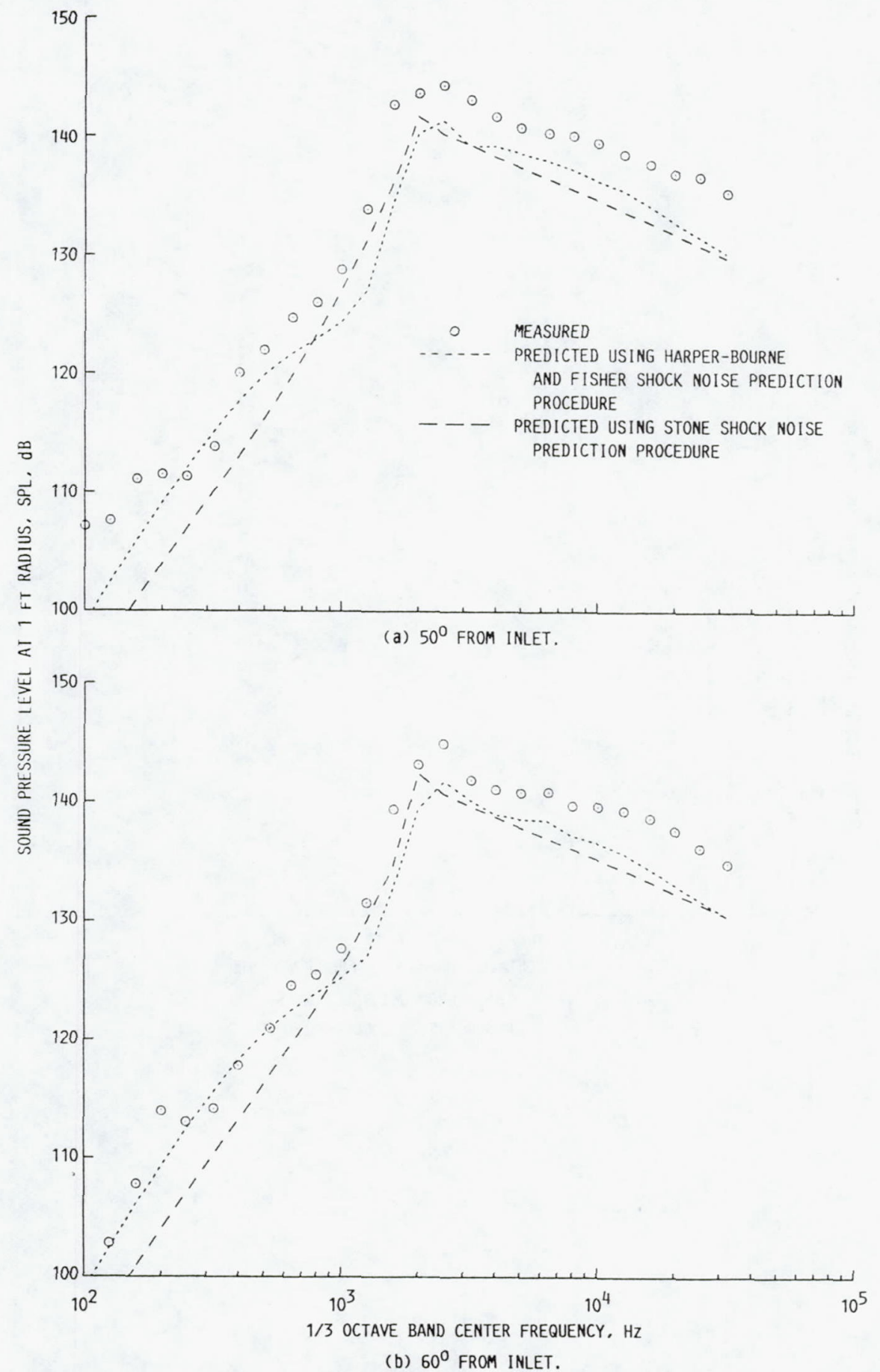

FigURE 17. - COMPARISON OF MEASURED AND PREDICTED JET NOISE SPECTRA. CONIC NOZZLE, NOZZLE PRESSURE RATIO $=4.0$. JET TEMPERATURE $=915^{\circ} \mathrm{R}$. 


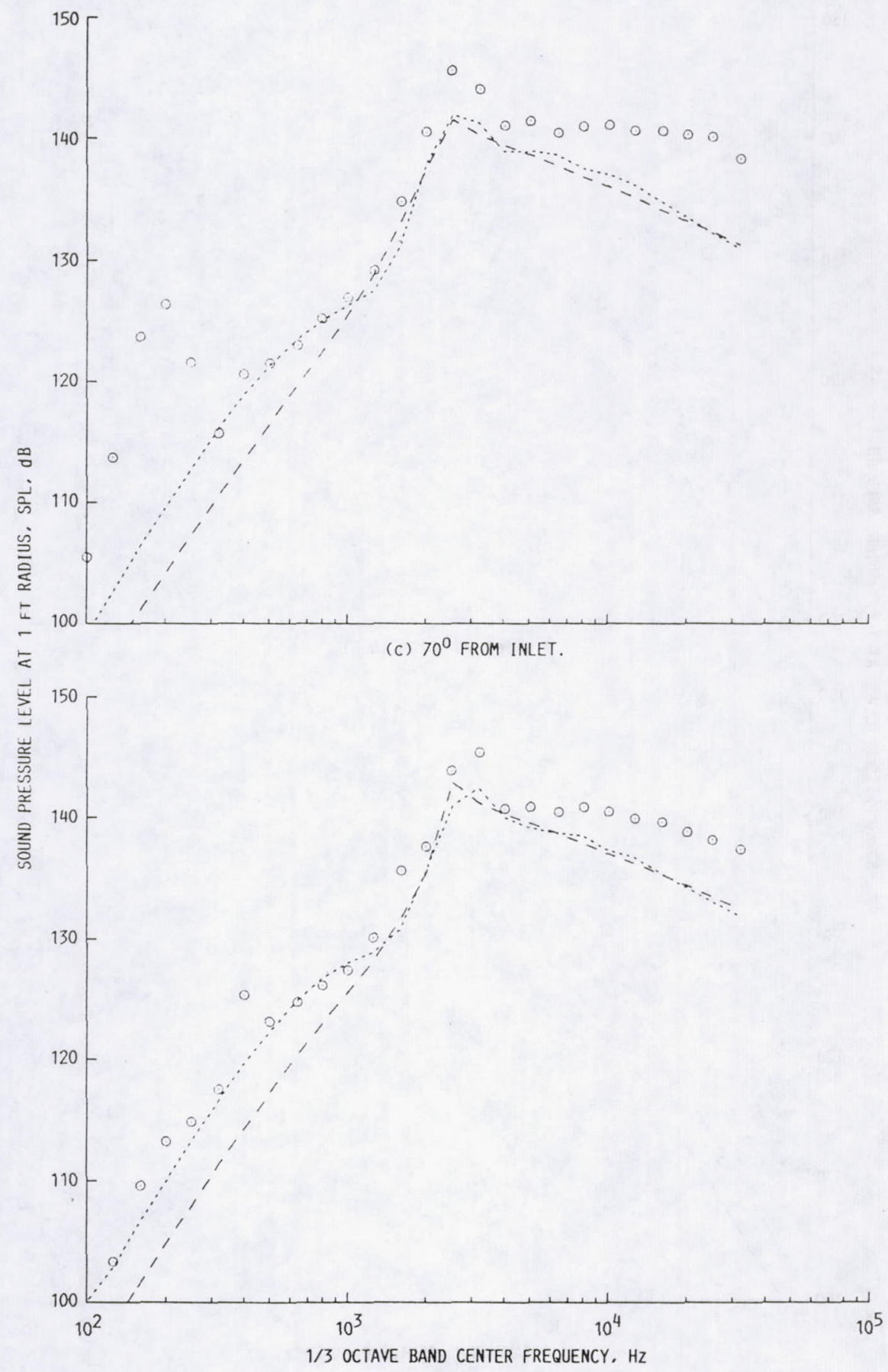

(d) $80^{\circ}$ FROM INLET.

FIGURE 17. - CONTINUED. 


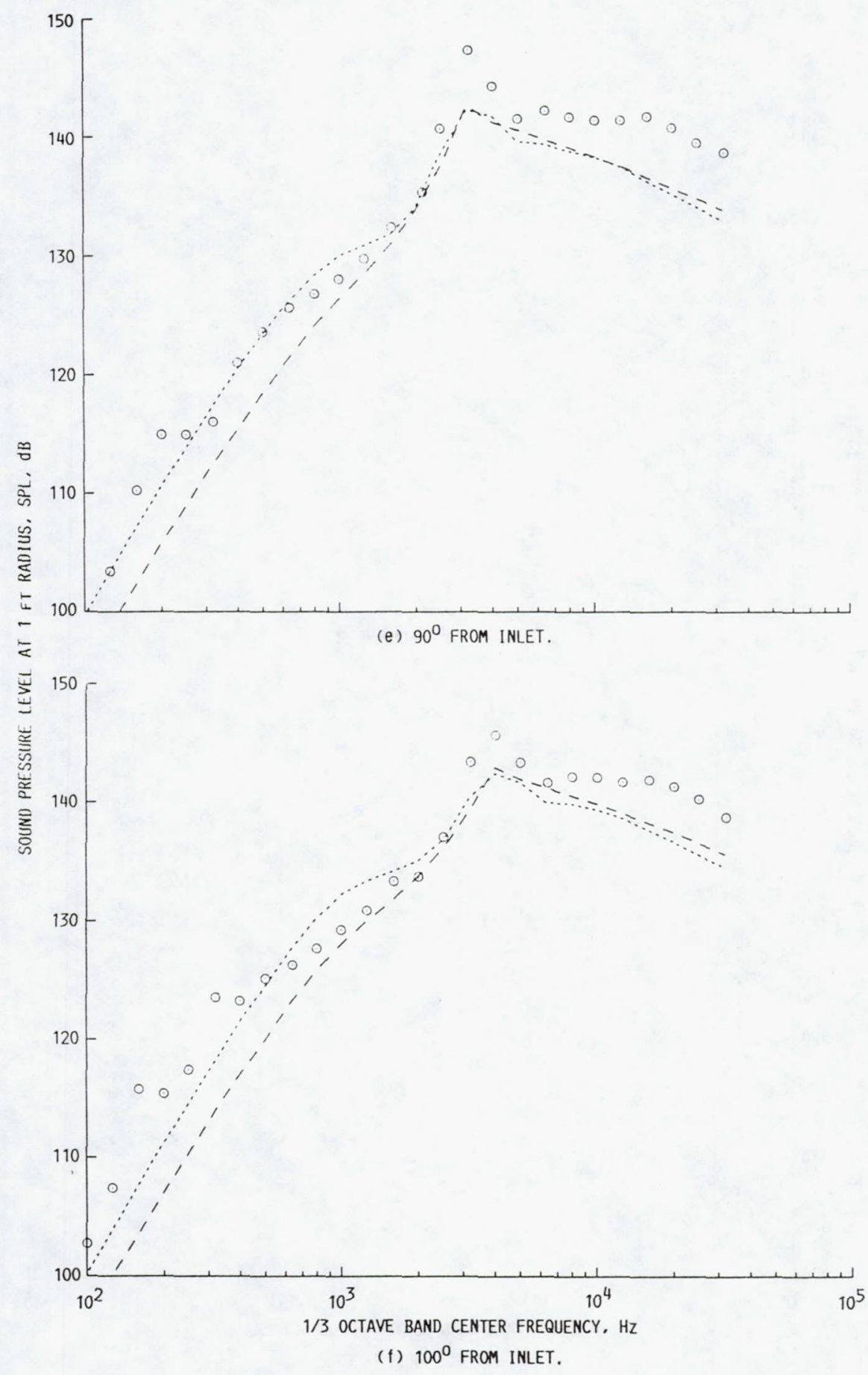

FIGURE 17. - CONTINUED. 


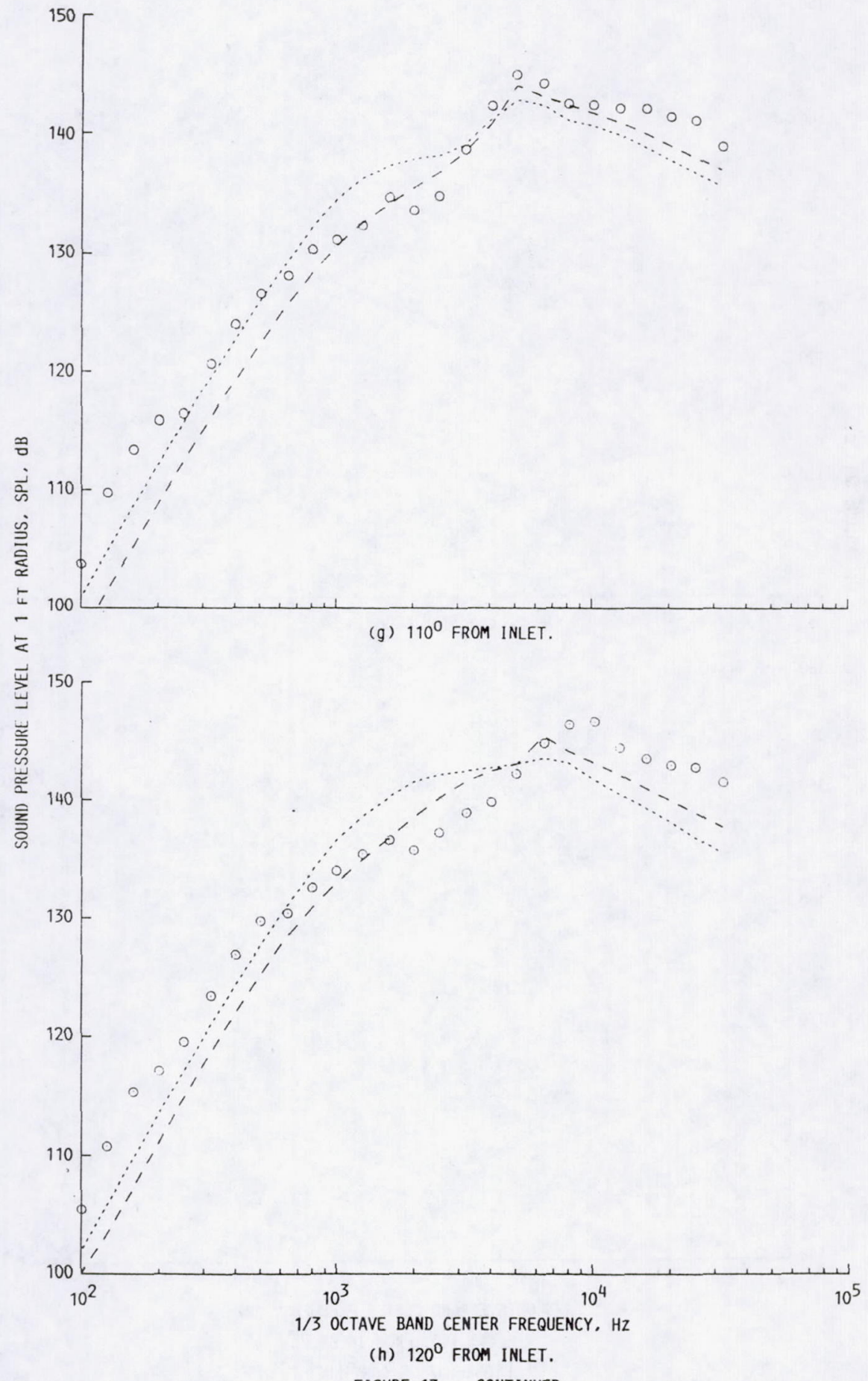

FIGURE 17. - CONTINUED. 


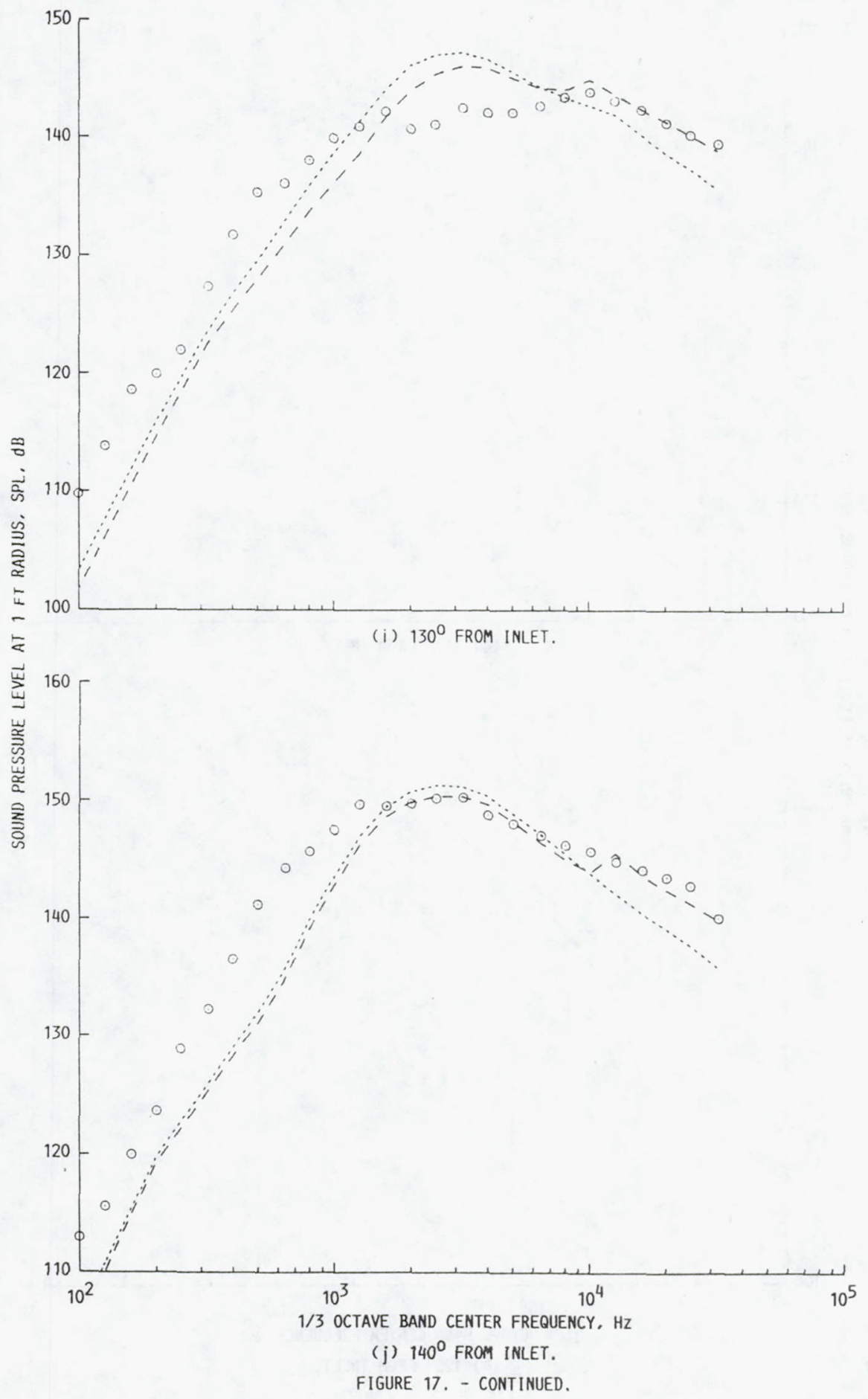




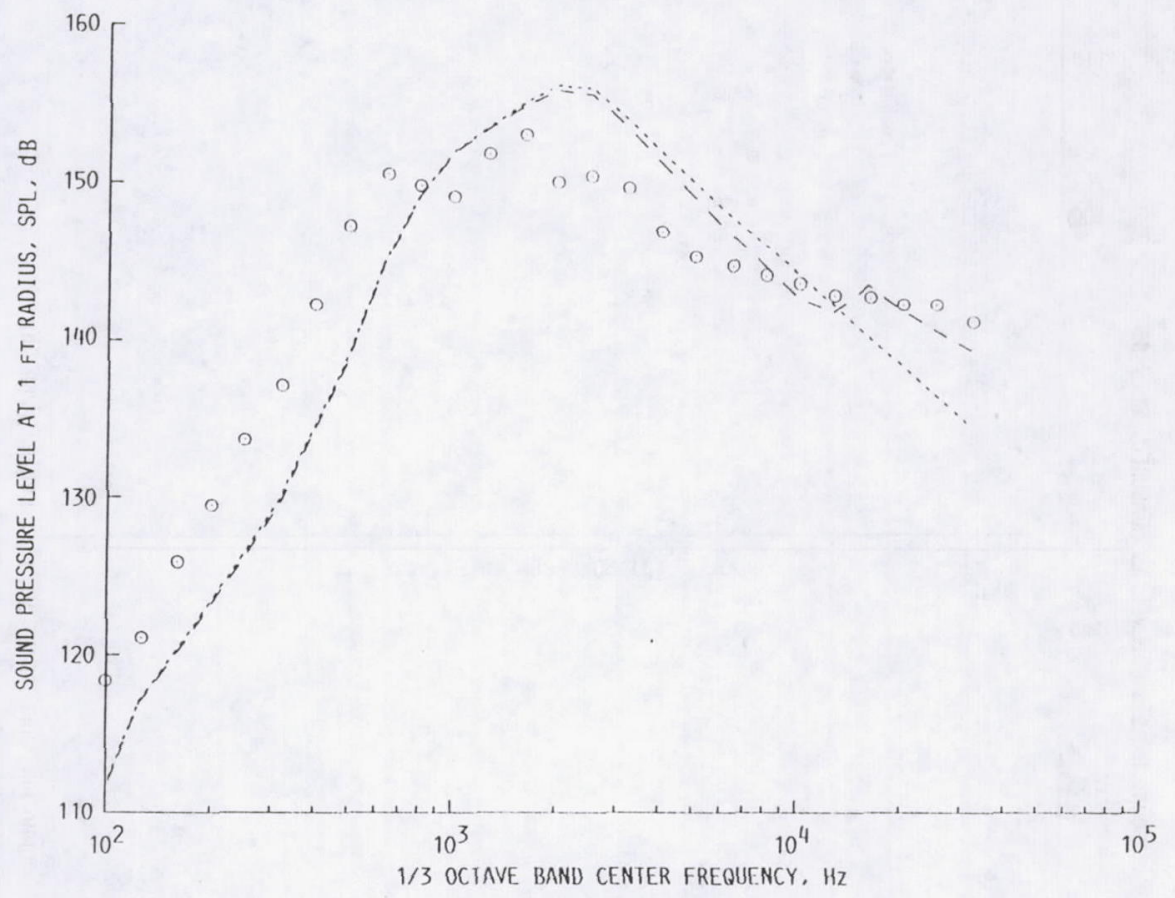

(k) $150^{\circ}$ FROM INLET.

FiguRE 17. - CONCLUDED.

33 


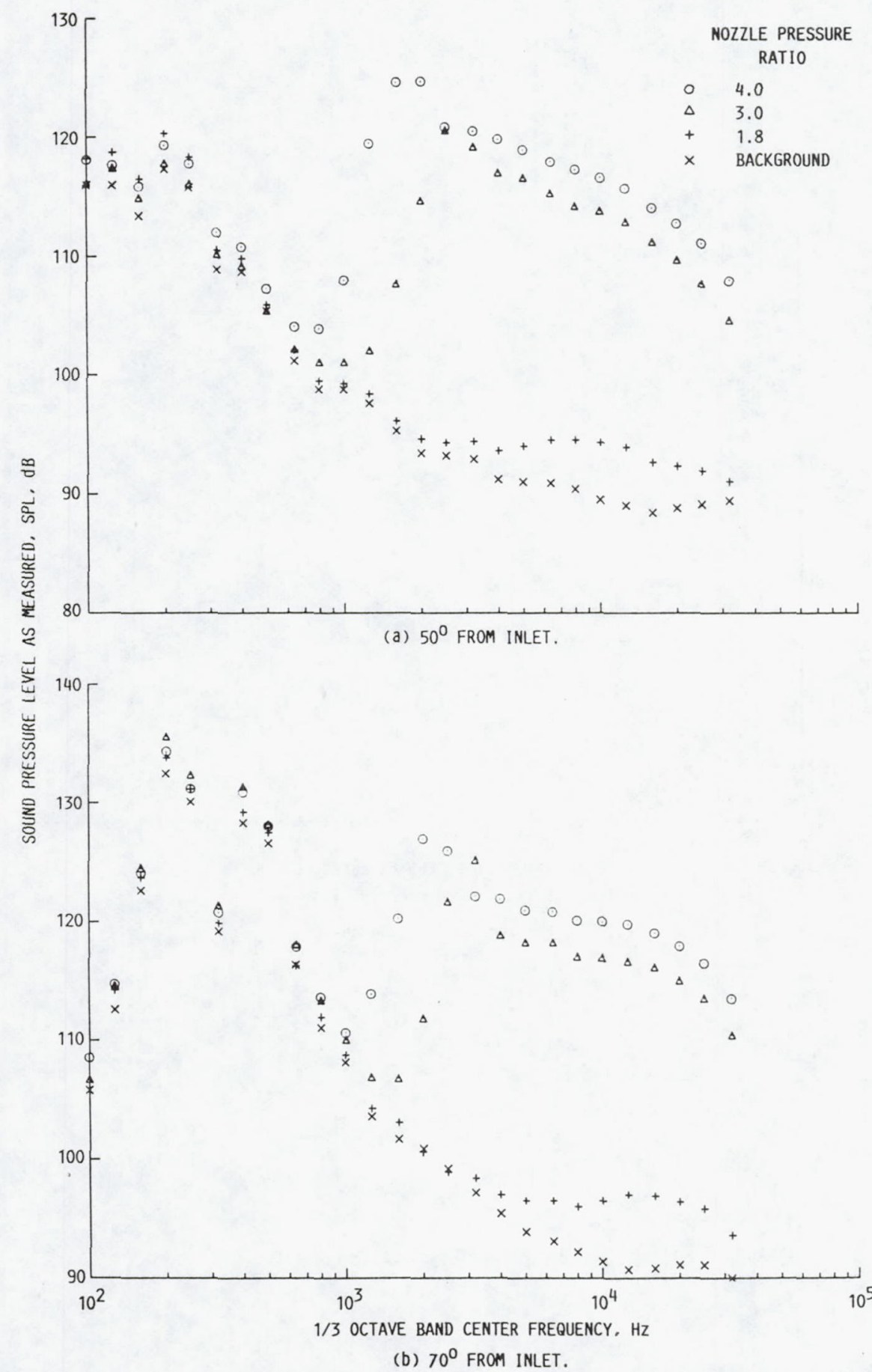

FIGURE 18. - COMPARISON OF CONIC SPECTRA HITH BACKGROUND NOISE SPECTRA. NOMINAL JET TEMPERATURE $=900^{\circ} \mathrm{R}$. , TUNNEL MACH NUMBER $=0.2$. 


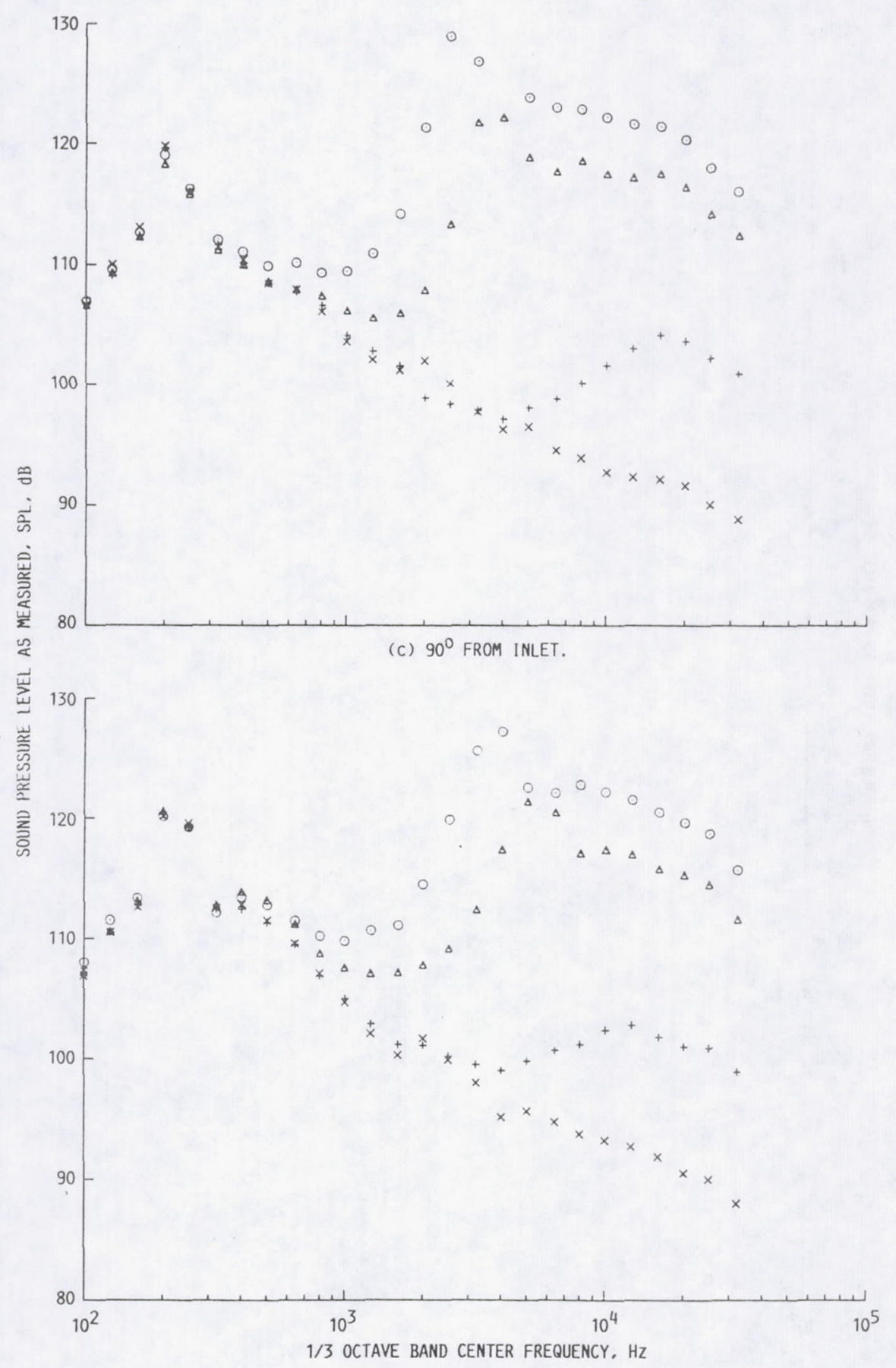

(d) $110^{\circ}$ FROM INLET.

FIGURE 18. - CONTINUED. 


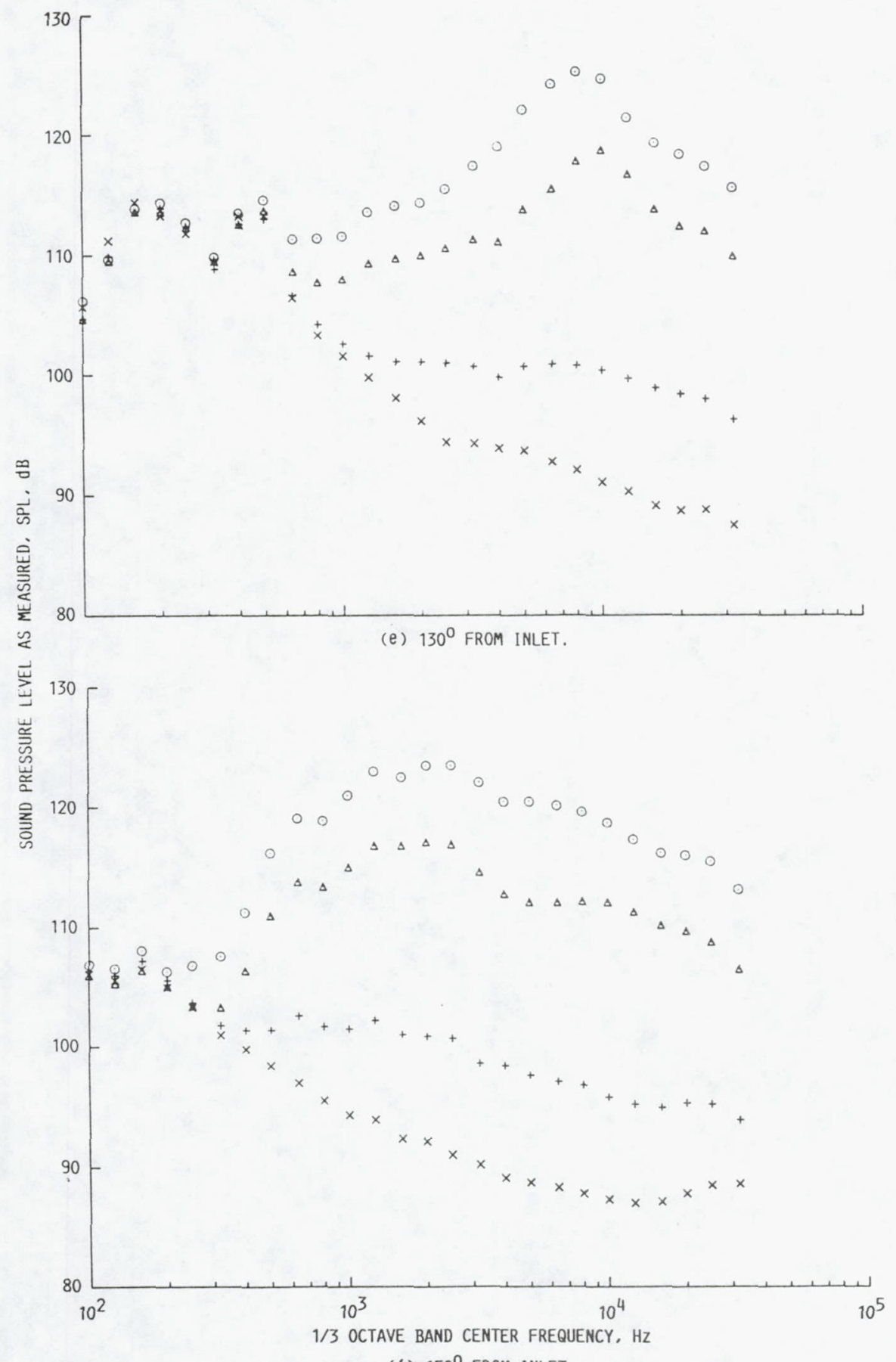

(f) $150^{\circ}$ FROM INLET.

FIGURE 18. - CONCLUDED. 


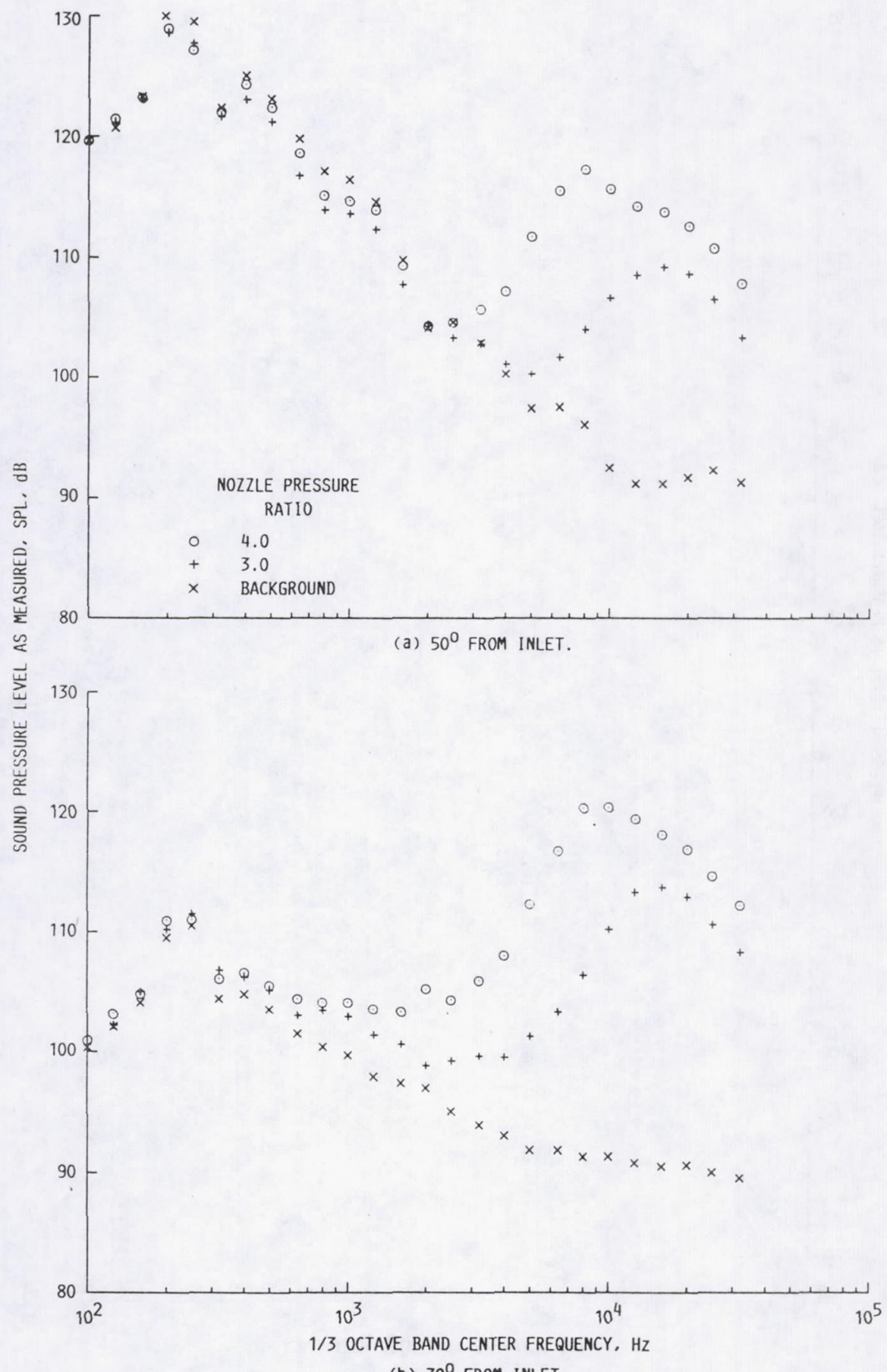

(b) $70^{\circ}$ FROM INLET.

FIGURE 19. - COMPARISON OF EJECTOR-MIXER NOZZLE SPECTRA WITH BACKGROUND NOISE SPECTRA. NOMINAL JET TEMPERATURE $=900^{\circ} \mathrm{R}$., TUNNEL MACH NUMBER $=0.2$. 


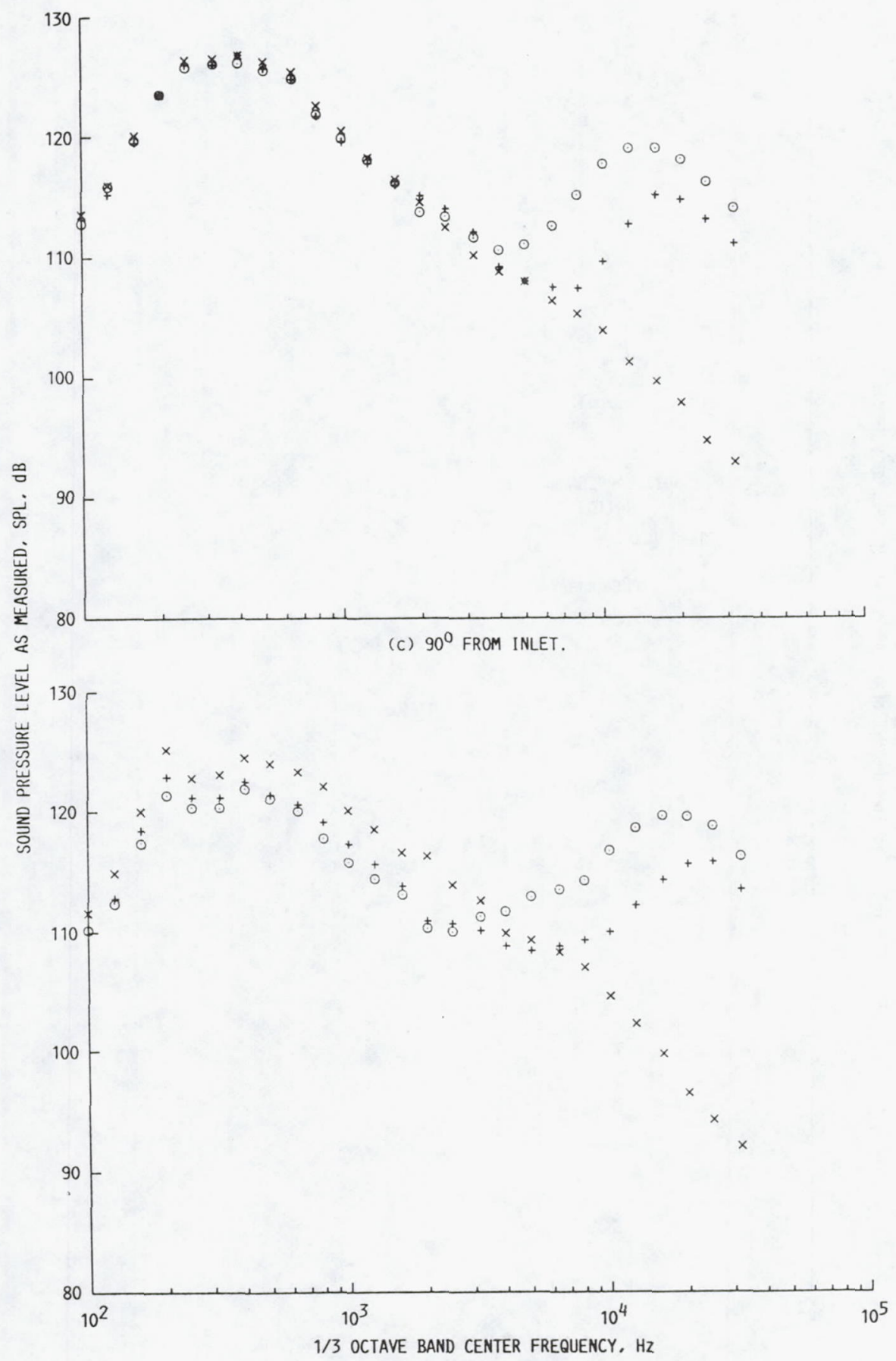

(d) $110^{\circ}$ FROM INLET.

FIGURE 19. - CONTINUED. 


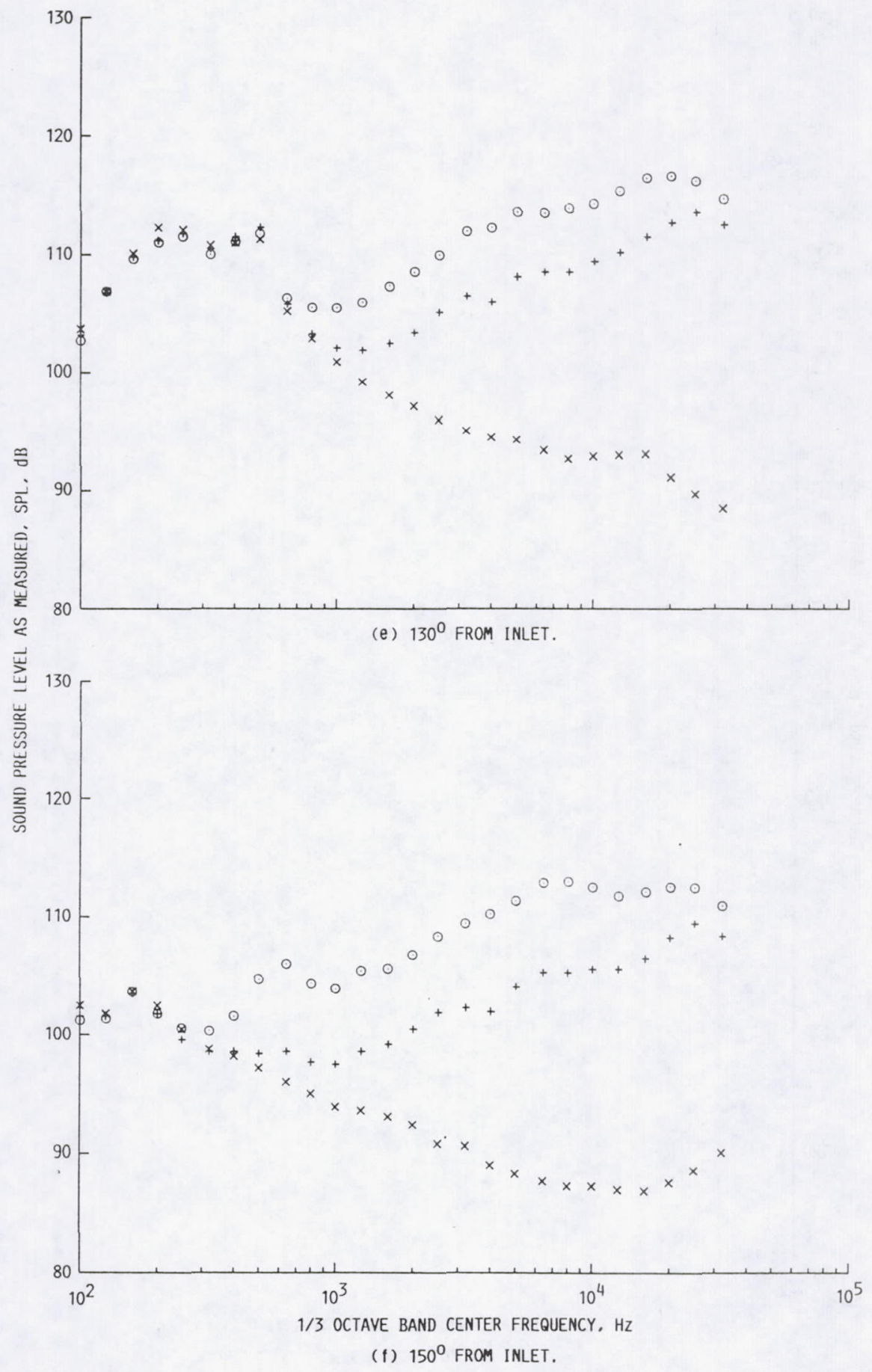

FIGURE 19, - CONCLUDED. 


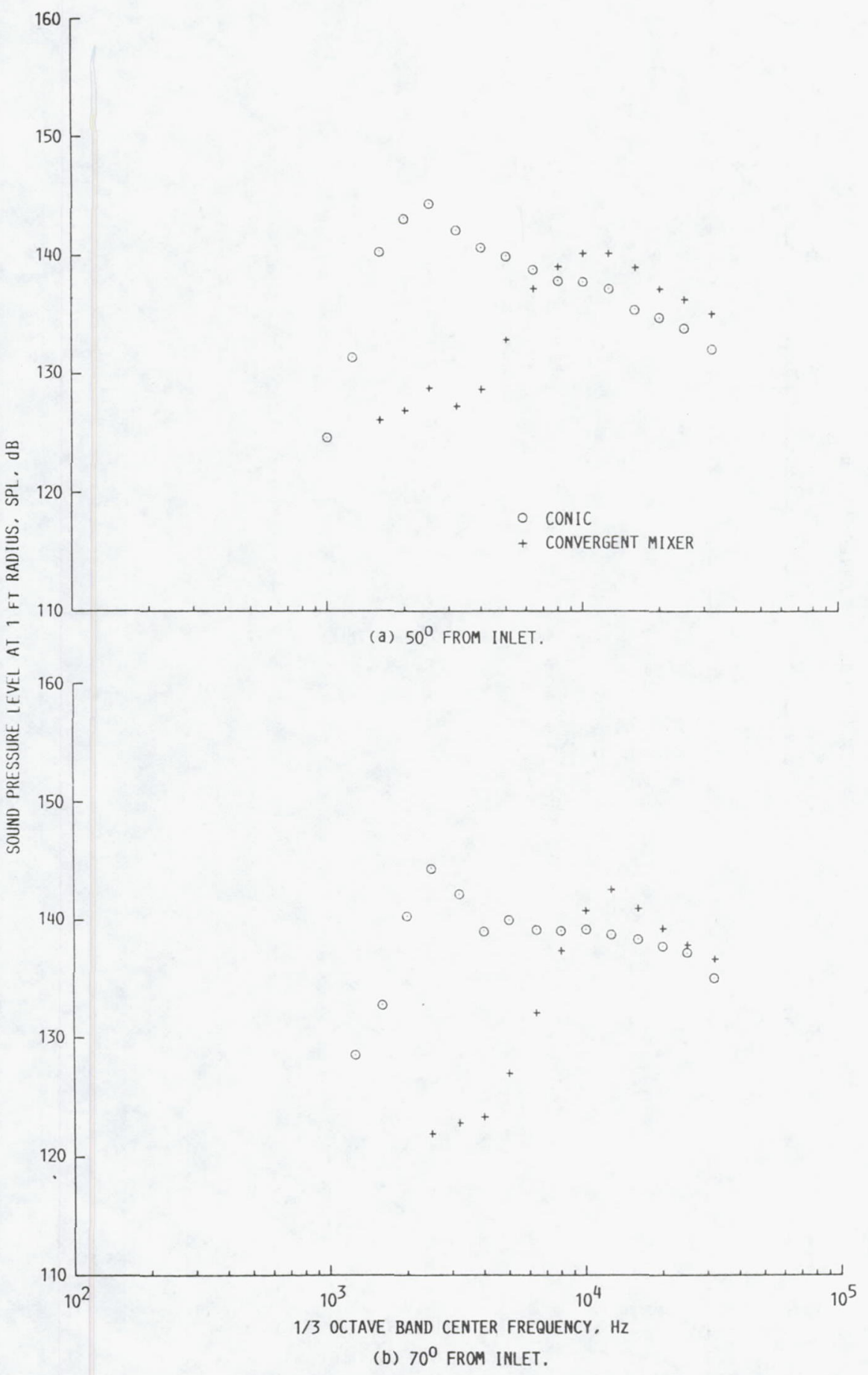

FIGURE 20. - COMPARISON OF CONIC AND CONVERGENT MIXER NOZZLE NOISE SPECTRA. NOZZLE PRESSURE RATIO $=3.5$, NOMINAL JET TEMPERATURE $900^{\circ} \mathrm{R}$, , TUNNEL MACH NUMBER $=0.2$. 


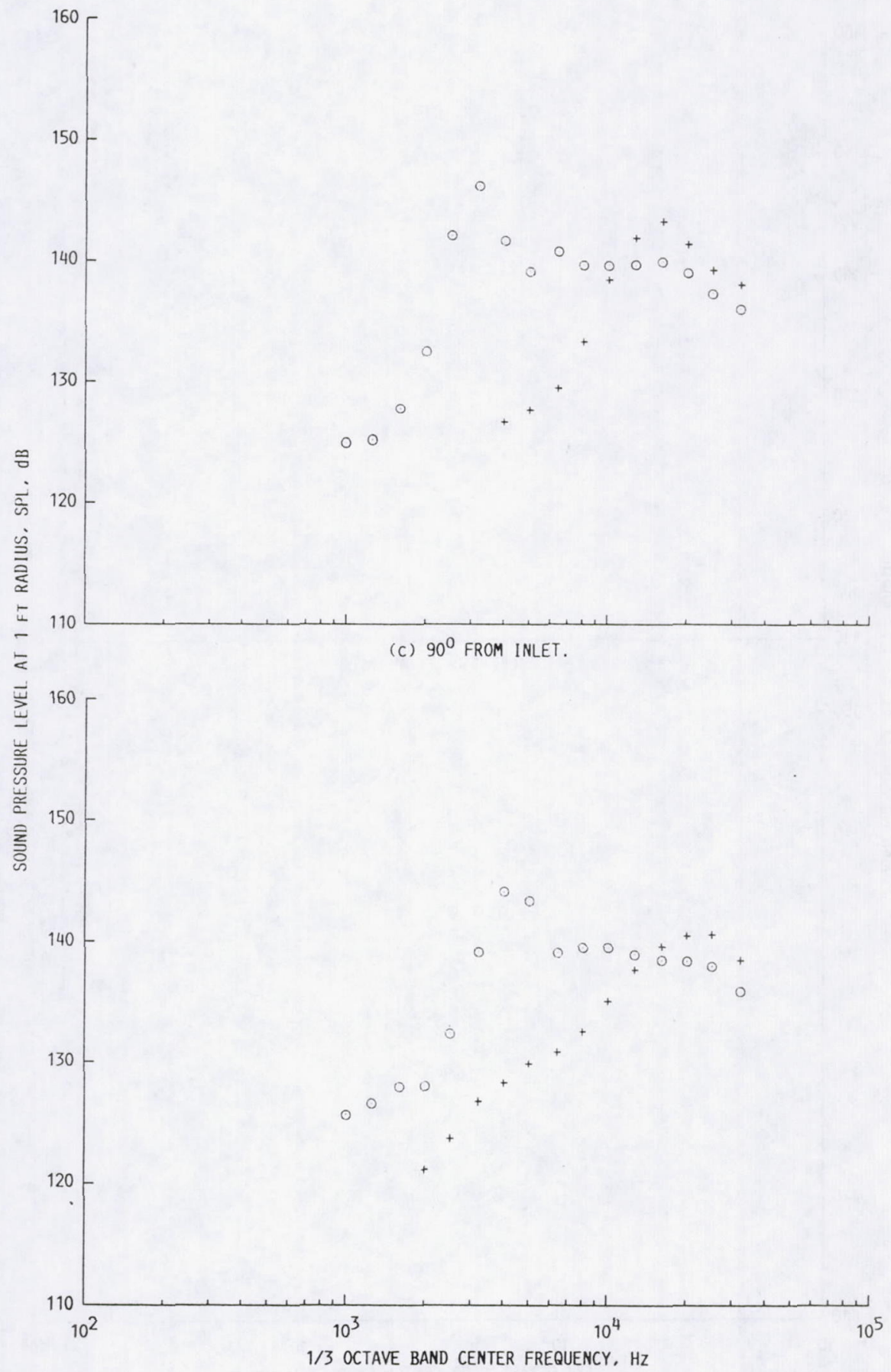

(d) $110^{\circ}$ FROM INLET.

figure 20. - CONTINUED. 


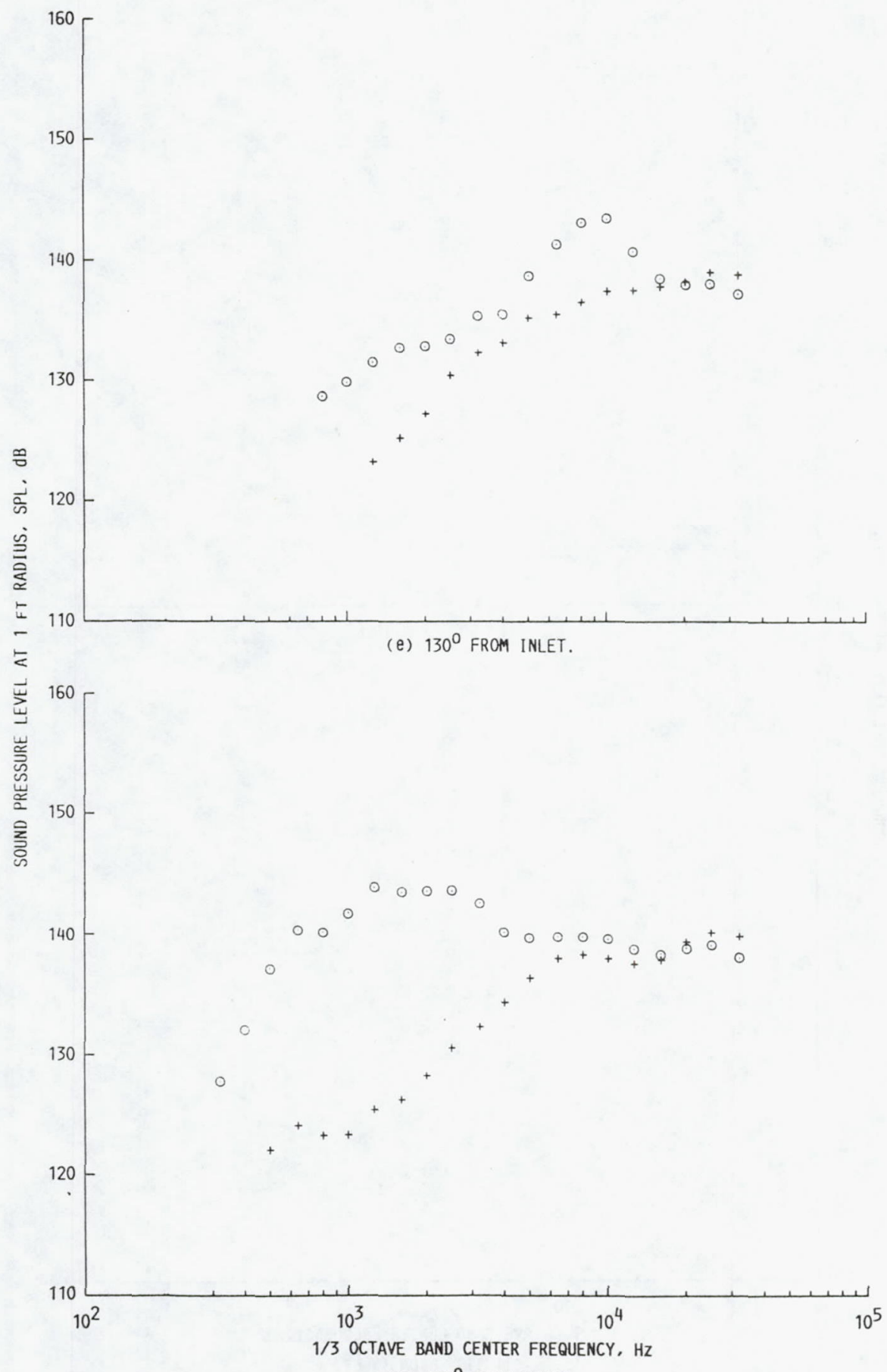

(f) $150^{\circ}$ FROM INLET.

FIGURE 20. - CONCLUDED. 


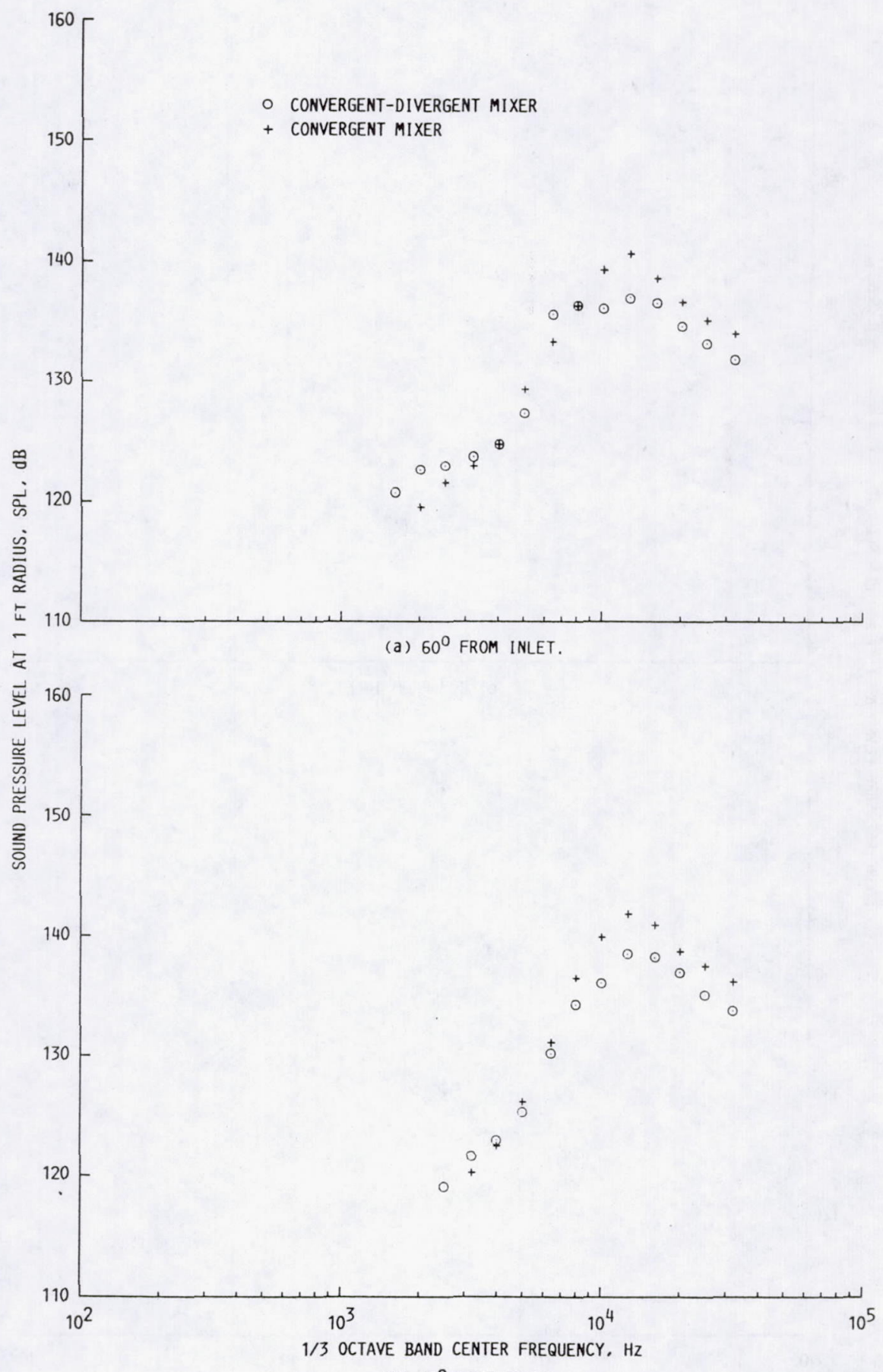

(b) $70^{\circ}$ FROM INLET.

FIGURE 21. - COMPARISON OF CONYERGENT-DIVERGENT MIXER AND CONVERGENT MIXER NOZZLE NOISE SPECTRA. NOZZLE PRESSURE RATIO $=3.4$. NOMINAL JET TEMPERATURE $=900^{\circ} \mathrm{R}$, TUNNEL MACH NUMBER $=0.2$. 


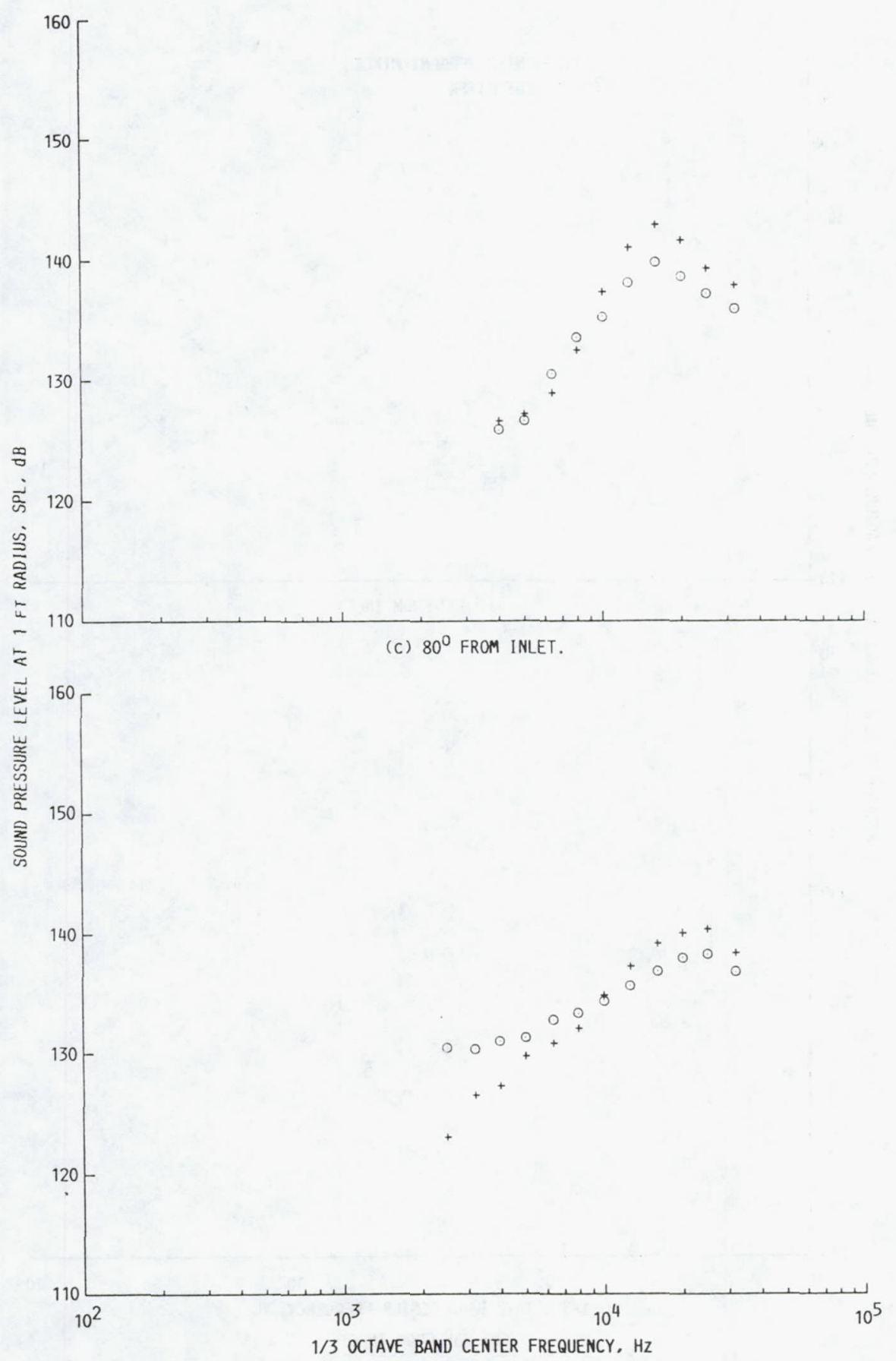

(d) $110^{\circ}$ FROM INLET.

FIGURE 21. - CONTINUED. 


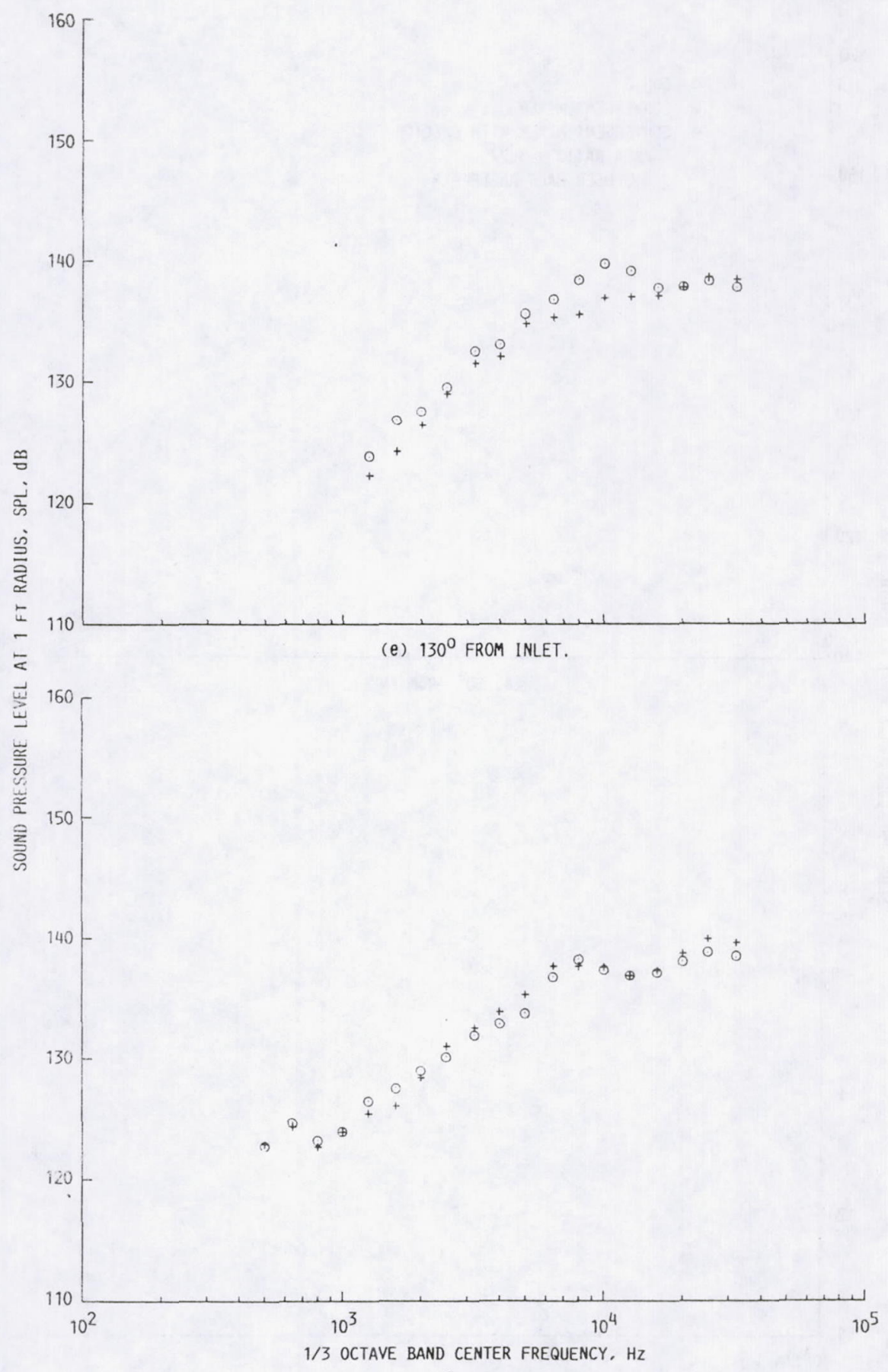

(f) $150^{\circ}$ FROM INLET.

FIGURE 21. - CONCLUDED. 


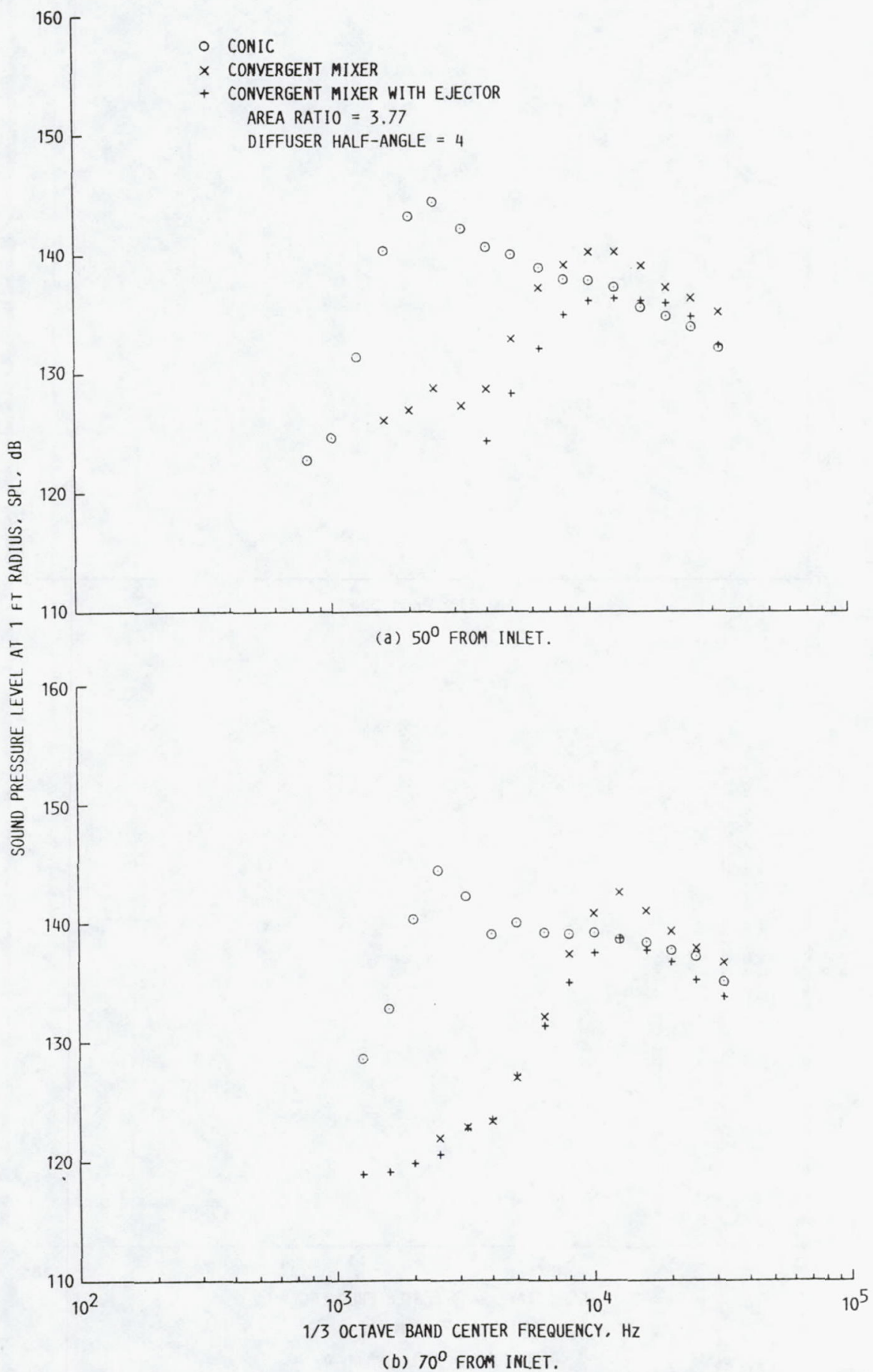

FIGURE 22. - COMPARISON OF MIXER-EJECTOR, CONVERGENT MIXER, AND CONIC NOZZLE NOISE SPECTRA. NOZZLE PRESSURE RATIO $=3.5$, NOMINAL JET TEMPERATURE $=900^{\circ} \mathrm{R}$., TUNNEL MACH NUMBER $=0.2$. 


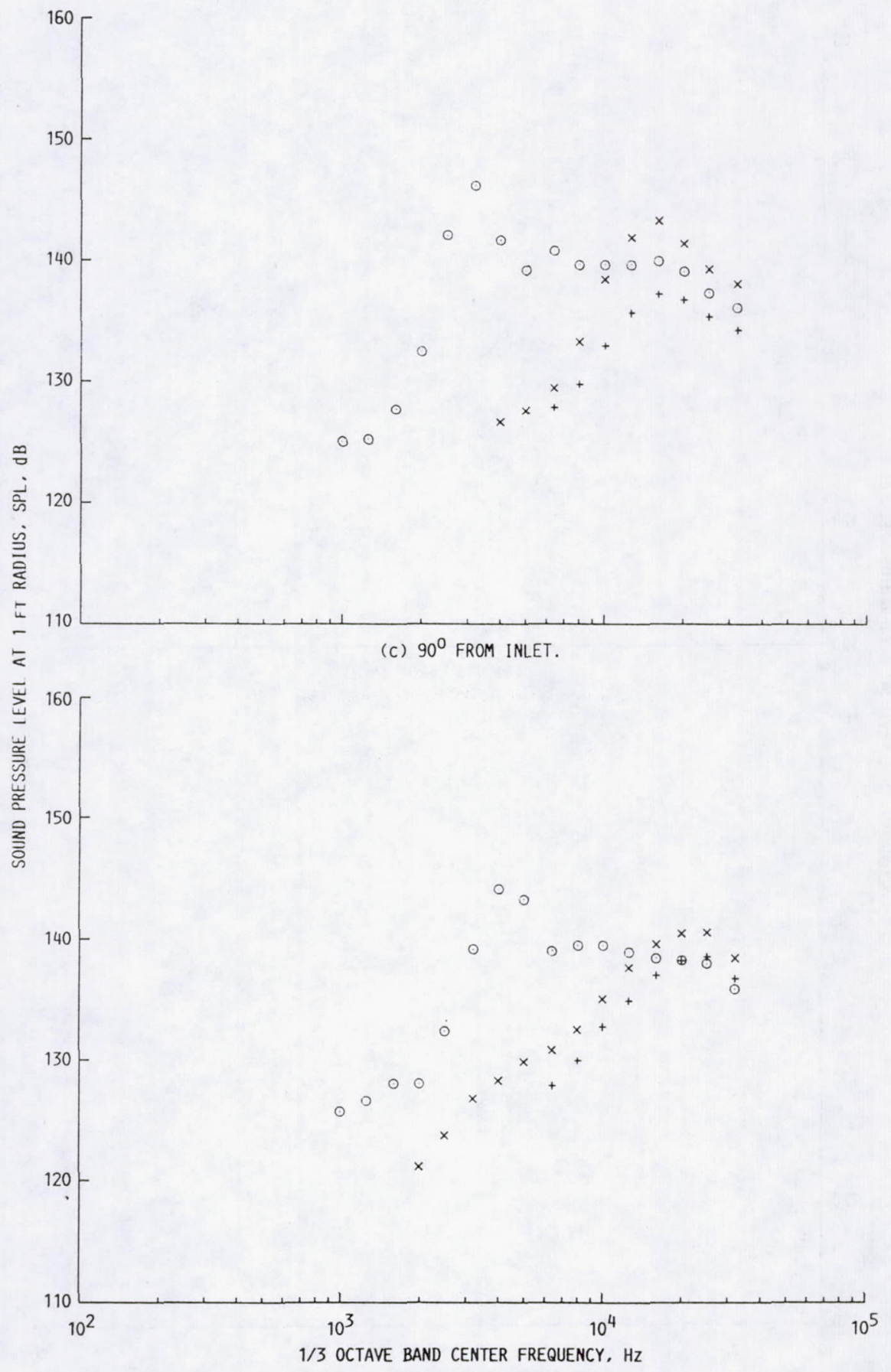

(d) $110^{\circ}$ FROM INLET.

F1GURE 22. - CONTINUED. 


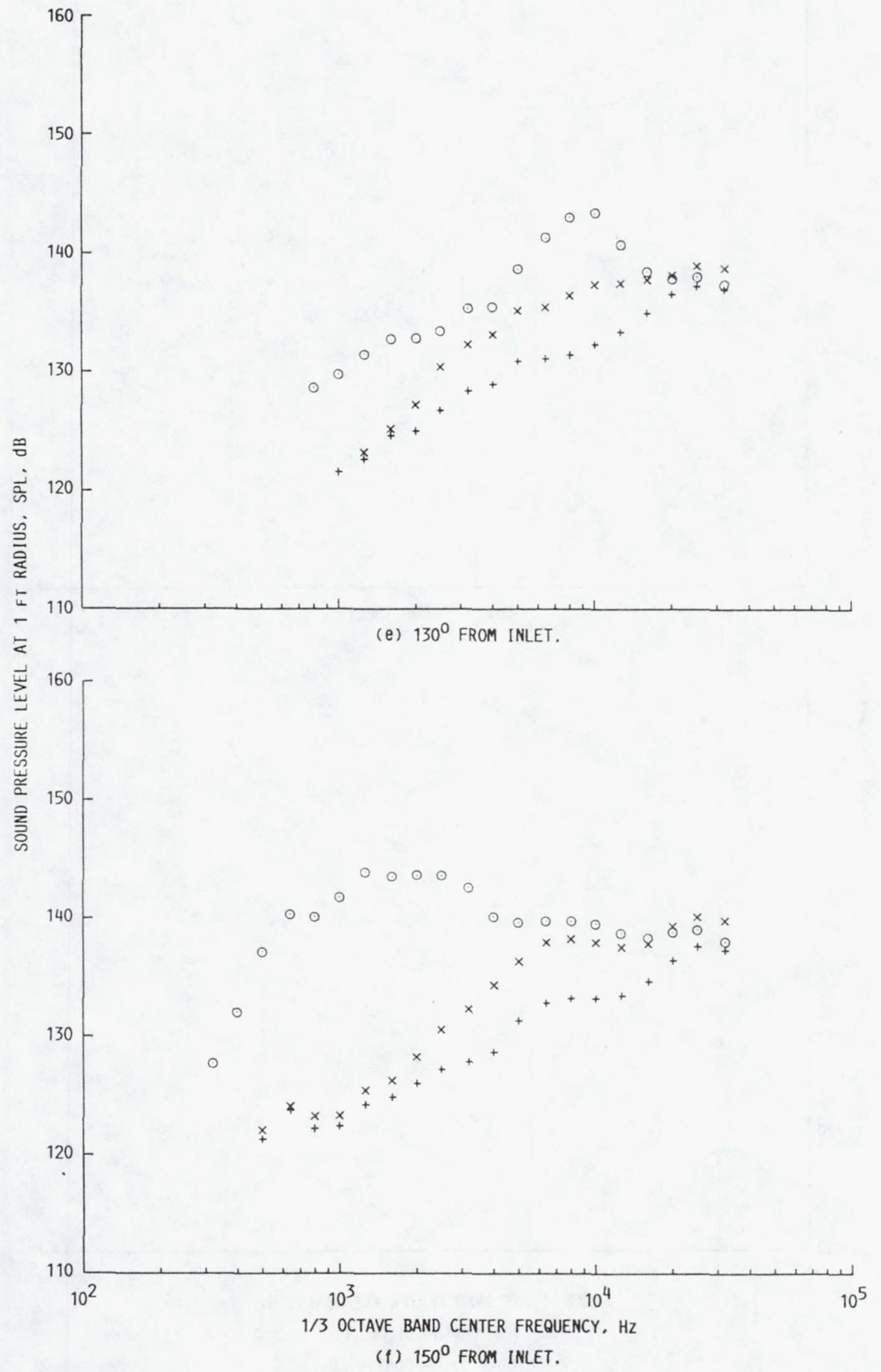

FIGURE 22. - CONCLUDED. 


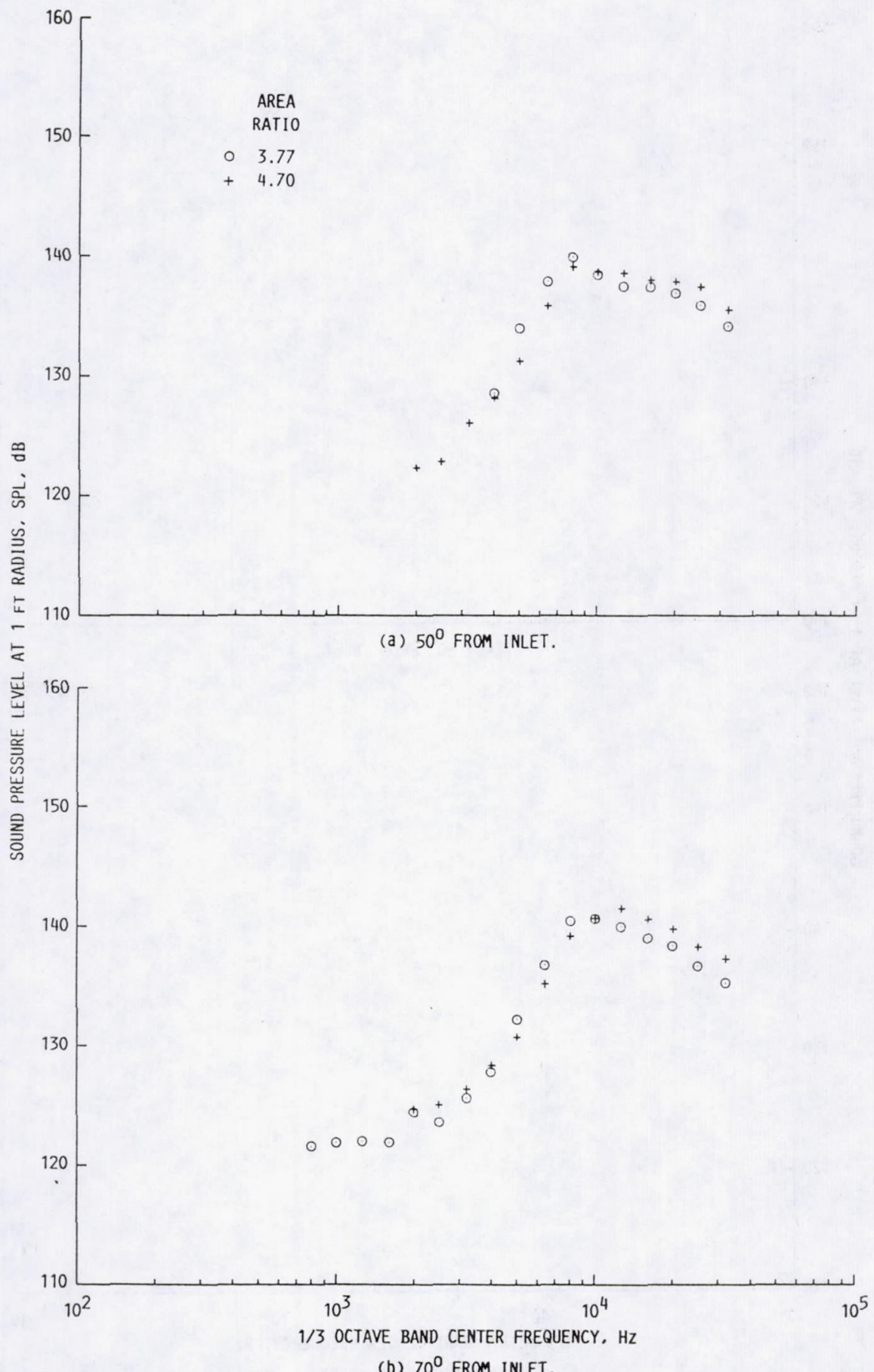

(b) $70^{\circ}$ FROM INLET.

FIGURE 23. - EFFECT OF EJECTOR TO NOZZLE AREA RATIO ON NOISE. CONVERGENT MIXER, NOZZLE PRESSURE RATIO $=4.0$, NOMINAL JET TEMPERATURE $=900^{\circ} \mathrm{R}$. . TUNNEL MACH NUMBER $=0.2$. 


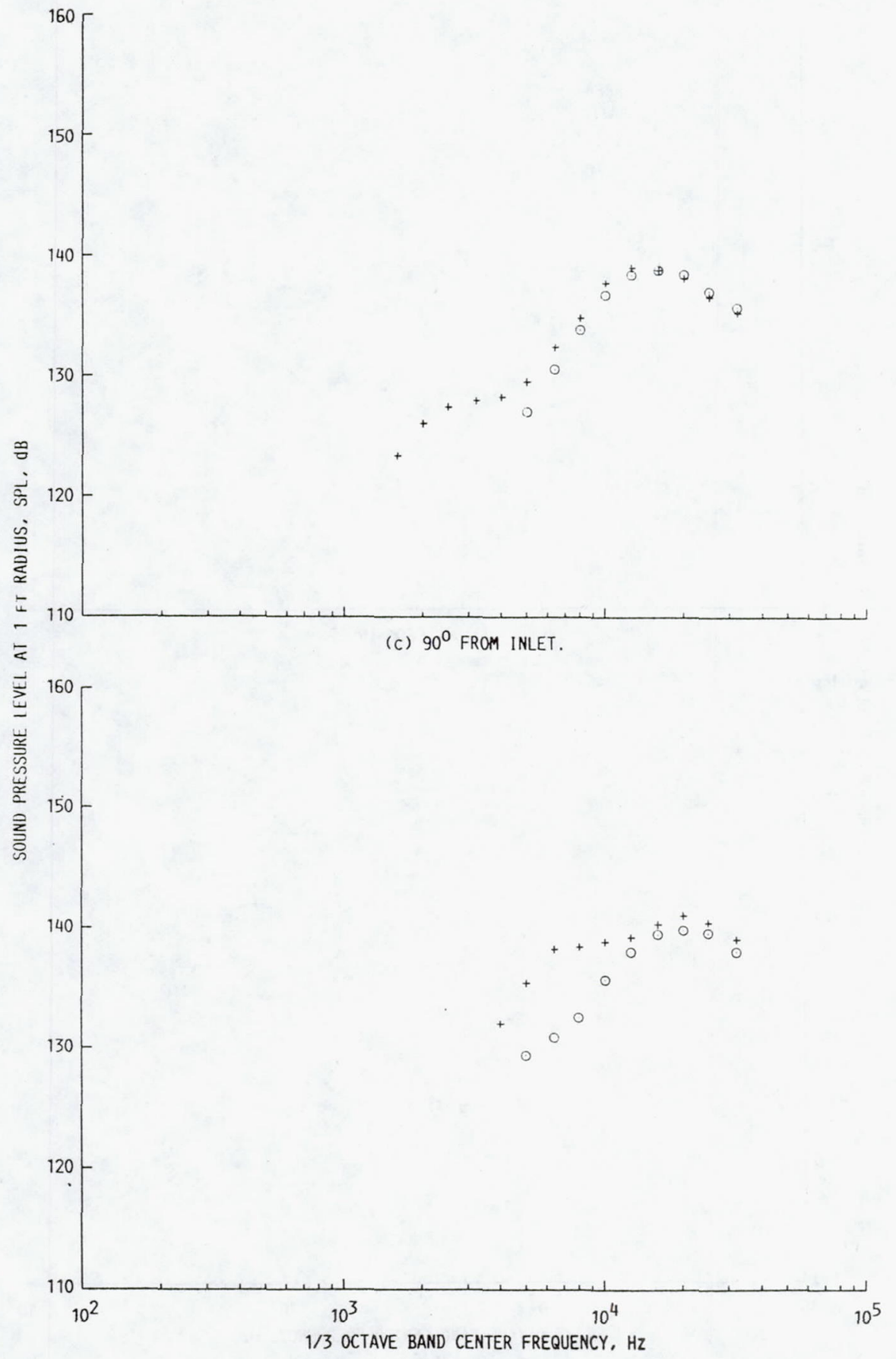

(d) $110^{\circ}$ FROM INLET.

FIGURE 23. - CONTINUED. 


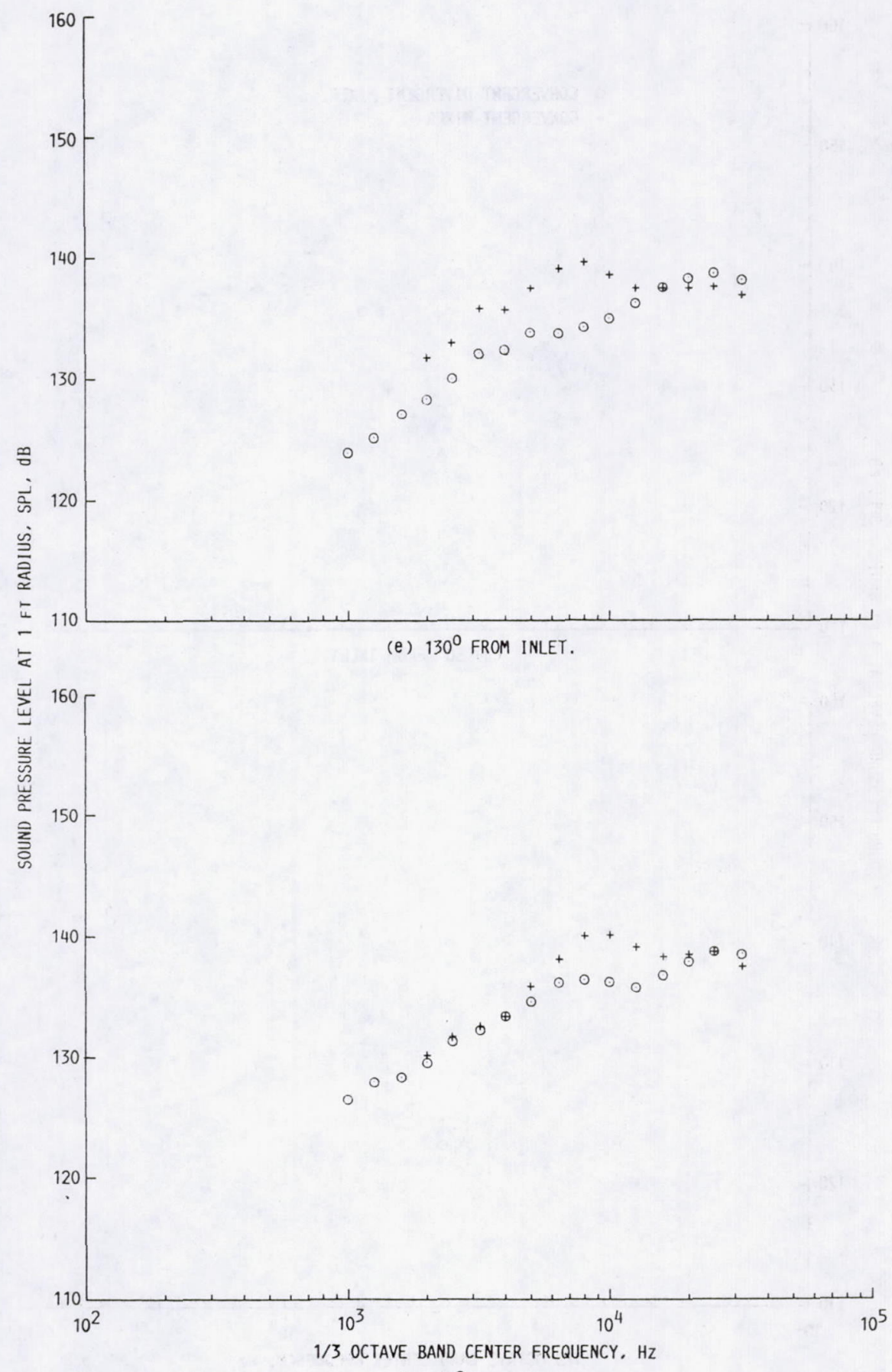

(f) $150^{\circ}$ FROM INLET.

FIGURE 23. - CONCLUDED. 


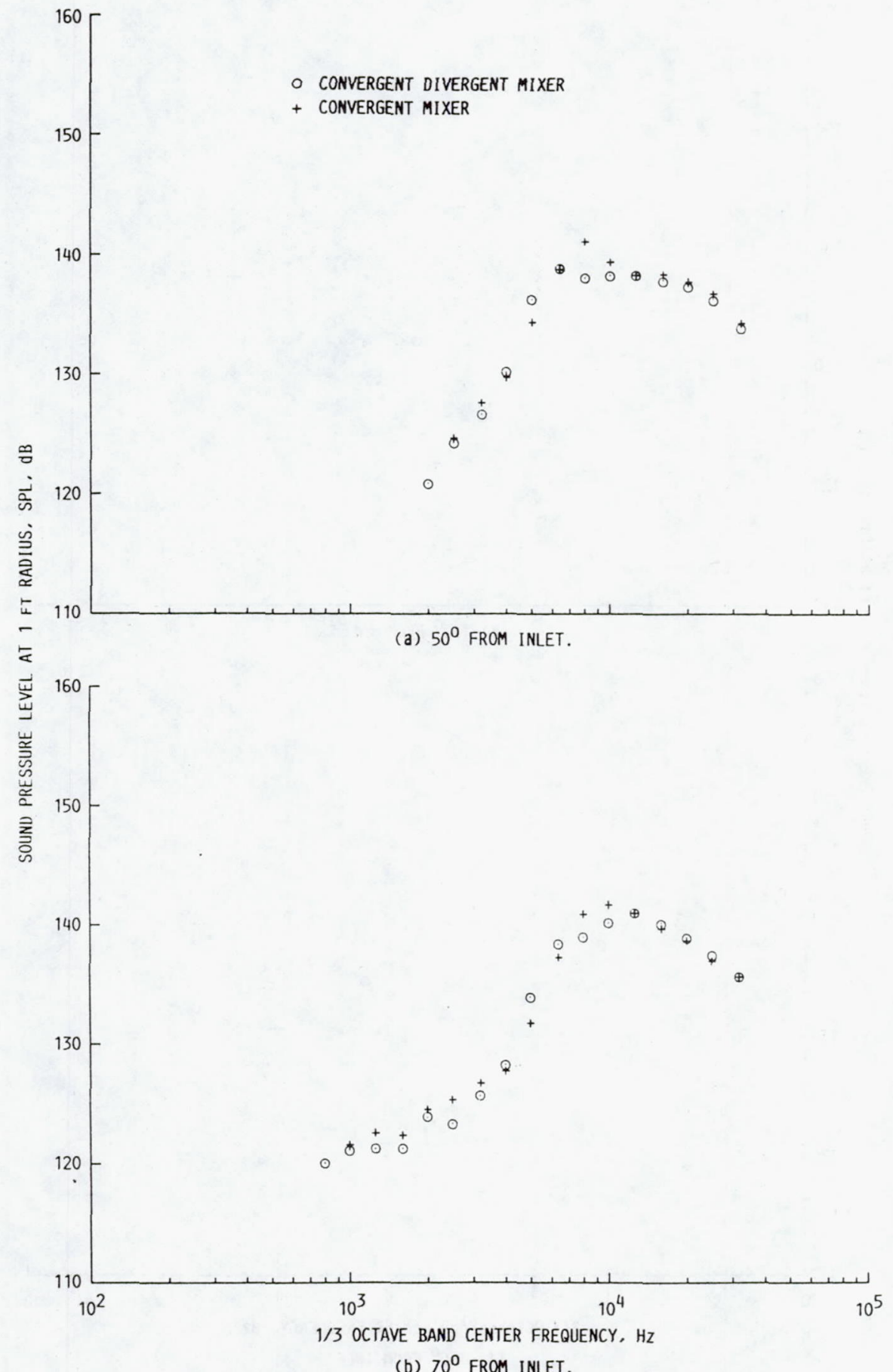

FIGURE 24. - EFFECT OF MIXER NOZZLE GEOMETRY ON MIXER-EJECTOR NOISE SPECTRA. NOZZLE PRESSURE RATIO $=4.0$, NOMINAL JET TEMPERATURE $=900^{\circ} \mathrm{R}$. TUNNEL MACH NUMBER $=0.2$. AREA RATIO $=4.23$, DIFFUSER HALF ANGLE $=4^{\circ}$. 


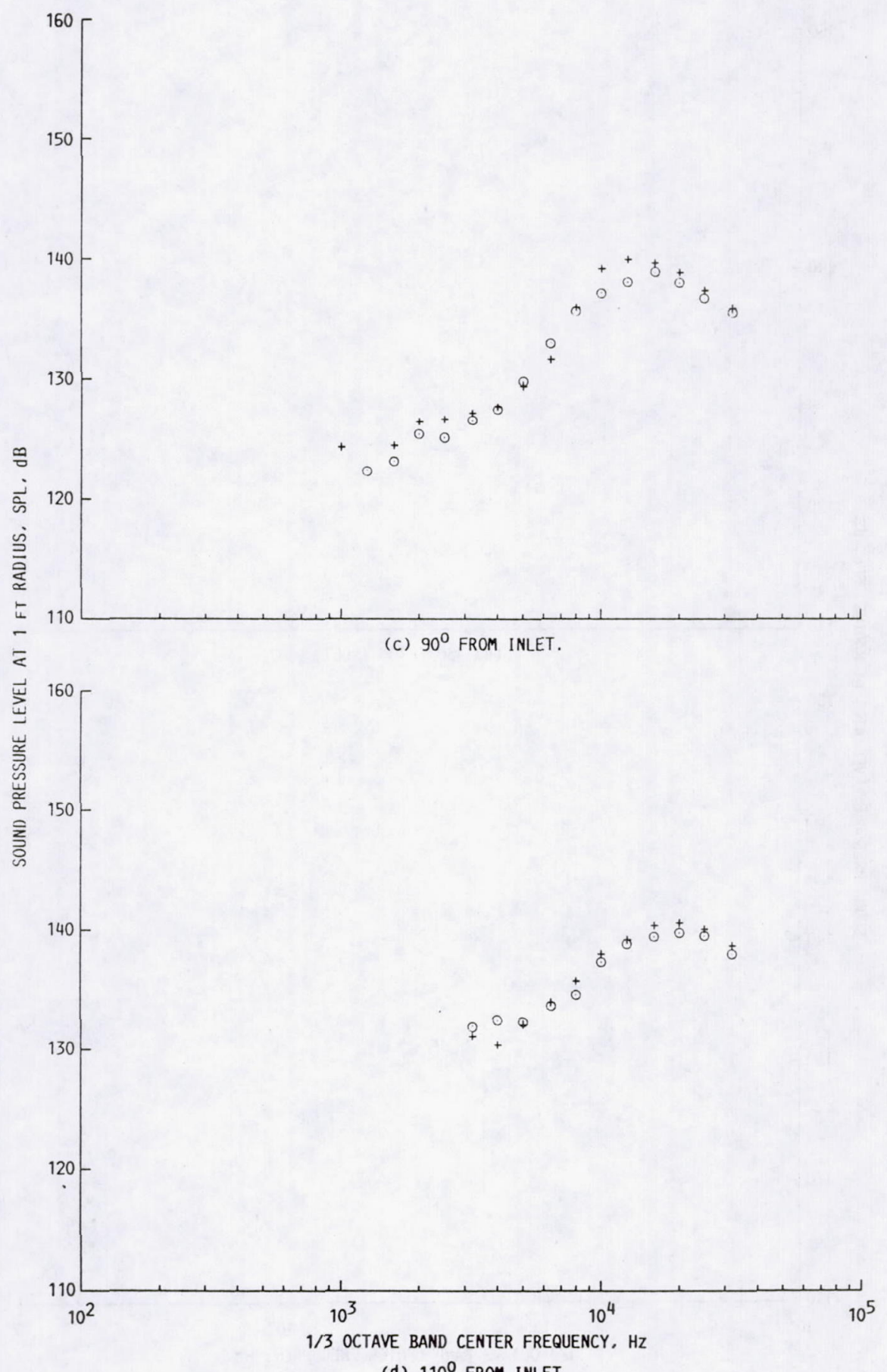

(d) $110^{\circ}$ FROM INLET.

FIGURE 24. - CONTINUED. 


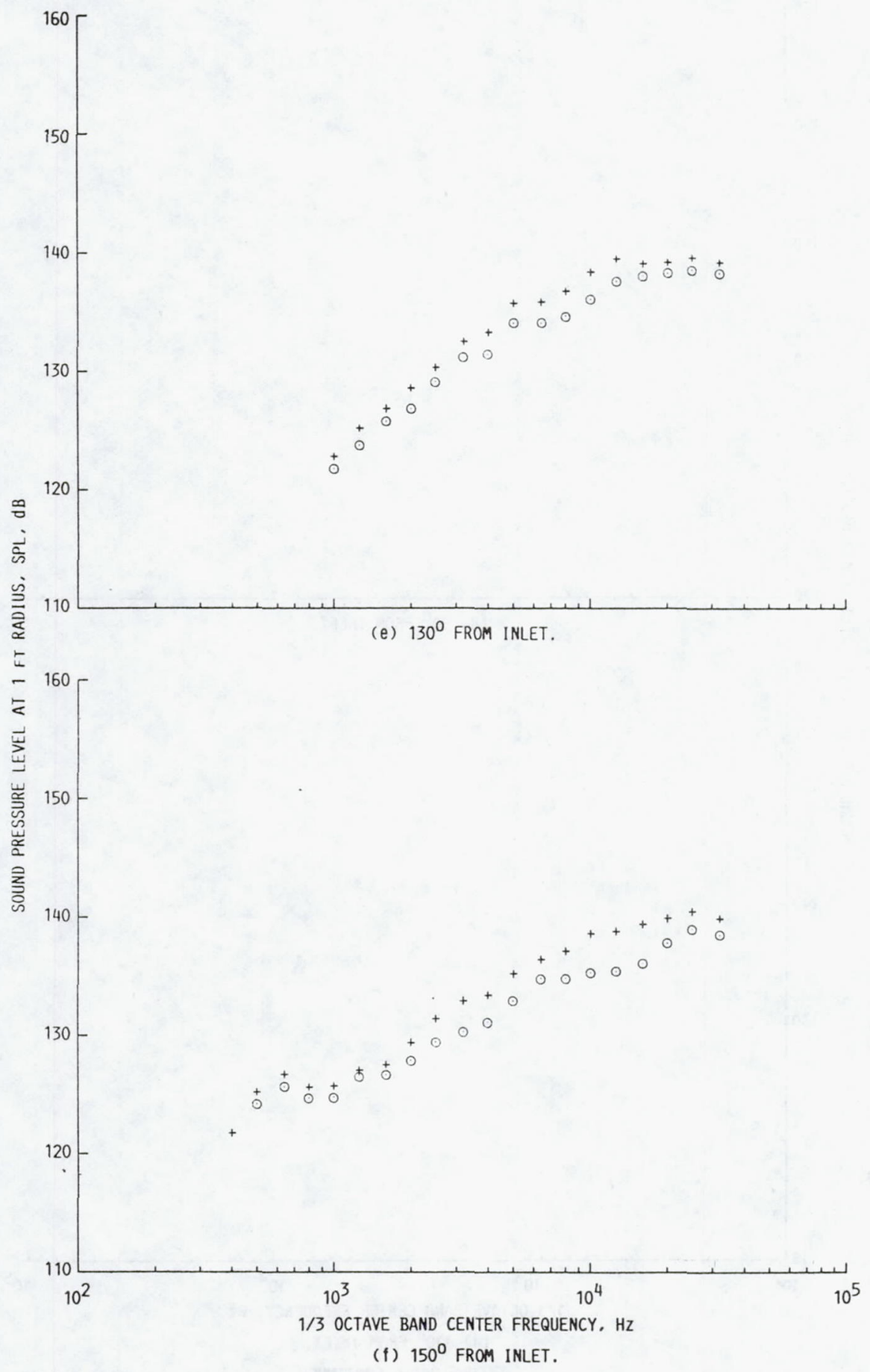

FIGURE 24. - CONCLUDED. 


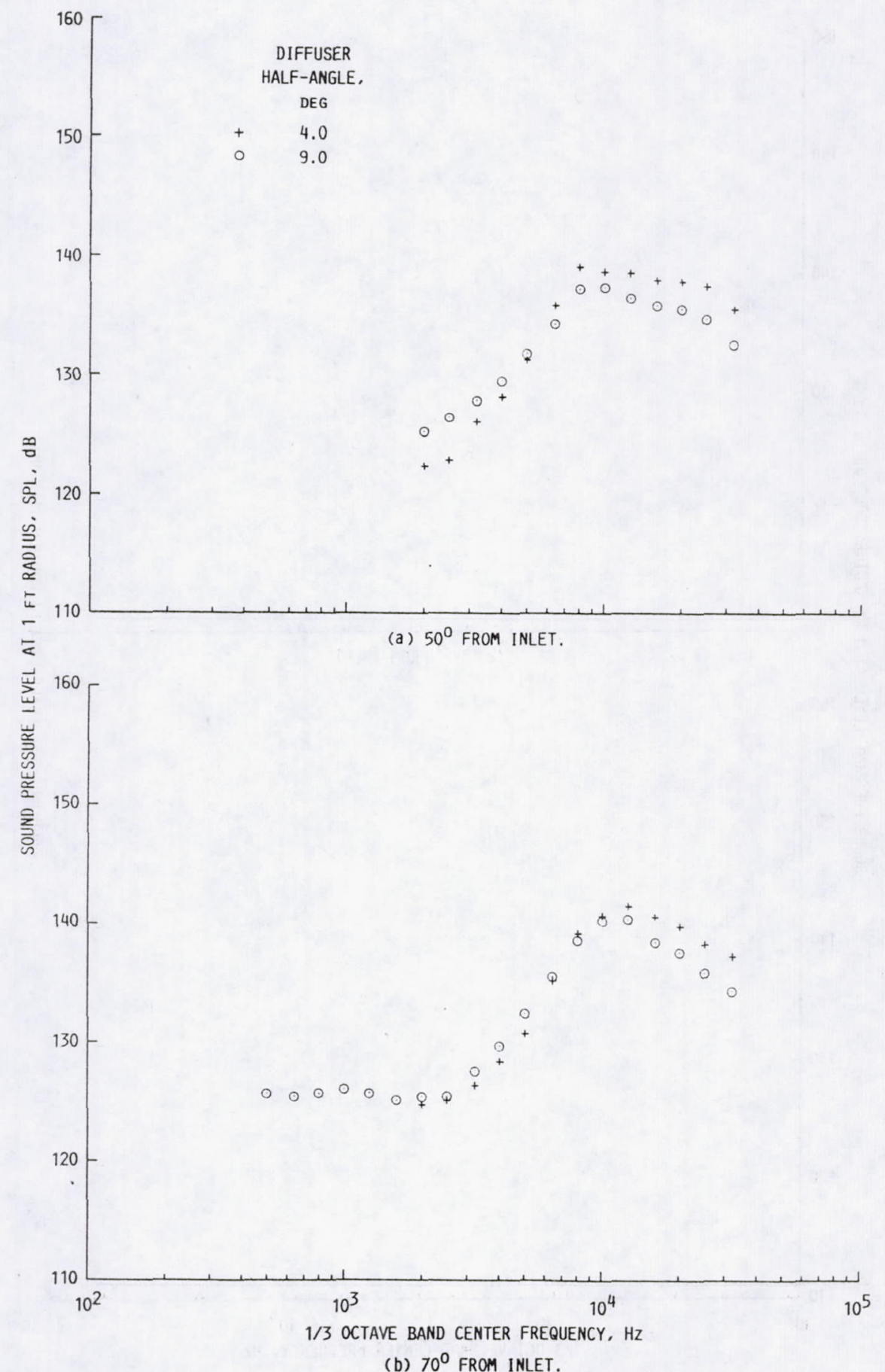

FIGURE 25. - EFFECT OF INCREASED DIFFUSION ON MIXER-EJECTOR NOISE SPECTRA. NOZZLE PRESSURE RATIO $=4.0$, NOMINAL JET TEMPERATURE $=900^{\circ} \mathrm{R}$., TUNNEL MACH NUMBER $=0.2$, AREA RATIO $=4.7$. 


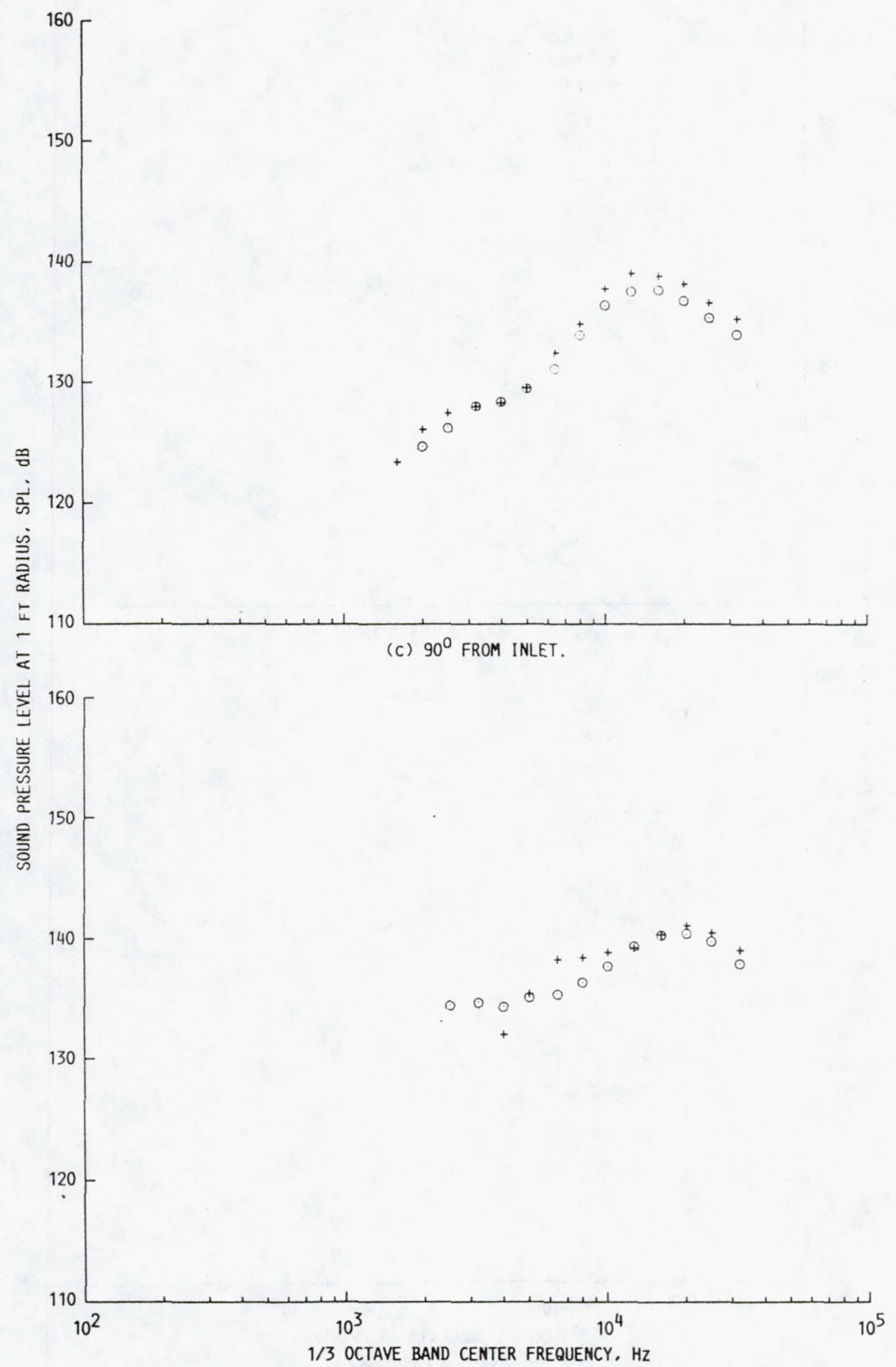

(d) $110^{\circ}$ FROM INLET.

FIGURE 25. - CONTINUED. 


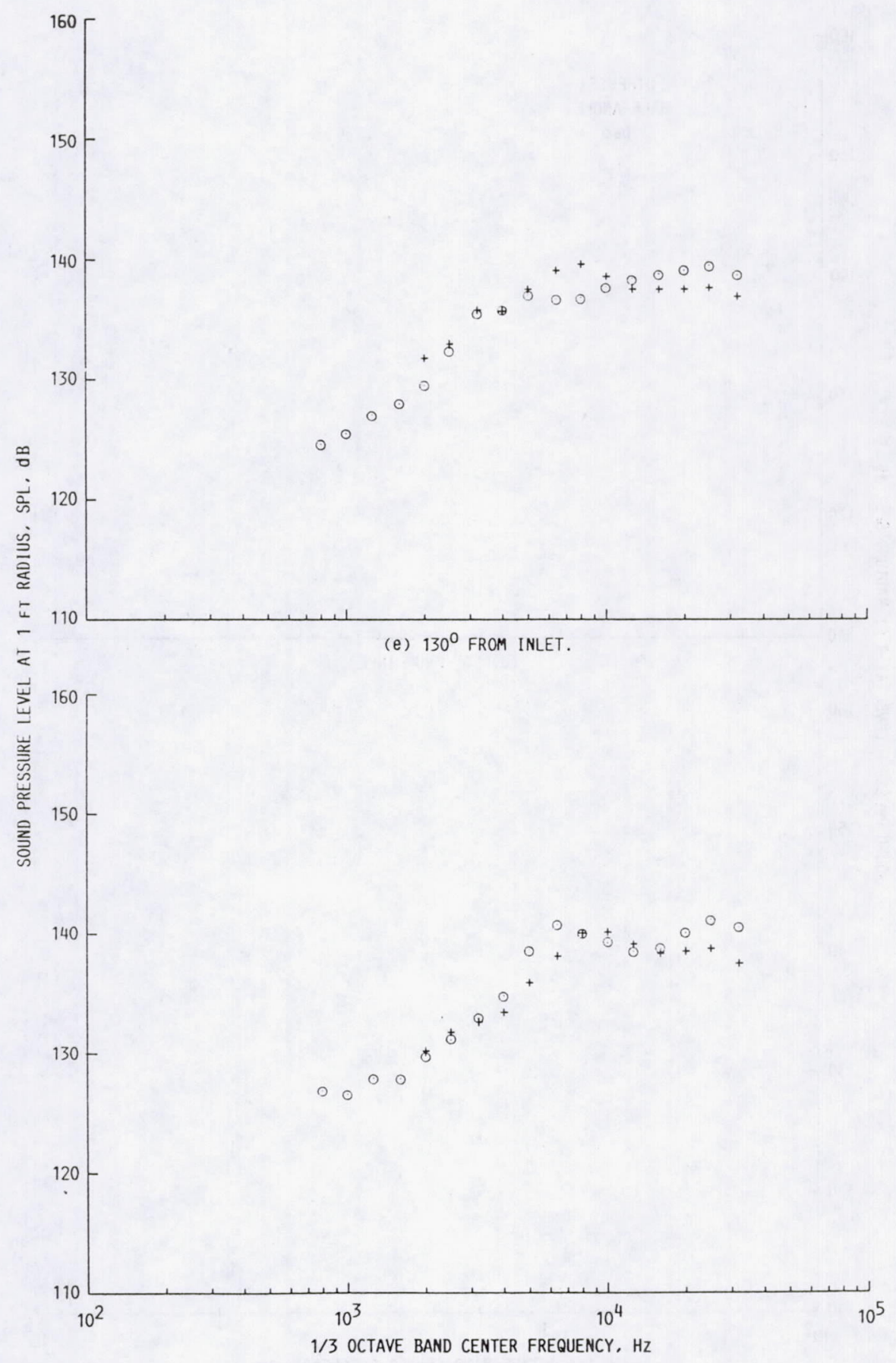

(f) $150^{\circ}$ FROM INLET.

FIGURE 25. - CONCLUDED. 


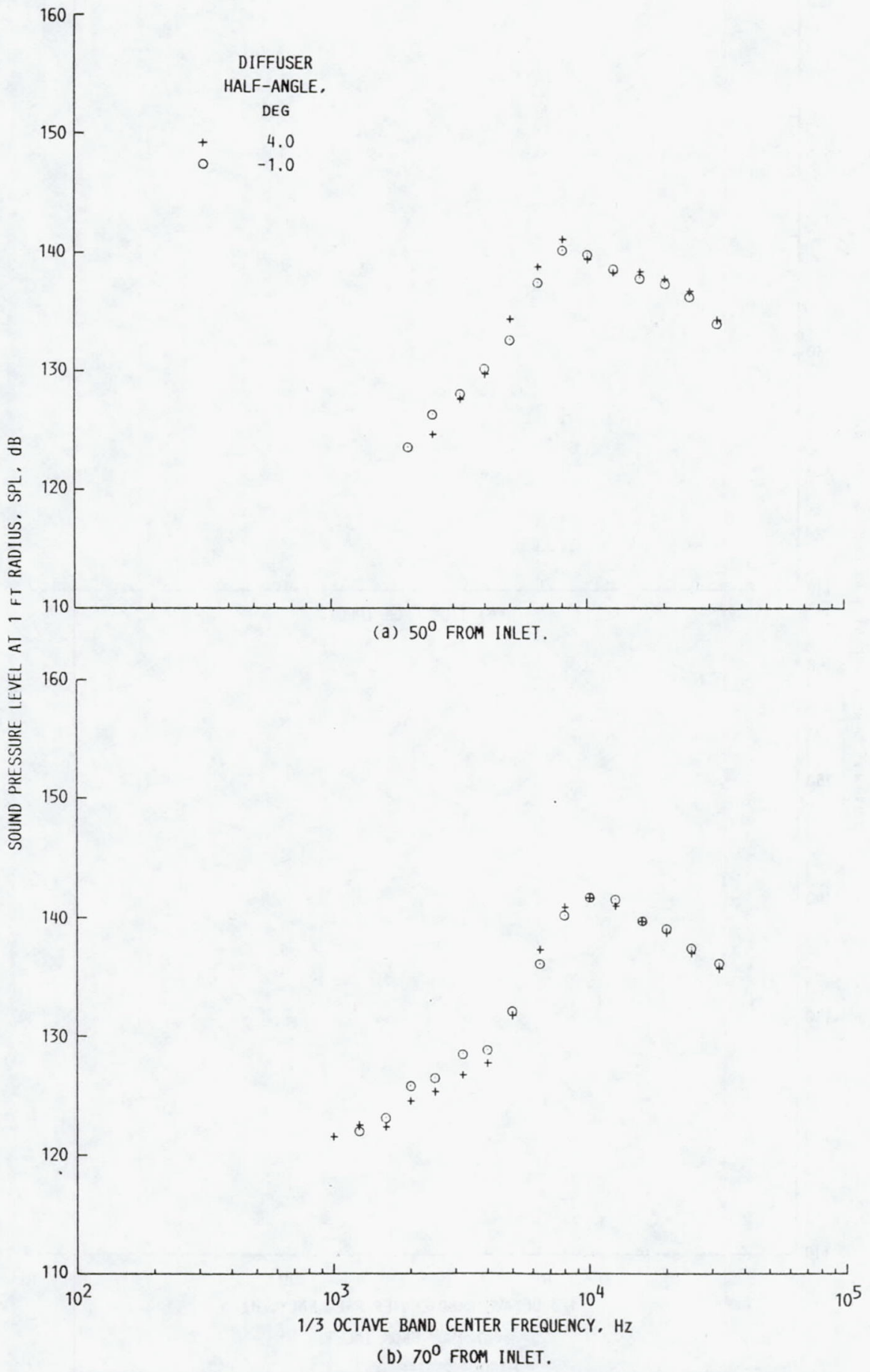

FIGURE 26. - EFFECT OF DECREASED DIFFUSION ON MIXER-EJECTOR NOISE SPECTRA. NOZZLE PRESSURE RATIO $=4.0$, NOMINAL JET TEMPERATURE $=900^{\circ} \mathrm{R}$., TUNNEL MACH NUMBER $=0.2$, AREA RATIO $=4.23$. 


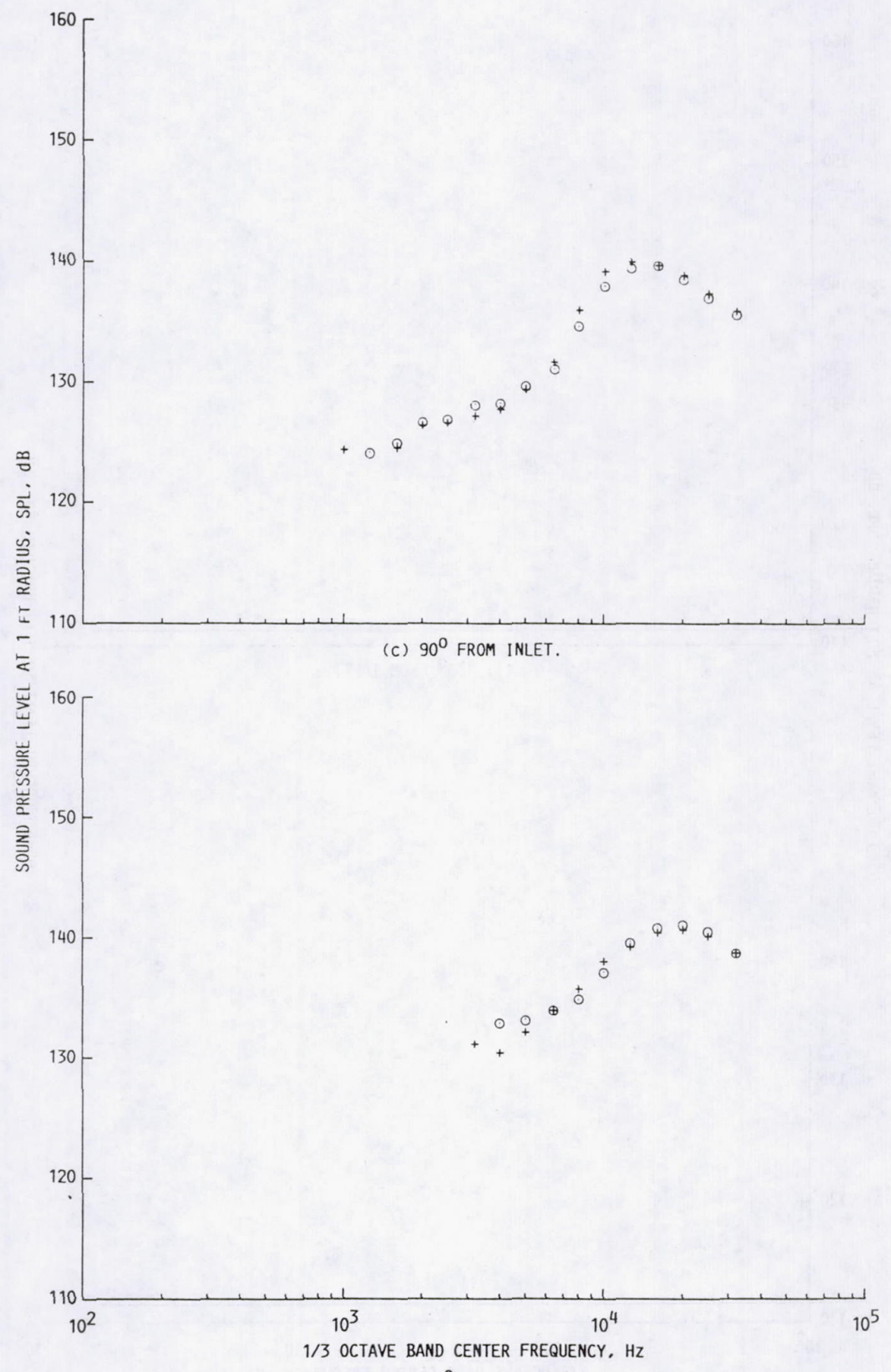

(d) $110^{\circ}$ FROM INLET.

FIGURE 26. - CONTINUED. 


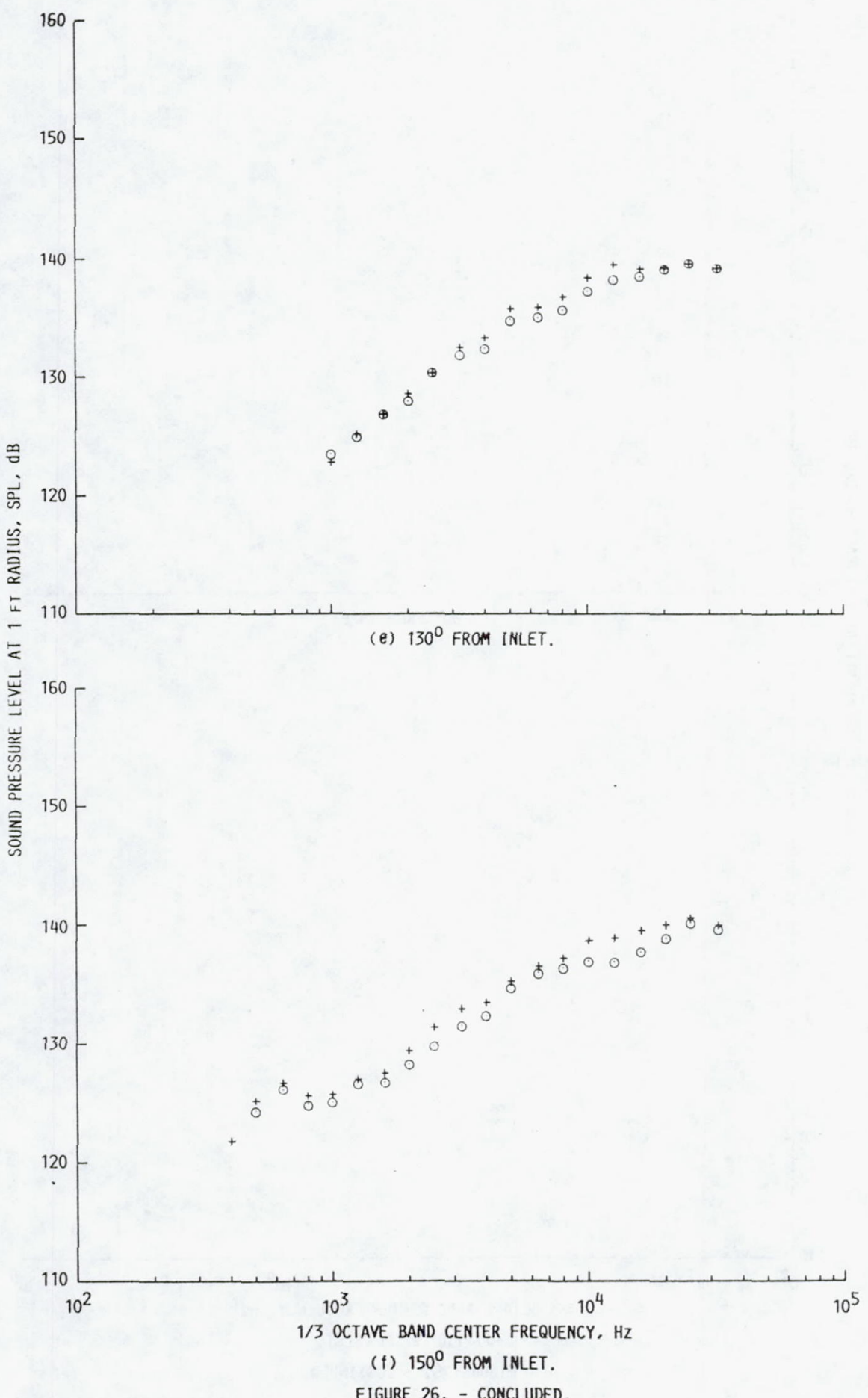

FIGURE 26, - CONCLUDED. 


\begin{tabular}{ll|l} 
1. Report No. & NASA TM-103628 \\
AIAA-90-3983 & 2. Government Accession No. \\
\hline
\end{tabular}

4. Title and Subtitle

Noise Measurements From an Ejector Suppressor Nozzle in the NASA Lewis 9- by 15 -Foot Low Speed Wind Tunnel

7. Author(s)

Eugene A. Krejsa, Beth A. Cooper, David G. Hall, and Abbas Khavaran
3. Recipient's Catalog No.

5. Report Date

6. Performing Organization Code

8. Performing Organization Report No. E-5717

10. Work Unit No. $505-62-40$

9. Performing Organization Name and Address

National Aeronautics and Space Administration

11. Contract or Grant No.

Lewis Research Center

Cleveland, Ohio 44135-3191

13. Type of Report and Period Covered

Technical Memorandum

12. Sponsoring Agency Name and Address

National Aeronautics and Space Administration

Washington, D.C. 20546-0001

14. Sponsoring Agency Code

15. Supplementary Notes

Prepared for the 13th Aeroacoustics Conference sponsored by the American Institute of Aeronautics and Astronautics, Tallahassee, Florida, October 22-24, 1990. Eugene A. Krejsa and Beth A. Cooper, NASA Lewis Research Center; David G. Hall and Abbas Khavaran, Sverdrup Technology, Inc., Lewis Research Center Group, 2001 Aerospace Parkway, Brook Park, Ohio 44142.

16. Abstract

This report presents the acoustic results of a cooperative nozzle test program between NASA and Pratt \& Whitney that was conducted in the NASA Lewis Research Center 9- by 15-Foot Anechoic Wind Tunnel. The nozzle tested was the Pratt \& Whitney "Hypermix" Nozzle concept, a two-dimensional lobed mixer nozzle followed by a short ejector section designed to promote rapid mixing of the nozzle flow with the flow induced by the ejector. Acoustic and aerodynamic measurements were made to determine the amount of ejector pumping, the degree of mixing, and the noise reduction achieved. A series of testes were run to verify the acoustic quality of this tunnel. The results indicated that the tunnel test section is reasonably anechoic but that background noise can limit the amount of suppression observed from suppressor nozzles. Also, a possible internal noise was observed in the air supply system. The Pratt \& Whitney ejector suppressor nozzle demonstrated the potential of this concept to significantly reduce jet noise. Significant reduction in low frequency noise was achieved by increasing the peak jet noise frequency. This was accomplished by breaking the jet into segments with smaller dimensions than those of the baseline nozzle. Variation in ejector parameters had little effect on the noise for the geometries and the range of temperatures and pressure ratios tested.

17. Key Words (Suggested by Author(s))

Acoustics

Jet noise

Noise suppressors

Nozzles
18. Distribution Statement

Unclassified-Unlimited

Subject Category 71 